\title{
Let's talk about sex! : sexual health and sexual dysfunction among adolescents
}

Citation for published version (APA):

Grauvogl, A. (2014). Let's talk about sex! : sexual health and sexual dysfunction among adolescents. [Doctoral Thesis, Maastricht University]. Datawyse / Universitaire Pers Maastricht. https://doi.org/10.26481/dis.20140214ag

Document status and date:

Published: 01/01/2014

DOI:

10.26481/dis.20140214ag

Document Version:

Publisher's PDF, also known as Version of record

\section{Please check the document version of this publication:}

- A submitted manuscript is the version of the article upon submission and before peer-review. There can be important differences between the submitted version and the official published version of record.

People interested in the research are advised to contact the author for the final version of the publication, or visit the DOI to the publisher's website.

- The final author version and the galley proof are versions of the publication after peer review.

- The final published version features the final layout of the paper including the volume, issue and page numbers.

Link to publication

\footnotetext{
General rights rights.

- You may freely distribute the URL identifying the publication in the public portal. please follow below link for the End User Agreement:

www.umlib.nl/taverne-license

Take down policy

If you believe that this document breaches copyright please contact us at:

repository@maastrichtuniversity.nl

providing details and we will investigate your claim.
}

Copyright and moral rights for the publications made accessible in the public portal are retained by the authors and/or other copyright owners and it is a condition of accessing publications that users recognise and abide by the legal requirements associated with these

- Users may download and print one copy of any publication from the public portal for the purpose of private study or research.

- You may not further distribute the material or use it for any profit-making activity or commercial gain

If the publication is distributed under the terms of Article $25 \mathrm{fa}$ of the Dutch Copyright Act, indicated by the "Taverne" license above, 



\section{Let's talk about sex! \\ Sexual health and sexual dysfunction among adolescents}


(C) A. Grauvogl, Maastricht 2014

Universitaire Pers Maastricht

ISBN 9789461592927

Layout: A. Grauvogl

Cover: J. Rinia

Production: Datawyse

All rights reserved. No part of this dissertation may be reproduced or transmitted in any form or by any means, electronic or mechanical, including photocopying, recording or any information storage or retrieval system, without permission in writing from the author, or, when appropriate, from the publishers of the publications. 


\title{
Let's talk about sex! \\ Sexual health and sexual dysfunction among adolescents
}

\author{
PROEFSCHRIFT \\ ter verkrijging van de graad van doctor aan de Universiteit Maastricht, \\ op gezag van de Rector Magnificus, Prof. dr. L.L.G. Soete, \\ volgens het besluit van het College van Decanen, \\ in het openbaar te verdedigen \\ op vrijdag 14 februari 2014 om 10.00 uur \\ door
}

Andrea Grauvogl 


\section{Promotores}

Prof. dr. J.J.D.M van Lankveld

Prof. mr. dr. S.M.A.A. Evers

Prof. dr. M.L. Peters

\section{Beoordelingscommissie}

Prof. dr. G. Kok (Voorzitter)

Dr. M. Dewitte

Prof. dr. C. Dirksen

Prof. dr. P. Enzlin (UZ Leuven)

Prof. dr. I. Vanwesenbeeck (UU)

The research presented in this dissertation was performed at the department of Clinical Psychological Science (CPS) of Maastricht University.

This dissertation was financially supported by ZonMw (grant nr. 120620025), Maastricht University and GGD Rotterdam-Rijnmond. 


\section{Table of contents}

$\begin{array}{ll}\text { Chapter 1: General Introduction } & 7\end{array}$

Chapter 2: Perceptions of sexuality and sexual health among young people in the Netherlands

Chapter 3: A new instrument to measure Sexual Competence and Interaction Competence in Youth (SCICY): Psychometric properties in female adolescents

Chapter 4: Disgust and sexual arousal in young adult men and women

Chapter 5: Clinical and cost-effectiveness of short term, cost free and anonymous sex counselling to improve sexual health: design of a randomized control trial

Chapter 6: The clinical effectiveness of brief sex counselling for sexually dysfunctional adolescents

Chapter 7: Economic evaluation of brief sex counselling for sexually dysfunctional 105 adolescents

Chapter 8: Summary and general discussion

Samenvatting

Dankwoord 

Chapter 1

General introduction 
SEX [seks]

Noun

1. the sum of the structural and functional differences by which the male and female are distinguished

2. the instinct or attraction drawing one sex toward another, or its manifestation in life and conduct

3. coitus

Idiom

1. to have sex, to engage in sexual intercourse

\section{Origin}

1350-1400; Middle English, derived from the Latin word sexus; perhaps akin to secare meaning "to divide" (Cambridge University Press, 2013)

During their entire lives, men and women may be engaged with sex. However, one period in their lives is especially interesting with regard to sexuality, namely the period of adolescence. In this dissertation different aspects of sex and sexual health during adolescence are addressed.

\section{Adolescence}

Adolescence, derived from the Latin verb adolescere meaning "to grow up", is a period of multiple transitional stages of physical (e.g., growth spurt, reproduction-related changes, changes in the brain), social (e.g., identity development, relationships), psychological (e.g., self-esteem) and cognitive (e.g., improvements in cognitive ability, abstract thinking) development (Choudhury, Blakemore, \& Charman, 2006; Dekovic, Noom, \& Meeus, 1997; Stoeckart, Swaab, Gijs, de Ronde, \& Slob, 2009; Susman \& Ragol, 2004). Adolescence is the stage of development between puberty and adulthood. In the United States, adolescence is considered to be the period between 13 and 24 years of age, whereas the World Health Organization (WHO) defines adolescence as the period between 10 and 20 years of age. In this dissertation we define adolescence as the period between 12 and 25 years of age. This age range corresponds with the age limits of eligibility for visitors of sexual health centers of the Public Health Services (PHS) in the Netherlands, called 'Sense'.

Sexuality and romantic relationships develop during adolescence. Sexual maturation and the development of more complex cognitive functions increases the likelihood of engaging in a long term romantic relationship, which allows adolescents to gain the skills necessary to maintain high-quality romantic relationships in adulthood (Collins, Welsh, \& Furman, 2009) and to develop feelings of self-esteem, self-confidence and social competence (ZimmermanGernbeck, Siebenbruner, \& Collins, 2004). However, adolescents also face some difficulties as their sexuality starts to develop. For example, transformation of their body during the transition from child to grown-up, the ending of a relationship, getting their heart broken, being rejected by another person, questions about their sexuality, etcetera. Furthermore, 
sexually transmitted infections (STIs including HIV/AIDS), unwanted pregnancy, abortion, sexual dysfunctions and sexual coercion are some more serious negative consequences of the development of sexuality (World Health Organization, 2002). STIs and their complications are among the top five diseases for which adults seek treatment (World Health Organization, 2002). Finally, the consequences of unintended pregnancy, teenage childbirth, and unsafe abortion all contribute to morbidity and mortality (World Health Organization, 2002). Sexual health problems are also very common in the Western world (Guttmacher Institute, 2010, 2012; Hamilton, Martin, \& Ventura, 2010; Pazol et al., 2011). De Graaf, Kruier, van Acker \& Meijer (2012) reported that adolescents in the Netherlands experience substantial rates of sexual dysfunctions (described in paragraph 1.4). Especially girls report these problems. The burden of these problems highlights the importance of further investigating sexuality and sexual health in adolescence.

\section{Sexual health}

According to the WHO, sexual health is "a state of physical, emotional, mental and social wellbeing in relation to sexuality; it is not merely the absence of disease, dysfunction or infirmity. Sexual health requires a positive and respectful approach to sexuality and sexual relationships, as well as the possibility of having pleasurable and safe sexual experiences, free of coercion, discrimination, and violence. For sexual health to be attained and maintained, the sexual rights of all persons must be respected, protected and fulfilled" (World Health Organization, 2002).

Evidently, sexual health is not merely the absence of disease. It also includes the right of every person to have access to sexual and reproductive health care and sexual education. Furthermore, one has the right to be sexually active, and to pursue a safe and pleasurable sex life (World Health Organization, 2002). Unfortunately, the vast majority of sexual health care, education and research, focus primarily on risk behavior, such as early first sexual intercourse, STIs, and unplanned or unwanted pregnancy (Bell, Richardson, Wall, \& Goldmeier, 2006; Deligeroroglou, Christopoulos, \& Creatsas, 2006; Fagen, Stacks, Hutter, \& Syster, 2010; Harrison, Charles, \& Britt, 2009; Kang, Skinner, \& Foran, 2007; Wellings \& Parker, 2006). However, other aspects of the sexual health of adolescents may need more attention of researchers, clinicians and policy makers. Among these aspects are problematic sexual functioning and sexual dysfunctions.

\section{Sexual function}

The normative human reaction to sexual stimulation has been explained by referring to the 'sexual response cycle'. This prototypical model of sexual responding was initially designed as a four-phase cycle, including the phases of sexual arousal, plateau, orgasm and resolution (Masters \& Johnson, 1966). In the sexual arousal phase, physical and mental reactions occur as a result of physical or mental erotic stimulation. For both sexes, both psychical and mental changes will occur to prepare the body for possible penetrative sexual contact (Janssen, Prause, \& Geer, 2007). In the plateau phase, all actions and reactions started in 
the arousal phase are intensified, leading up to the point of orgasm. Orgasm is the climax of the sexual response cycle and can be experienced by both men and women. During resolution, which is the end phase of the sexual response cycle, the body slowly returns to its normal level of functioning. This phase is characterized by a general sense of wellbeing. Most men are not able to reach another orgasm during the same phase of sexual activity, because they need some recovery time. Therefore, the resolution phase is also called refractory period. During this period male sexual arousal is low or absent (see figure 1a). Some women are capable to return to the orgasm phase with further sexual stimulation and may experience multiple orgasms (see figure 1b) (Stoeckart et al., 2009). In the 1980s the phase of sexual desire was added to the sexual response cycle model, preceding the phases previously mentioned. This resulted in five phases of the sexual response cycle, including sexual desire, arousal, plateau, orgasm, and resolution (Kaplan, 1981).

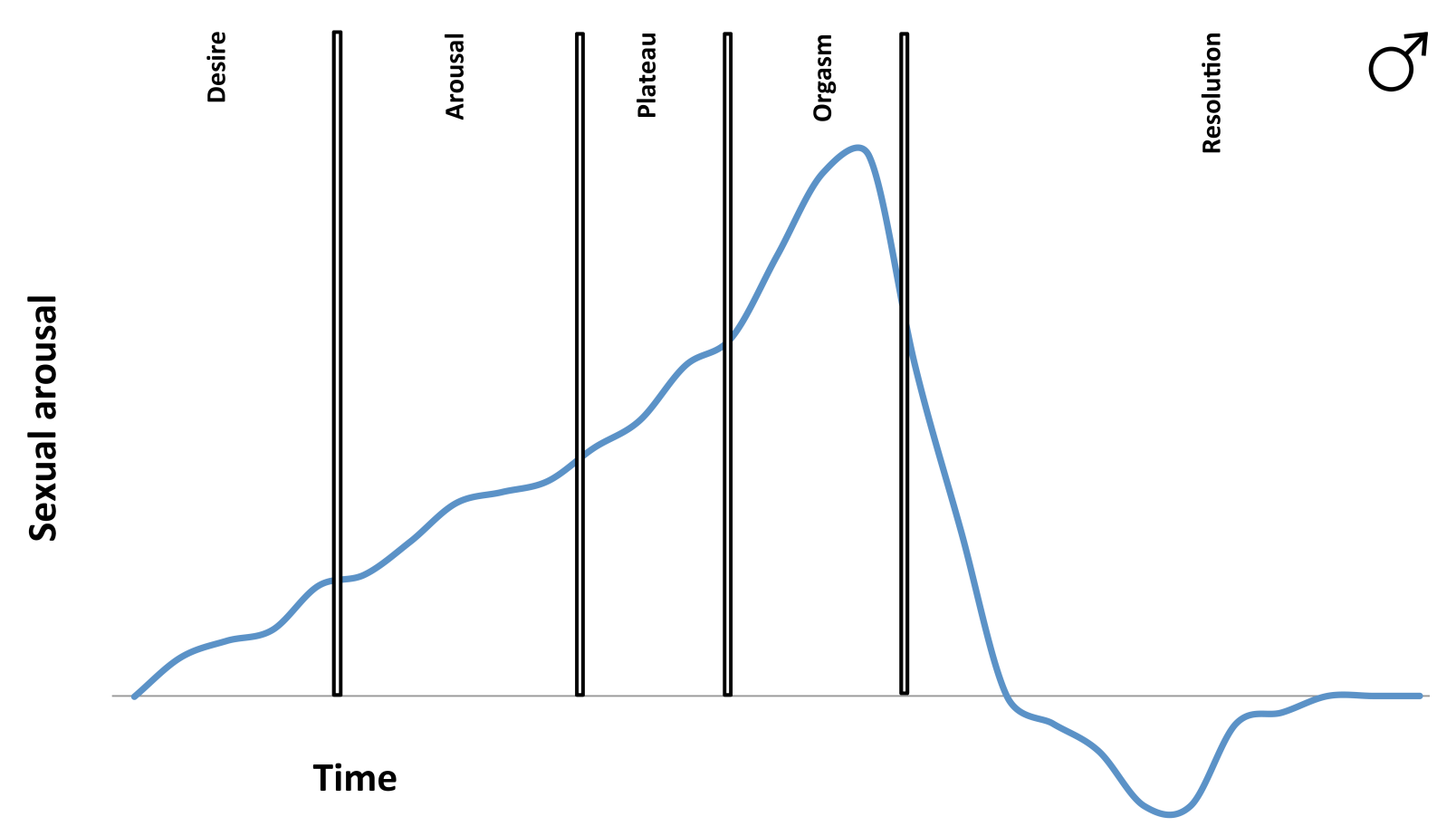

Figure 1a: The sexual response cycle in men 


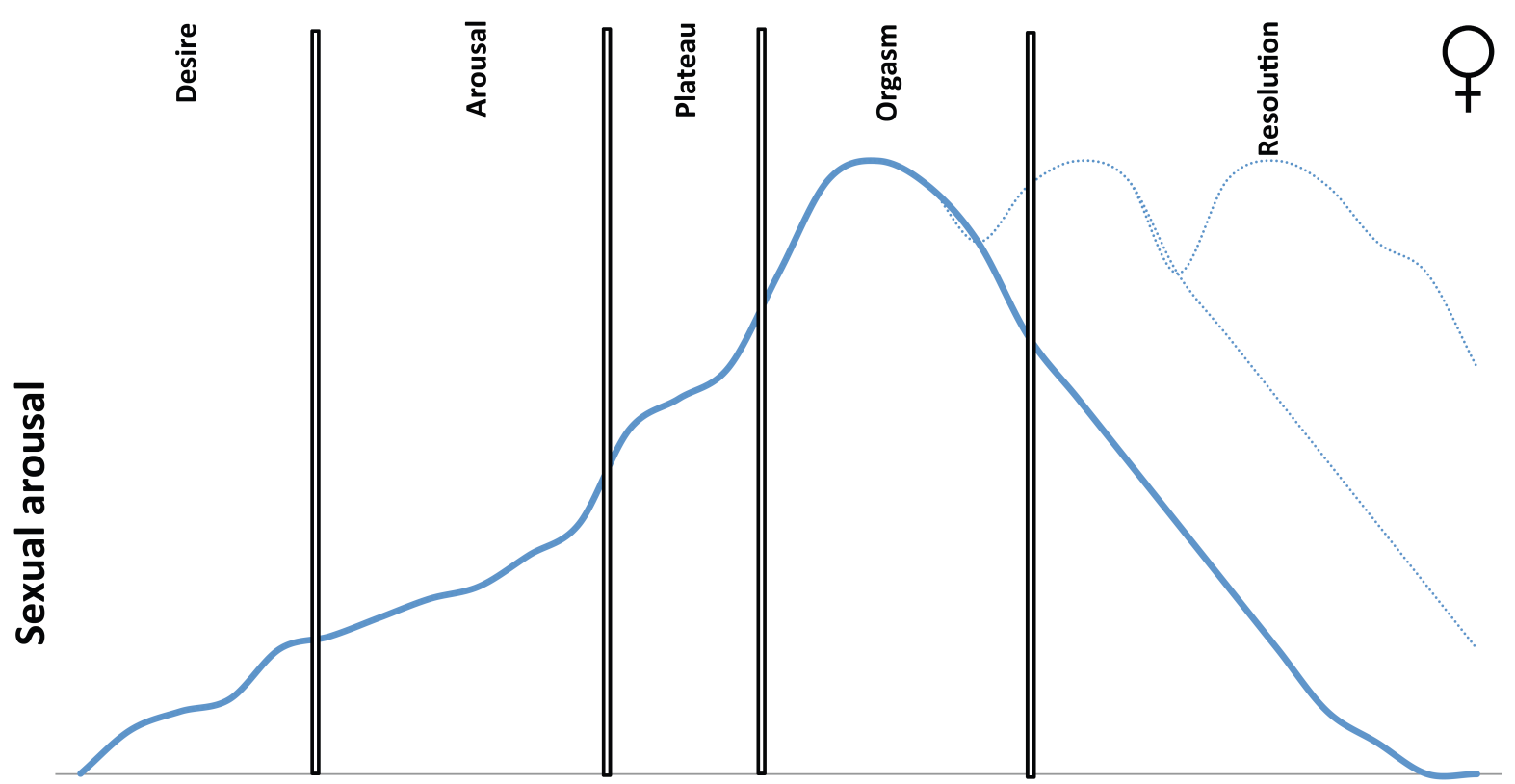

Time

Figure 1b: Sexual response cycle(s) in women (Stoeckart, et al., 2009)

\section{Sexual dysfunction}

In sexually normally functioning individuals, the transition through the sexual response cycle occurs without problems. However, this is not always the case. When someone's reaction to sexual stimulation is different from what is expected, this person may experience a sexual dysfunction. According to the Diagnostic and Statistical Manual of Mental Disorders, fifth edition (DSM-5; American Psychiatric Association, 2013), sexual dysfunctions are defined as disorders that are typically characterized by a clinically significant disturbance (present for a minimum duration of approximately 6 months) in a person's ability to respond sexually or to experience sexual. The problems can be primary (life-long) or secondary (acquired), and generalized (present in all sexual activities and situations) or situational (not present in all sexual activities and situations, for example no problems during masturbation). These disorders are not caused by another mental disorder and are not due exclusively to the direct physiological effects of a substance of a general medical condition.

In women the following sexual dysfunctions are distinguished:

- Female orgasmic disorder: marked delay in, marked infrequency of, or absence of orgasm and a markedly reduced intensity of orgasmic sensations

- Female sexual interest/arousal disorder: lack of, or significantly reduces, sexual interest/arousal, as manifested by at least three of the following:

- Absent/reduced interest in sexual activity

- Absent/reduced sexual/erotic thoughts or fantasies 
- No/reduced initiation of sexual activity, and typically unreceptive to a partners' attempts to initiate

- Absent/reduced sexual excitement/pleasure during sexual activity in almost all or all sexual encounters

- Absent/reduces sexual interest/arousal in response to any internal or external sexual/erotic cues

- Absent/reduced genital or nongenital sensations during sexual activity in almost all or all sexual encounters

- Sexual aversion disorder: persistent or recurrent extreme aversion to, and avoidance of, all (or almost all) genital sexual contact with a sexual partner

- Genito-pelvic pain/penetration disorder: persistent or recurrent difficulties with one (or more) or the following:

- Vaginal penetration during intercourse

- Marked vulvovaginal or pelvic pain during vaginal intercourse or penetration attempts

- Marked fear or anxiety about vulvovaginal or pelvic pain in anticipation of, during or as a result of vaginal penetration

- Marked tensing or lightening of the pelvic floor muscles during attempted vaginal penetration

In men the following sexual dysfunctions are distinguished:

- Delayed ejaculation: marked delay in, or absence of orgasm

- Erectile disorder: marked difficulty in obtaining and maintaining an erection during and until completion of sexual activity. Furthermore a marked difficulty in erectile rigidity

- Male hypoactive sexual desire disorder: persistently or recurrently deficient (or absent) sexual fantasies and desire for sexual activity

- Premature (early) ejaculation: persistent or recurrent pattern of ejaculation occurring during partnered sexual activity within approximately 1 minute following vaginal penetration and before the individual wishes it

Sexual dysfunctions are not uncommon in the Netherlands. Among women between the age of 15 and 70 years old, 26.7\% experience at least one sexual dysfunction. Almost every woman in this age category (92.8\%) experiences some sexual difficulties at least once in her life. Among men between the age of 15 and 70 years old, 19\% experience at least one sexual dysfunction. More than 90 percent $(90.6 \%)$ of the men in this age category experience some sexual difficulties at least once in their lives (Kedde, 2012).

Sexual dysfunctions were also explored among 608 female and 459 male adolescents, aged 15 to 24 . Among the girls, $43.4 \%$ experienced at least one sexual dysfunction. Among the boys, 27.3\% experienced at least one sexual dysfunction (Kedde, 2012).

Experiencing a sexual dysfunction can significantly impact one's emotional, mental, and social wellbeing. Men who experience premature ejaculation report reduced levels of sexual satisfaction, in addition to increased levels of personal distress and interpersonal difficulties 
(Rowland, Patrick, Rothman, \& Gagnon, 2007). Men who suffer from erectile disorder also experience considerable psychological distress and negative social consequences (Althof, 2002). Sexual dysfunctions in women are strongly linked to a lack of physical and emotional satisfaction and to unhappiness (Laumann, Paik, \& Rosen, 1999). Since it is a common disorder among both adults and adolescents, it is necessary to get more insight in the factors that are associated with the development and maintenance of sexual dysfunctions.

\section{Causes of sexual dysfunction}

Theories addressing the etiology of sexual dysfunctions predominantly state that sexual dysfunctions are not caused by one single factor, but that such problems are the result of a synthesis between biological, psychological, and social factors (Everaerd \& Moors, 1995). Biological factors that negatively impact sexual functioning may be diseases or malfunction of, among others, the skin, the nervous system, the cardiovascular and respiratory systems, muscles, and the endocrine system. For example, it is known that diabetes, asthma, kidney failure and multiple sclerosis are associated with sexual dysfunctions (Weijmar-Schultz, Incrocci, Weijenborg, van de Wiel, \& Gianotten, 2009). Furthermore, several psychological factors may cause sexual dysfunctions, including - among others - cognitive interference by distraction, irrational sexual beliefs and negative expectations about sexual performance (Barlow, 1986; de Jong \& Peters, 2009). Another influencing factor is mental status; persistent and recurrent psychological problems are often accompanied by sexual dysfunctions. Finally, social factors affect sexual functioning in many ways, especially in the context of sexual interaction. Relational problems and communication problems are not uncommon in sexually dysfunctional individuals (van Lankveld, 2007).

In addition to this more general explanation of the etiology of sexual dysfunctions, other models are proposed to explain specific sexual dysfunctions. These models focus primarily on cognitive processes linked to fear and pain (Payne, Binik, Amsel, \& Khalifé, 2005). An example is the model proposed by Barlow (1986) that explains the causes and maintaining factors of erectile disorder. Men with erectile disorder experience performance anxiety during sexual encounters, resulting in a lack of focus on sexual stimuli, hence resulting in problems with the generation or maintenance of an erection. The anxiety will be experienced again at subsequent sexual encounters, and may result in a negative spiral of fear and avoidance of sexual activities. The role of fear and fear of pain has also been confirmed in the development and maintenance of genito-pelvic pain/penetration disorders. When intercourse is experienced as painful, (the thought of) a new sexual encounter will evoke fear. The fear of pain is presumed to decrease genital sexual arousal on the one hand and to increase pelvic floor muscle tension on the other hand. The combination of vaginal dryness and pelvic floor muscle tension causes friction between the penis and the vagina, resulting in tissue damage, which proximally causes pain (Spano \& Lamont, 1975).

However, the link between sexual dysfunctions and fear and (fear of) pain appears insufficient, because it explains only part of the variability of problematic sexual functioning. Disgust might be one of the additional factors that may have a role in sexual dysfunctions. It has been proposed that disgust is evolved as a first line of defense to protect humans from 
contamination by infectious agents (Oaten, Stevenson, \& Case, 2009). Via eliciting the urge to withdraw from the disgusting cue, disgust facilitates the avoidance of physical contact with pathogens. Sexual behavior represents an obvious threat for the transmission of disease. The close physical contact, body apertures, and exchange of bodily fluids that are implied in sexual behavior provide ample opportunity for the transmission of pathogens. In line with the idea that disgust might be involved in sexual dysfunctions, it has been found that women with vaginismus (form of genito-pelvic pain/penetration disorder as defined by DSM-IV-TR; American Psychiatric Association, 2000) show enhanced automatic sex-disgust associations and facial expressions of disgust when exposed to a sex stimuli (Borg, de Jong, \& Weijmar-Schultz, 2010). Subsequent research corroborated these findings by showing that women with vaginismus are characterized by heightened disgust for sexual contaminants (e.g. sperm) (van Overveld et al., 2012). Although these earlier studies provided evidence to suggest that enhanced sexual disgust is involved in sexual dysfunctions, the question remains whether this relationship represents a general phenomenon that can also be found in adolescents in a non-clinical range and whether enhanced sexual disgust might indeed be involved with sexual arousal. In this dissertation the association between sex and disgust in an adolescent non-clinical population will also be discussed in more detail.

\section{Sexual competence and interaction competence}

The prevention of sexual health problems is an important aspect of sexual health education. Two factors that are involved in sexual health education are sexual competence and interaction competence (Hirst, 2008; Wellings, et al., 2001). Sexual competence can be described as the ability, the skills and knowledge to be involved in sexual activities. A successful outcome would be a positive sexual experience, more specifically an experience that does not threaten sexual health in the physical sense (avoiding STIs and to use contraception) and in the emotional sense (experiencing pleasure and minimal or no regret). Interaction competence can be described as the ability, skills or knowledge regarding the interactional process with respect to sexual activities. It concerns honoring the rights, wishes and desires of all those involved (Hirst, 2008). Due to the lack of a suitable questionnaire to measure these aspects, we developed the Sexual Competence and Interaction Competence in Youth ( $\mathrm{SCICY}$ ) questionnaire. In this dissertation the development process and the psychometric properties of this new instrument will be discussed.

\section{Treatment of sexual dysfunction in adolescents}

For the treatment of sexual dysfunctions a wide range of interventions is available, including psycho-education and advice, psychological interventions, and biomedical interventions.

In psycho-education the causal and maintaining factors are explained that may play a role in the specific sexual dysfunction. Merely providing adequate and relevant information about potential causes of the client's problem may yield a positive therapeutic effect (van Lunsen, Weijenborg, Vroege, \& Meinhardt, 2009). The client and the partner may start applying this information to improve their sexual functioning. For example, it is possible that 
after only a single session of psycho-education the communication between both partners improves significantly. Furthermore, psycho-education to correct myths about sexuality can be very important in this first phase of sexual health care provision (van Lunsen, et al., 2009). With respect to psychological interventions, several treatment options are possible. In most cases, psychological interventions for sexual dysfunctions are based on the principles of cognitive behavior therapy. From a learning psychology perspective, sexual dysfunctions are the result of learned fear, such as performance anxiety and fear of pain. Therefore, behavioral approaches in the treatment of sexual dysfunction focus on reducing fear and avoidance behavior. Several interventions are used, including systematic desensitization (SD). SD uses counterconditioning and relaxation instructions to reduce the conditioned fear (van Lankveld, 1998). Another behavioral procedure is exposure in vivo in which avoidance behavior is prevented, allowing anxiety responses to extinguish. The components of the sex therapy of Masters and Johnson, especially the sensate focus exercises, which can be seen as behavioral procedures, can be integrated in the treatment. From a cognitive perspective, sexual dysfunctions are seen as the result of dysfunctional or irrational sexual cognitions. Therefore, cognitive treatment focuses on modifying these dysfunctional cognitions (Everaerd \& Dekker, 1985). Sexual fantasy training is an example of cognitive therapy (Koukounas \& Over, 1997). In clinical practice these two components, behavioral and cognitive interventions, are often combined in the treatment of sexual dysfunctions (van Lankveld, 2007).

Finally, biomedical interventions may also be suitable in the treatment of sexual dysfunctions. Especially for male sexual dysfunctions, several pharmacotherapeutic options (such as sildenafil ${ }^{\circledR}$ for erectile dysfunction) are available. Pelvic floor physical therapy is often used in women with sexual pain disorders.

In general, the before mentioned treatment options were developed to treat adults with sexual dysfunctions. Unfortunately, there is no scientific information available if they can be also used successfully in the treatment of adolescents. In addition to the lack of evidence regarding the efficacy in adolescents, the acceptability and accessibility of these treatment options for adolescents have been questioned. De Graaf, Meijer, Vanwesenbeeck and Poelman (2005) found that the referral rate to regular sexual health care of adolescents with sexual dysfunctions by general practitioners or Public Health Service (PHS) is lower than the percentage of sexual dysfunctions among adolescents might suggest due to the loss of anonymity, financial costs and lack of familiarity with and confidence in regular sexual health care.

To provide adequate treatment for adolescents with sexual dysfunctions, a new treatment is necessary that overcomes the problems that go with referral to intensive sexual healthcare. For this purpose, the Rotterdam-Rijnmond PHS appointed a sex counselor who provides three, free of charge, and anonymous consultations for adolescents with a sexual dysfunction. This treatment is called 'brief sex counseling' (BSC) and aims to provide tailored and practical advice. The sessions include providing information, psycho-education and cognitive behavior therapy aspects. Furthermore, home exercises, based on the sensate 
focus exercises of Masters and Johnson (1970), have a prominent role in the sessions. In this dissertation the specific elements of this treatment will be explained in more detail

\section{Aim and outline of this dissertation}

As mentioned before, previous research on sexual health has predominantly focused on preventing STIs, HIV and unwanted pregnancy. However, sexual dysfunctions are common among adolescents, research addressing these problems is very limited. The aim of the research reported in this dissertation was to explore several aspects of sexual dysfunctions among adolescents. The first aspect that is addressed is the level of knowledge that adolescents have about sexuality and sexual health. Furthermore, the relationship between disgust and sexual health was examined. Furthermore, a questionnaire that measures sexual competence and interaction competence in adolescents was developed and its psychometric properties were investigated. Finally, the efficacy of treatment of sexual dysfunctions in adolescents and its cost-effectiveness from a societal viewpoint were investigated. These research interests were pursued in separate empirical studies, which are reported in the remaining chapters of the dissertation.

In chapter two, adolescents' perceptions of their sexuality, sexual health and sexual health problems, and sexual dysfunctions are investigated using a qualitative study method. This study contributes to the insight regarding young people's perceptions of sexual health and has served as a starting point for the development of a suitable and potentially effective novel treatment approach for sexual health problems.

In chapter three, the development and validation of a questionnaire, which aims to measure the sexual competence and interaction competence in adolescents, is reported. Other measures of sexual competence and interaction competence have previously been developed (de Graaf et al., 2005; Snell, 1995; Wellings et al., 2001). However, concerns can be raised about the effectiveness and usefulness of these measures. Although these instruments measure relevant aspects of sexual health, they do not incorporate the full range of elements of sexual competence and interaction competence. Furthermore, these components have not yet been combined in one single questionnaire. To address the need for a single questionnaire for adolescents, we aimed to construct a questionnaire, called the Sexual Competence \& Interaction Competence in Youth (SCICY) that measures both sexual competence and interaction competence in youth.

In chapter four an experimental study is reported. The aim was to investigate the association between disgust and sexual functioning in a non-clinical adolescent group and to investigate the association between the automatic sex-disgust association and sexual arousal. Both implicit and explicit measures were used.

In the subsequent chapters, three studies related to the treatment of sexual dysfunctions in adolescents are described. Chapter five presents the design of the study. The treatment, recruitment strategy, procedure, primary and secondary outcome measures, and planned analyses are described. 
In chapter six a study is reported into the clinical effectiveness of BSC for sexual dysfunctions. It is hypothesized that BSC will be more effective with respect to sexual, mental and physical functioning than no treatment and equally effective as intensive sexual healthcare.

In chapter seven the findings are reported from the economic evaluation of BSC, in which its cost-effectiveness is investigated from a societal perspective. It is hypothesized that BSC will be more cost-effective than no treatment and intensive sexual healthcare. 


\section{REFERENCES}

Althof, S. (2002). Quality of life and erectile dysfunction. Urology, 59, 803-810.

American Psychiatric Association. (2013). Diagnostic and statistical manual of mental disorders (5th, ed.). Washington, DC.

American Psychiatric Association. (2000). Diagnostic and statistical manual of mental disorders (4th, text revised ed.). Washington, DC.

Barlow, D. (1986). Causes of sexual dysfunction: The role of anxiety and cognitive interference. Journal of Consulting and Clinical Psychology, 54, 140-148.

Borg, C., de Jong, P., \& Weijmar-Schultz, W. (2010). Vaginismus and dyspareunia: Automatic vs. deliberate disgust responsivity. Journal of Sexual Medicine, 7, 2149-2157.

Bell, C., Richardson, D., Wall, M., \& Goldmeier, D. (2006). HIV-associated female sexual dysfunction - clinical experience and literature review. International Journal of STD \& AIDS, 17, 706-709.

Choudhury, S., Blakemore, S., \& Charman, T. (2006). Social cognitive development during adolescence. Social Cognitive and Affective Neuroscience, 1, 165-174.

Collins, W., Welsh, D., \& Furman, W. (2009). Adolescent romantic relationships. Annual Review of Psychology, 60, 631-652.

de Graaf, H., Meijer, S., Vanwesenbeeck, I., \& Poelman, J. (2005). Seks onder je 25e. Seksuele gezondheid van jongeren in Nederland anno 2005. Delft: Eburon.

de Graaf, H., Kruijer, H., van Acker, J., \& Meijer, S. (2012). Seks onder je 25e: Rutgers WPF.

de Jong, P., \& Peters, M. (2009). Sex and the sexual dysfunctions: The role of disgust and contamination sensitivity. Washington, DC: American Psychological Association.

Dekovic, M., Noom, M., \& Meeus, W. (1997). Verwachting van jongeren en ouders over ontwikkelingstaken in de adolescentiefase. Kind en Adolescent, 18, 114-125.

Deligeroroglou, E., Christopoulos, P., \& Creatsas, G. (2006). Contraception in adolescence. Annals of the New York Academy of Sciences, 1092, 78-90.

Everaerd, W., \& Dekker, J. (1985). Treatment of male sexual dysfunction: Sex therapy compared with systematic desensitization and rational emotive therapy. Behaviour Research and Therapy, 23, 13-25.

Everaerd, W., \& Moors, J. (1995). De biopsychosociale benadering van seksualiteit. In K. Slob, C. Vink, J. Moors \& W. Everaerd (Eds.), Seksuologie voor de arts. Houten: Bohn Stafleu van Loghum.

Fagen, M. C., Stacks, J. S., Hutter, E., \& Syster, L. (2010). Promoting implementation of a school district sexual health education policy through an academic-community partnership. Public Health Reports, 125, 352358.

Guttmacher Institute. (2010). U.S. teenage pregnancies, births and abortions: National and state trends and trends by race and ethnicity.

Guttmacher Institute. (2012). Facts on American teens' sexual and reproductive health.

Hamilton, B., Martin, J., \& Ventura, S. (2010). Births: Preliminary data for 2009: National Vital Statistics Reports.

Harrison, C., Charles, J., \& Britt, H. (2009). Sexual health. Australian Family Physician, 38, 379.

Hirst, J. (2008). Developing sexual competence? Exploring strategies for the provision of effective sexualities and relationships education. Sex Education, 8, 399-413.

Janssen, E., Prause, N., \& Geer, J. (2007). The sexual response. In J. Cacioppo, L. Tassinary \& G. Berntson (Eds.), Handbook of psychophysiology. New York: Cambridge University Press.

Kang, M., Skinner, R., \& Foran, T. (2007). Sex, contraception and health. Australian Family Physician, 36, 594600.

Kaplan, H. (1981). Stoornissen in het seksueel verlangen. Nijmegen: Dekker en van de Vegt.

Kedde, H. (2012). Seksuele disfuncties in Nederland: prevalentie en samenhangende factoren. Tijdschrift voor Seksuologie, 36, 98-108.

Koukounas, E., \& McGabe, M. (1997). Sexual and emotional variables influencing sexual response to erotica. Behaviour Research and Therapy, 35, 221-231.

Laumann, E., Paik, A., \& Rosen, R. (1999). Sexual dysfunctions in the United States: prevalence and predictions. Journal of the American Medical Association 281, 537-544. 
Masters, W., \& Johnson, V. (1966). Human sexual respons. Boston: Little, Brown \& Co.

Masters, W., \& Johnson, V. (1970). Human sexual respons. Boston: Little, Brown \& Co.

Oaten, M., Stevenson, R., \& Case, T. (2009). Disgust as a disease-avoidance mechanism. Psychological Bulletin, 135, 303-321.

Payne, K., Binik, Y., Amsel, R., \& Khalifé, S. (2005). When sex hurts, anxiety and fear orient attention towards pain. European Journal of Pain, 9, 427-436.

Pazol, K., Zane, S., Parker, W., Hall, L., Gamble, S., Hamdan, S., et al. (2011). Abortion surveillance: United States, 2007: National Center for Chronic Disease Prevention and Health Promotion, CDC.

Rowland, D. L., Patrick, D. L., Rothman, M., \& Gagnon, D. D. (2007). The psychological burden of premature ejaculation. The Journal of Urology, 177, 1065-1070.

Spano, L., \& Lamont, J. (1975). Dyspareunia: A symptom of female sexual dysfunction. The Canadian Nurse, 71, $22-25$.

Stoeckart, R., Swaab, D., Gijs, L., de Ronde, P., \& Slob, K. (2009). Biologie van de seksualiteit: Endocrinologische, anatomische en fysiologische aspecten. In L. Gijs, W. Gianotten, I. Vanwesenbeeck \& P. Weijenborg (Eds.), Seksuologie. Houten: Bohn Stafleu van Loghum.

Susman, E., \& Ragol, A. (2004). Puberty and psychological development. In R. Lerner \& L. Steinberg (Eds.), Handbook of adolescent psychology. New York: Wiley.

van Lankveld, J. (1998). Seksuele dysfuncties. Houten: Bohn Stafleu van Loghum.

van Lankveld, J. (2007). Omgaan met een seksueel probleem. Houten: Bohn Stafleu van Loghum.

van Lunsen, R., Weijenborg, P., Vroege, J., \& Meinhart, W. (2009). Diagnostiek en interventies. In L. Gijs, W. Gianotten, I. Vanwesenbeeck \& P. Weijenborg (Eds.), Seksuologie. Houten: Bohn Stafleu van Loghum.

van Overveld, M., De Jong, P., Peters, M., van Lankveld, J., Melles, R., \& Ter Kuile, M. (2012). The sexual disgust questionnaire: A psychometric study and first exploration in patients with sexual dysfunctions. Journal of Sexual Medicine, 10, 396-407.

Wellings, K., Nanchahal, K., Macdowall, W., McManus, S., Erens, B., Mercer, C., et al. (2001). Sexual behaviour in Britain: early heterosexual experience. The Lancet, 358, 1843-1850.

Wellings, K., \& Parker, R. (2006). Sexuality education in Europe - A reference guide to policies and practices: IPPF European Network.

Weijmar-Schultz, W., Incrocci, L., Weijenborg, P., van de Wiel, H., \& Gianotten, W. (2009). Ziekte, handicap en medische interventies. In L. Gijs, W. Gianotten, I. Vanwesenbeeck \& P. Weijenborg (Eds.), Seksuologie. Houten: Bohn Stafleu van Loghum.

World Health Organization. (2002). Defining sexual health. Report of a technical consultation on sexual health. Geneva: World Health Organization.

Zimmerman-Gernbeck, M., Siebenbruner, J., \& Collins, W. (2004). A prospective study of intraindividual and peer influences on adolescents' heterosexual romantic and sexual behavior. Archives of Sexual Behavior, 33, 381-394. 
Chapter 1 


\section{Chapter 2}

\section{Perceptions of sexuality and sexual health among young people in the Netherlands}

A. Grauvogl, S. Stutterheim, S. Evers, \& J. van Lankveld

This chapter has been published as:

Grauvogl, A., Stutterheim, S., Evers, S., \& van Lankveld, J. (2012). Perceptions of sexuality and sexual health among young people in the Netherlands. Sexual and Relationship Therapy, $27,110-121$ 


\section{ABSTRACT}

Sexual health problems are not uncommon among adolescents in the Netherlands, and finding the proper treatment for such problems is often challenging. More insight regarding adolescents' perceptions of sexuality and its associated problems is needed to improve both treatment and education. This qualitative study of 22 adolescents (13 to 25 years) explored perceptions of sexuality and sexual health. The results show that sexuality is narrowly defined by adolescents, with focus clearly being placed on physical aspects of sexuality and sexual intercourse in particular. Sexual problems are usually defined as physical or medical problems. The data show that participants had limited knowledge regarding sexual problems associated with sexual functioning. Schools, parents, and culture all appear to play a role in perceptions of sexuality and sexual health. In their totality, the findings suggest that knowledge about the complexity of sexuality and sexual health is lacking among adolescents in the Netherlands. We recommend broader sexual health education programs in schools that include the discussion of multiple aspects of sexuality, including pleasure. We also suggest that parents take a more prominent role in educating their children about sexuality. 


\section{INTRODUCTION}

Sexual health is described by the World Health Organization (WHO) as: "... a state of physical, emotional, mental and social wellbeing in relation to sexuality; it is not merely the absence of disease, dysfunction or infirmity" (World Health Organization, 2002).

Evidently, sexual health is not merely the absence of disease. Unfortunately, in most sexual health research and prevention programs, focus is primarily placed on risk behavior, such as unplanned or unwanted pregnancy and sexually transmitted infections (STIs) (Bell, Richardson, Wall, \& Goldmeier, 2006; Deligeroroglou, Christopoulos, \& Creatsas, 2006; Department of Health, 2009; Harrison, Charles, \& Britt, 2009; Kang, Skinner, \& Foran, 2007). This is exemplified by a study that investigated the sexual health of young people in the Netherlands. De Graaf, Meijer, Poelman and Vanwesenbeeck (2005) explored sexual health among 2382 boys and 2439 girls aged 12 to 25 and concluded that Dutch young people are, generally speaking, sexually healthy. This conclusion was based on data showing, firstly, that, among youth attending school, 90-93\% used contraception during their first intercourse and, secondly, non-use of condoms decreased from $27 \%$ in 1995 to $17 \%$ in 2005 . The emphasis in this study was clearly on risk reduction and the presence of sexual function problems as factors contributing to sexual health was disregarded in their conclusion. However, at the same time, in the same study, data on sexual dysfunction were collected. This data showed that young people in the Netherlands experience problems with sexual desire (e.g. a lack of sexual desire or differences in sexual desire between partners) and sexual arousal (e.g. male erectile dysfunction, female lubrication disorder and low subjective sexual arousal among both men and women) as well as orgasm or pain problems (de Graaf et al., 2005; see also APA, 2000). Approximately one in every six girls reported reduced sexual desire and one in every four reported that they frequently or often do not have an orgasm during sex. Further, a significant portion of the girls (57\%) reported experiencing pain during intercourse regularly or often. Boys reported fewer problems. What is most striking is that these problems were perceived as normal (de Graaf et al., 2005). One must ask if young people in the Netherlands are indeed sexually healthy when sexual health problems are so prevalent?

Experiencing a sexual function problem, even if it is regarded as normal, can significantly impact one's emotional, mental and social wellbeing. Research has shown that men who experience premature ejaculation also report lower levels of sexual satisfaction in addition to higher levels of personal distress and interpersonal difficulties (Rowland, Patrick, Rothman, \& Gagnon). Men who suffer from erectile dysfunction also experience considerable psychological distress and negative social consequences (Althof, 2002) and sexual function problems in women are strongly linked to a lack of physical and emotional satisfaction and unhappiness (Laumann, Paik, \& Rosen, 1999). Further, leaving sexual function problems untreated can result in secondary problems like depression and relationship problems (Grauvogl et al., 2009). Women are particularly at risk for these secondary problems. Bakker and Vanwesenbeeck (2006) reported that only a third of women who experience a sexual function problem, and are in need of help, actually receive 
help. This is in contrast to men, who generally find the help they need. In men with a sexual function problem, only $4 \%$ go untreated (Akre, Michaud, \& Suris, 2010).

The tendency to focus primarily on the (absence of) disease is not only present in sexual health research but also in sexual health education. In fact, the focus in sexual health education programs is often limited to pregnancy and disease prevention and the placement of such programs in school curriculum reflects this. In the USA (Fagen, Stacks, Hutter, \& Syster, 2010) and in Europe (Wellings \& Parker, 2006) sexual health is typically taught in the biology curriculum. This incorporation of sexual health education in the biology curriculum reflects a fairly pervasive emphasis on the physical, health-related aspects of sexual health and a weaker focus on the emotional, mental and psychological aspects of sexual health (Wellings \& Parker, 2006). A lack of awareness regarding emotional, mental, and psychological aspects of sexual health is highly problematic. If adolescents are uninformed regarding the importance of these aspects and if they are uninformed about the importance of pleasure during sex and how such pleasure can be achieved and maintained, they may, as demonstrated by Bakker and Vanwesenbeeck's (2006) findings, not be alarmed or likely to seek help if sexual functioning problems present. In the absence of broader sexual health education, adolescents are likely to perceive sexual problems as normal and thereby risk potential physical and psychological side effects.

When adolescents who experience sexual health problems recognize and acknowledge that they have a problem, help should be sought. Unfortunately, a substantial barrier to seeking help exists. The most important reasons for not seeking help for a sexual health problem include finding it too difficult to look for help and being afraid to ask for help. Furthermore, thresholds like a lack of familiarity with, and lack of confidence in, the healthcare services available may inhibit help seeking. Also, a loss of anonymity and financial costs further reduce the likelihood that adolescents find suitable treatment when confronted with a sexual health problem (Akre, et al., 2010; Bakker et al., 2009; Bakker \& Vanwesenbeeck, 2006).

In this exploratory study, we set out to identify adolescent's perceptions of sexual health and sexual health problems. We considered this to be imperative as greater insight regarding adolescents' perceptions of sexual health serves as important input for the development and implementation, or adaptation, of suitable and effective treatment for sexual health problems and appropriate sexual health education.

\section{METHODS}

\section{Study settings and design}

Qualitative data were gathered in the Netherlands in May and June of 2009 at a secondary school in Hoensbroek and at the Rotterdam-Rijnmond Public Health Service (PHS). The goal of this qualitative research was to illuminate social phenomena in natural rather than experimental settings by emphasizing the meanings, experiences, and views of participants. Adolescents' help seeking behavior and their interactions with health care professionals are 
highly complex phenomena that, in our opinion, could benefit from an inductive approach that provides answers to complex questions being posed by health care professionals and policymakers (Pope \& Maysa, 1995).

Our data were derived from face-to-face, semi-structured individual interviews and a focus group discussion (FGD). Both individual interviews and FGDs are widely used to explore people's perceptions, attitudes, and behaviors towards health and healthcare (Boldero \& Fallon, 1995; Klein, Wild, \& Cave, 2005; Pope \& Maysa, 1995). We opted to combine methods so as to gain insight from an individual perspective as well as insight brought forth by stimulating group dynamics and interaction.

\section{Participants}

A total of 22 heterosexual adolescents aged 13 to 25 residing in either Hoensbroek or Rotterdam participated in this study. This particular age group was chosen because it covers an important developmental phase in which perceptions of sexuality and accompanying problems are formed. Furthermore, the selected age range included adolescents at different stages of their sexual development (e.g. with and without experience with sexual intercourse) and personal development (in school and in the transition from school to work). In sampling, we did not seek to acquire a large, representative, probability-based sample. Rather, as is the norm in exploratory studies, sampling was purposive. Participants were sampled based on specific predetermined criteria in order to cover a broad range of heterogeneous characteristics (Polit \& Beck, 2010; Pope, van Royen, \& Baker, 2002). We thus opted to sample two different areas in the Netherlands as this allowed for the representation of both adolescents living in a rural area with predominantly European ethnicity (Hoensbroek) and adolescents living in an urban center with substantial ethnic diversity (Rotterdam).

\section{Procedure}

Prior to conducting the interviews and FGD, a topic list with open-ended questions was constructed via two consensus meetings with experts in the field of adolescent development and sexual health care and the researchers. The resulting topic list, used as a guide during both the interviews and the FGD, comprised three major components: 1) perceptions of sexuality and sexual health; 2) perceptions of problems and concerns regarding sexuality and sexual health; and 3) how to treat sexual health or sexual functioning problems. The final component was included as a means to explore possible new treatment strategies. At the same time, opportunities to discuss other relevant matters were provided. This was particularly important in the investigation of sensitive subjects like sexual health (Forman et al., 2008; Hancock, 2002; Power, 2002).

Participants were recruited through a secondary school in Hoensbroek and the local public health service (PHS) in Rotterdam. The secondary school and PHS were first approached and asked if they would permit the recruitment of students (at the school) and STI clinic clients (at the PHS). Both agreed to cooperate. At the school, the parental advisory 
board was first consulted and once approval was granted, an information letter was distributed to several classes. Interested participants contacted the researcher who subsequently scheduled an interview or FGD. At the PHS, the researcher approached adolescents waiting for an STI consultation directly and asked them if they would be willing to participate in an interview immediately after their consultation. For participants under 18 , parental consent was provided. For participants over 18, informed consent was provided directly. The individual interviews took approximately 45 minutes and the FGD lasted about 90 minutes. The five FGD participants were selected from one class as it was thought that students who knew each other would be more open and trusting during the FGD. To stimulate discussion, the researcher used group process techniques such as summarizing statements, asking for examples, encouraging less dominant participants, and using generic prompts (e.g. "tell me more" and "yes"). All participants received a $€ 10$ credit note for their participation.

\section{Data analysis}

Audiotape recordings were made of the individual interviews and the FGD. These recordings were subsequently transcribed verbatim and then imported into one file. To gain an overall impression, the first author and a research assistant independently read the data repeatedly. Text representing participant's responses to the questions were then marked and a preliminary description of their individual views was noted. Relevant excerpts of text were then grouped into categories and given a suitable label (coding). This process was conducted manually and continued until saturation (e.g., no new themes presented and redundancy is achieved) was reached (Polit \& Beck, 2010).

\section{RESULTS}

\section{Demographics}

A total of 22 heterosexual adolescents participated in this study, 17 of which were interviewed and 5 of which participated in the FGD. Among interview participants, eleven were girls (nine from the Netherlands, one from Suriname, and one from the former Netherland Antilles) and six were boys (five from the Netherlands and one from Suriname). Ages ranged from 13 to 25 . Five were in a relationship at the time of the interview. All had completed primary school, nine were attending secondary school, five were enrolled in postsecondary education, and three had completed postsecondary education and were working. The FGD comprised three boys (two from the Netherlands and one from Suriname) and two girls (one from the Netherlands and one from India), aged 16 to 18. One was in relationship at the time of the study and all were attending secondary school.

The ratio of participants with European versus non-European ethnicity was representative of the Dutch population in 2010 (i.e. 13.7\% of participants had a non- 
European ethnicity versus $10 \%$ in the general population) (Central Bureau for Statistics, 2010).

Table 1: Demographics

\begin{tabular}{|c|c|c|c|}
\hline & Age & Sexual experience & Relationship \\
\hline \multirow[t]{13}{*}{ Female } & 13 & None & No \\
\hline & 14 & None & No \\
\hline & 14 & None & No \\
\hline & 14 & None & No \\
\hline & 15 & Intercourse, oral and manual sex & Yes \\
\hline & 16 & Intercourse and manual sex & No \\
\hline & 17 & Oral and manual sex & No \\
\hline & 23 & Intercourse, oral and manual sex & No \\
\hline & 23 & Intercourse, oral and manual sex & No \\
\hline & 24 & Intercourse, oral and manual sex & Yes \\
\hline & 24 & Intercourse, oral and manual sex & Yes \\
\hline & 24 & Intercourse, oral and manual sex & Yes \\
\hline & 25 & Intercourse, oral and manual sex & Yes \\
\hline \multirow[t]{9}{*}{ Male } & 14 & None & No \\
\hline & 14 & None & No \\
\hline & 14 & None & No \\
\hline & 17 & Oral and manual sex & No \\
\hline & 17 & Intercourse, oral and manual sex & Yes \\
\hline & 18 & Intercourse, oral and manual sex & No \\
\hline & 19 & Oral and manual sex & No \\
\hline & 23 & Intercourse, oral and manual sex & No \\
\hline & 25 & Intercourse, oral and manual sex & Yes \\
\hline
\end{tabular}

\section{Interviews}

\section{Perceptions of sexuality and sexual health}

When asked what sexuality and sexual health means to them, most participants emphasized sexuality as actual sexual intercourse. In the words of one girl (aged 15), sexuality is "physical contact with someone else". Another participant stated that sexuality is "simply having sex with your partner" (14 year old girl). In most responses, participants conveyed what sexual intercourse means to them. They frequently indicated that sex is about pleasure: "It's not about procreation but more for pleasure" (17 year old boy). According to one young woman, "it's relaxing" (24 year old girl). At the same time, many participants conveyed that sexual intercourse is about more than merely physically connecting and experiencing pleasure. Most stated that sex is something you do when you love someone and some said that sex creates an emotional bond: "It's about expressing your love for your 
boyfriend. It's attraction - something that makes you feel good. It strengthens your connection" (24 year old girl). In the words of one young man, aged 25, sex is, "a way of expressing love with both your body and your spirit. It's not just about needs but about sharing how you feel about one another". Not unsurprisingly, sexual intercourse was considered by many participants to be integral: "Sex is very important in my life. I don't think I could do without if I had to" (23 year old girl). Occasionally, participants indicated that they have sex in the context of one-night stands: "Most of my sex is with different partners. I do know them and I have sex with them" (24 year old girl).

In addition to connecting sexuality with sexual intercourse, participants, especially the younger participants, connected sexuality and sexual health with pregnancy and STI prevention: "At school, we were told about STIs" (14 year old boy); "We also received sex education about contraception" (14 year old girl). Occasionally, participants mentioned sexual preference as an aspect of sexuality: "It's, in any event, about what your orientation is" (19 year old boy).

What is noteworthy regarding participants' responses to questions about the meaning of sexuality is the fact that the focus was clearly physical. In all responses, sexuality was either about sexual intercourse, STIs, pregnancy prevention, or sexual orientation. Emotional aspects, albeit mentioned, played a subordinate role. It is possible that the young age of some of the participants, possibly combined with a lack of experience, contributed to the subordinate role of emotional aspects of sexual health. Furthermore, we found no differences between boys and girls. Additionally, the mental and social function of sexuality and the existence of sexual functioning problems were not mentioned at all.

\section{Discussing sexual preferences}

In order to gain additional insight in participant's conceptions of sexuality, we asked about communication with partners. Most reported intentions to talk to their partner about their sexual desires but that this is not always easy. Some reported feeling ashamed or uncomfortable but that this dissipates in time. The longer you are together with someone, the easier it is to discuss sexual preferences. One girl, aged 16, stated: "If you've been in a relationship for a while, then you can do it [talk about sexual preferences] but if you do it early on, it's embarrassing. You haven't been with that person for very long and you like them. With everything you do and say, you think, 'I hope I'm not doing something wrong.' And once you've been together for a while, then you trust each other more". Another participant said, "I think if you do that [talk about sexual preferences] early on, that the whole thing will flop. It's a total letdown" (17 year old boy). Lastly, one young woman, aged 23, said that she talks about, "what I like and what he likes. I'm open about that - less so in the beginning. You have to get to know each other." These statements suggest that being in a long-term relationship improves one's willingness and capacity to communicate with one's partner about sexuality and sexual health. Thus a long-term relationship may act as a protective factor against sexual health problems. 


\section{Influences on perceptions of sexuality and sexual health}

Participants were also asked about the role their parents have played in their perceptions of sexuality. Some indicated that their parents were particularly open about sex. One participant said, "My mom and I are close. We've always been able to talk about things" (15 year old girl). Another stated, "We could talk about everything at home. I was brought up pretty liberally. I appreciated that. We still talk about things - not in detail - but if there's something I need to talk about" (25 year old girl). Other participants indicated that sexuality is not something they can discuss with their parents. One girl, aged 17, conveyed that, "In my home, we don't talk about it. If you say sex, they totally shut down". Another participant said, "My parents are pretty conservative and there's not a lot of talk. I'm the oldest and I was also the quietest. They never worried about me but the first time I went on vacation, there was this five minute talk with, 'Take condoms along, etc.'” (23 year old boy).

Culture was also suggested as a relevant influence on participants' perceptions of sexuality and sexual health. Western cultures were perceived to foster a more open and permissive perception of sexuality and sex than Islamic cultures, where, according to participants, the normative view of sexuality is considered more restrictive. In the words of one participant, "I had a Muslim girlfriend. She was open with me but really careful with her previous boyfriend. She was scared that her family would find out and they are really strict. Muslims do it secretly. Even though we had a steady relationship, it had to be a secret" (25 year old boy).

Clearly, schools, parents, and culture were considered by participants to play a substantial role in the development of adolescents' concept of sexuality and sexual health. It seems that when sexual health education at school focuses on mere disease prevention, when parents fail to discuss sexuality with their children, and when cultural taboos on talking about sexuality pervade, perceptions of what sexuality and sexual health entail are limited and quite narrow in focus.

\section{Problems with or concerns about sexuality and sexual health}

When asked if they had problems, concerns, or questions about sexuality and sexual health, most participants indicated no problems or concerns. Exceptions were some younger participants that had little or no experience with partnered sexual contact. These participants reported curiosity about sex and wondering what they would need to do if they had sex. For example, one boy, aged 15, said he had concerns, "a while ago, about how things work with sex and what you do. Now I know through my brother and stuff." Another participant said she went to youth information services to ask about sex and safe sex (14 year old girl).

Participants were subsequently asked to imagine possible problems related to sexuality and sexual health. Their answers were consistently limited to problems relating to STIs and pregnancy: "A condom could break and the girl could get pregnant, or you could get a STI" (17 year old boy). No other potential problems were mentioned.

Evidently, participants' perception of sexual health problems were, like their perceptions of sexual health, limited to the physical aspects of sexuality. This is perhaps because adolescents are less capable of imagining themselves experiencing a sexual health problem 
(e.g. male erectile disorder, premature ejaculation) or, alternatively, because their knowledge regarding sexual health problems is lacking. This is important as a lack of awareness could inhibit the recognition and acknowledgement of sexual health problems if present. It is possible that younger adolescents without experience struggle to discuss these problems. If so, it is important parents and schools provide a safe and trusting environment in which adolescents feel safe to discuss sexual health problems.

\section{Care needs}

Participants clearly struggled to communicate care needs (i.e., the help they would like to receive when experiencing sexual health problems) regarding sexuality and sexual health likely because of their lack of knowledge regarding sexual health problems. They were unable to convey the form or content professional care should take, although many indicated that their general practitioner would, in their opinion, be an adequate starting point for seeking care for sexual health problems. Further, they reported that what is most important is that the care provided is effective: "I don't care what needs to be done as long as it works" (19 year old boy); "It doesn't matter [content and form] as long as it gets better" (14 year old boy).

What participants were able to do was indicate the people outside of the health care sector that they would discuss a sexual health problem with if they experienced one. Most said that they would likely discuss this first with their friends. One participant said she would talk to friends as "they are usually helpful" (23 year old girl). Another stated, "I have a good friend, a kind of mentor and I can go to him whenever I have questions" (25 year old boy). Female but not male participants said they could also voice their concerns with a relative like a mother or sister if need be: "My mom provides good advice. She knows more than my boyfriend" (15 year old girl). Additionally, the internet was reported to be a useful source of information: "I'd type the problem into Google. And sometimes you know where you need to look like at the Public Health Services [site]" (23 year old girl).

As with sexual health problems, adolescents with mental health problems often rely first on friends or try to cope alone and, subsequently, turn to an adult or professional help (Barker, 2007). This suggests that adolescents' help seeking behavior for sexual problems is likely not very different than their help seeking behavior for other problems. Further, because help seeking behavior tends to focus on the internet, professionals should make an effort to be accessible and present on the internet.

\section{DISCUSSION}

This study set out to document adolescents' perceptions of sexuality and sexual health (problems). The findings suggest that perceptions of sexuality and sexual health problems are greatly influenced by the information, or rather the lack thereof, adolescents receive from their parents and at school.

When asked what sexuality and sexual health means to them, most participants emphasized the physical aspects of sexuality, namely actual sexual intercourse. Participants 
reported a willingness to talk about sexuality and sexual health with their partner but only when sufficient trust has been established. Otherwise, shame or discomfort would arise. Also, for many participants, sexuality and sexual health was not something they could easily discuss with their parents. Perhaps parents feel uncomfortable talking about sexuality with their children and thus leave this role, intentionally or unconsciously, to schools that focus primarily on physical aspects of sexual health. As a logical consequence, adolescents' perceptions of sexuality and sexual health are also limited to physical aspects of sexuality. Emotions and other aspects play a minor role. Participants were, generally speaking, completely unaware of the complexity sexuality and sexual health entail. The findings further show that most participants had no problems or concerns regarding sexuality and sexual health. When asked to imagine possible problems, they consistently reported problems relating to STIs and pregnancy. Clearly, when it comes to sexual health problems, the adolescents in our study again focused on only the physical. The possibility of experiencing, for example, a sexual functioning problem was relatively unfathomable, perhaps because adolescents are less capable of imagining themselves experiencing these problems or, alternatively, because their knowledge regarding sexual health problems is lacking. This is consistent with De Graaf et al. (2005) who, despite paying little attention to this, found, in their study, that adolescents perceive sexual functioning problems to be normal (de Graaf, Meijer, Vanwesenbeeck, \& Poelman, 2005).

We contend that a lack of knowledge regarding sexual health and sexual health problems made it difficult for participants to convey care needs regarding sexuality and sexual health. They simply could not imagine having such a problem. Nonetheless, they could report how they would seek information (via the internet) and what they find important in the treatment of sexual health problems (effectiveness). Previous research has shown that adolescents do struggle to seek help for sexual health problems (Akre et al., 2010; Bakker et al., 2009; Bakker \& Vanwesenbeeck, 2006) and that the resulting biological, psychological, and social consequences can be extensive (Althof, 2002; Grauvogl et al., 2009; Laumann et al., 1999; Rowland et al., 2007). Bakker and Vanwesenbeeck (2009) have shown that a mere third of women with sexual health problems seek treatment.

As suggested above, the lack of knowledge the study participants had regarding the complexity of sexuality and sexual health problems may be rooted in the sexual health education adolescents receive. As previously outlined by Fagen, Stacks, Hutter, and Syster (2010) and by Wellings and Parker (2006), sexual health education in the US and in Europe is usually incorporated in the biology curriculum and tends to focuses on physical, healthrelated aspects of sexuality. Little attention is paid to emotional, mental, and psychological aspects of sexual health. Sexual health education rarely discusses the meaning of a (sexual) relationship, the pleasurable aspects of sex, and how to recognize sexual dysfunctions that can lead to less pleasurable sexual experiences. If adolescents were to be made more aware of such aspects, acknowledging and seeking help for sexual health problems would be more acceptable. This, in turn, could reduce secondary problems like depression. It is therefore necessary that sexual health education programs in schools be developed or revised such that a broader concept of sexual health is taught. Additionally, parents can be encouraged to 
play a more prominent role in educating their children about sexuality and sexual health problems.

The present study has a number of strengths but also some limitations. Strengths include the heterogeneity and diversity of our study population in terms of age and location. A second strength is that we accessed adolescents directly and gained their trust such that they were willing to discuss a sensitive and difficult topic. Also, our sample size yielded saturation. A final strength was our use of a voice recorder and verbatim transcriptions. This increased the rigor and trustworthiness of our data. Given the qualitative nature of the data, however, we suggest that caution be applied in generalizing the results of this study to other populations. A limitation of our study is that it included adolescents who had little or no sexual experience. It might be more suitable to include sexual experience as a selection criterion in future research.

In conclusion, our findings point to the need to increase adolescents' knowledge and awareness of the complexity of sexuality and sexual health. Sexual health education in schools and at home are important tools by which knowledge and awareness can be created, and through which perception of sex and sexuality can develop such that it encompasses more than the physical aspects of sex and sexuality. Furthermore, by providing more accessible information, possible problems can be alleviated quicker and more directly. The current study can be considered an entry point for further research on how to best provide adolescents with high quality sexual health education and youth-friendly sexual health services. 


\section{REFERENCES}

Akre, C., Michaud, P. A., \& Suris, J. C. (2010). "I'll look it up on the web first": Barriers and overcoming barriers to consult for sexual dysfunction among young men. Swiss Medical Weekly, 140, 348-353.

Althof, S. E. (2002). Quality of life and erectile dysfunction. Urology, 59, 803-810.

American Psychiatric Association. (2000). Diagnostic and statistical manual of mental disorders (4th, text revised ed.). Washington, DC.

Bakker, F., de Graaf, H., De Haas, S., Kedde, H., Kruijer, H., \& Wijsen, C. (2009). Seksuele gezondheid in Nederland 2009. Utrecht: Rutgers Nisso Group.

Bakker, F., \& Vanwesenbeeck, I. (2006). Seksuele gezondheid in Nederland 2006. Delft: Eburon.

Bell, C., Richardson, D., Wall, M., \& Goldmeier, D. (2006). HIV-associated female sexual dysfunction - clinical experience and literature review. International Journal of STD \& AIDS, 17, 706-709.

Boldero, J., \& Fallon, B. (1995). Adolescent help-seeking: what do they get help for and from whom? Journal of Adolescence, 18, 193-209.

Central Bureau for Statistics. (2010). Population diversity: Central Bureau for Statistics.

de Graaf, H., Meijer, S., Vanwesenbeeck, I., \& Poelman, J. (2005). Seks onder je 25e. Seksuele gezondheid van jongeren in Nederland anno 2005. Delft: Eburon.

Deligeroroglou, E., Christopoulos, P., \& Creatsas, G. (2006). Contraception in adolescence. Annals of the New York Academy of Sciences, 1092, 78-90.

Department of Health. (2009). Moving forward: progress and priorities - working together for high-quality sexual health. Government response to the Independent Advisory Group's review of the National Strategy for Sexual Health and HIV. London: DH.

Fagen, M. C., Stacks, J. S., Hutter, E., \& Syster, L. (2010). Promoting implementation of a school district sexual health education policy through an academic-community partnership. Public Health Reports, 125, 352358.

Forman, J., Creswell, J., SDamschroder, L., Kowalski, C., \& Krein, S. (2008). Qualitative research methods: Key features and insights gained from use in infection prevention research. American Journal of Infection Control, 36, 764-771.

Grauvogl, A., Evers, S., van den Hoek, K., van der Veen, E., Franke, A., \& van Lankveld, J. (2009). Research into the efficacy and cost-effectiveness of brief, free of charge and anonymous sex counselling to improve (mental) health in youth: Design of a randomised controlled trial. BMC Public Health, 9, 459.

Hancock, B. (2002). An introduction to qualitative research: Trent Focus Group.

Harrison, C., Charles, J., \& Britt, H. (2009). Sexual health. Australian Family Physician, 38, 379.

Kang, M., Skinner, R., \& Foran, T. (2007). Sex, contraception and health. Australian Family Physician, 36, 594600.

Klein, D., Wild, C., \& Cave, A. (2005). Understanding why adolescents decide to visit family physicians. Canadian Family Physician, 51, 1660-1661.

Laumann, E., Paik, A., \& Rosen, R. (1999). Sexual dysfunctions in the United States: prevalence and predictions. Journal of the American Medical Association 281, 537-544.

Polit, D., \& Beck, C. (2010). Essentials of nursing research: appraising evidence for nursing practice: Wolters Kluwer Health / Lippincott Williams \& Wilkins.

Pope, C., \& Maysa, N. (1995). Qualitative research: Reaching the parts other methods cannot reach: an introduction to qualitative methods in health and health services research. BMJ, 311.

Pope, C., van Royen, P., \& Baker, R. (2002). Qualitative methods in research on healthcare quality. Quality and Safety in Health Care, 11, 148-152.

Power, R. (2002). The application of qualitative research methods to the study of sexually transmitted infections. Sexual Transmitted Infections, 78, 87-89.

Rowland, D. L., Patrick, D. L., Rothman, M., \& Gagnon, D. D. (2007). The psychological burden of premature ejaculation. The Journal of Urology, 177, 1065-1070.

Wellings, K., \& Parker, R. (2006). Sexuality education in Europe - A reference guide to policies and practices: IPPF European Network. 
Chapter 2

World Health Organization. (2002). Defining sexual health. Report of a technical consultation on sexual health. 


\section{Chapter 3}

\section{A new instrument to measure Sexual Competence and Interaction Competence in Youth (SCICY): Psychometric properties in female adolescents}

A. Grauvogl, M. Peters, S. Evers, \& J. van Lankveld

This chapter has been submitted for publication as:

Grauvogl, A., Peters, M., Evers, S., \& van Lankveld, J. A new instrument to measure Sexual Competence and Interaction Competence in Youth (SCICY): Psychometric properties in female adolescents. 


\section{ABSTRACT}

To address the need for a single, short questionnaire for male and female adolescents to measure sexual and interaction competence, we aimed to construct and validate a new instrument. The Sexual Competence and Interaction Competence in Youth ( $\mathrm{SCICY}$ ) is a selfreport questionnaire, which was developed to measure sexual competence (knowledge, psychological aspects associated with sexuality, etc.) and the ability to communicate with the partner about sex in adolescents. We describe the development and the psychometric qualities of the SCICY. The study sample consisted of 276 female undergraduate students ( $\mathrm{M}$ $=20.95$ years, $\mathrm{SD}=2.00)$. The factor structure of the SCICY was calculated on full sample data. A subsample was used to calculate the validity and internal consistency $(N=236 ; M=$ 20.88 years, $S D=1.96)$. The test-retest reliability was also calculated in a subsample $(N=82$; $M=21.45$ years, $S D=1.74)$. Based on an exploratory factor analysis eight factors were extracted: Communication about sex, Refusing sex, Positive sexual attitudes, Male role in sexual interaction, Contraceptive use, Not suppressing problems and desires regarding sex, Sexual assertiveness and Sexual hedonism. The subscales possess adequate internal consistency and moderate to excellent test-retest reliability. The SCICY correlated significantly with the Partner Communication Scale (.14 - .32) and the Multidimensional Sexual Self-Concept Questionnaire (.13 - .67), indicating good convergent validity. Finally, the SCICY total, and all subscale scores except Sexual hedonism were higher in the high sexual functioning group than in the low sexual functioning group, indicating good discriminant validity. The results indicate that the SCICY could be a useful instrument to measure sexual and interaction competence amongst adolescents. 


\section{INTRODUCTION}

Sexuality and romantic and sexual relationships develop during adolescence. Sexual maturation and the development of more complex cognitive functions and skills (e.g. problem-solving, decision-making, etcetera; World Health Organization, 2011) increase the likelihood of engaging in a long term romantic relationship. Being in an enduring relationship during this phase of life allows adolescents to develop the skills necessary to maintain highquality romantic relationships in later adulthood (Collins, Welsh, \& Furman, 2009). Furthermore, it helps to develop emotional coping skills (i.e. feelings of self-esteem, selfconfidence; World Health Organization, 2011) and social or interpersonal skills (i.e. assertiveness, refusal skills and social competence; World Health Organization, 2011; Zimmerman-Gernbeck, Siebenbruner, \& Collins, 2004). These skills further contribute to healthy sexual development. Sexual health can be defined as: "a state of physical, emotional, mental and social wellbeing in relation to sexuality, which is not merely the absence of disease, dysfunction or infirmity. Sexual health requires a positive and respectful approach to sexuality and sexual relationships, as well as the possibility of having pleasurable and safe sexual experiences" (World Health Organization, 2002).

Sexual health problems among adolescents and young adults are very common both in the Western world (Guttmacher Institute, 2010, 2012; Hamilton, Martin, \& Ventura, 2010; Pazol et al., 2011) and in other global regions (World Health Organization, 2002). De Graaf, Kruier, van Acker and Meijer (2012) reported that substantial numbers of adolescents in the Netherlands experience sexual dysfunctions (problems with sexual desire, sexual arousal, orgasm, and pain during sexual encounters). Especially many female adolescents report these problems. Kedde (2012) explored the prevalence of sexual dysfunctions among 608 female adolescents and 459 male adolescents aged 15 to 24 . Among the female adolescents, 43.4\% experienced at least one sexual dysfunction. Orgasmic disorders were the most frequently reported sexual dysfunction type (20.3\%), followed by lubrication problems (13.8\%), dyspareunia (11.5\%), sexual aversion (8.3\%), vaginismus (7.9\%), and hypoactive sexual desire disorder (2.2\%). Among the male adolescents, $27.3 \%$ were found to experience at least one sexual dysfunction. Premature ejaculation was the most frequently reported sexual dysfunction type (12.6\%), followed by erectile disorder (6.4\%), sexual aversion (5.4\%), orgasmic disorders (4.5\%), dyspareunia (2.1\%), and hypoactive sexual desire disorder (0.6\%).

Sexual competence and interaction competence can be considered as contributors to sexual health. Sexual competence can be described as the ability, based on the pertinent skills and knowledge, to be involved in sexual activities with successful outcomes and in which sexual health is preserved (Hirst, 2008; Wellings, et al., 2001). A successful outcome would be a positive sexual experience, one that does not threaten sexual health, as it prevents unwanted pregnancy and transmission of sexually transmitted infections (STIs), and avoids the development of sexual dysfunctions, such as pain during intercourse. Furthermore, it means that sexual health is protected in the emotional sense of having enjoyed the encounter, with minimal or no regret afterwards. A successful process concerns the interpersonal process between the individuals participating in a sexual encounter with each respecting the other's sexual health and rights (Hirst, 2008; Wellings et al., 2001). 
Interaction competence includes expressing desires and boundaries, but also taking the initiative in sexual activities (Bakker \& Vanwesenbeeck, 2006).

The role of sexual competence and interaction competence in sexual health of adolescents has received some empirical support. Results indicate that sexually competent adolescents delayed their first sexual intercourse to a later age (Wellings et al., 2001), had a gradual or progressive sexual development type (from kissing, to caressing, caressing without clothes, etcetera; De Graaf, Meijer, Poelman, \& Vanwesenbeeck, 2005), whereas sexual incompetence was associated with early pregnancy (Wellings, et al., 2001) and a jump style or nonlinear sexual development (from kissing almost immediately to sexual intercourse). Interaction competence has been found to be associated with prevention of STI, HIV/AIDS (Bakker \& Vanwesenbeeck, 2006; Crosby, et al., 2002; DiClimente, 1991), pregnancy and sexual dysfunctions (Bakker \& Vanwesenbeeck, 2006), and promoting emotional wellbeing (Ferroni \& Taffe, 1997; Widman, Welsh, McNulty, \& Little, 2006).

Given the contribution of sexual competence and interaction competence to the development and maintenance of sexual health, an appropriate and psychometrically sound instrument is needed to allow identification of groups in need of help, and to be able to monitor the effect of interventions. Other measures of sexual competence and interaction competence have previously been developed (de Graaf, Meijer, Vanwesenbeeck, \& Poelman, 2005; Snell, 1995; Wellings et al., 2001). However, concerns can be raised about the effectiveness and usefulness of these measures. Wellings and colleagues (2001) operationalized sexual competence by asking questions about contraceptive use, the main reason for first intercourse, the willingness of the adolescent to engage in sexual encounters, and about the nature of the relationship with their partner. De Graaf et al. (2005) operationalized interaction competence by asking questions about expressing sexual feelings, having influence during sexual encounters, taking the initiative in sexual encounters, and about refusing sexual activities. Similarly, Milhausen and colleagues (2007) measured adolescents' frequency of communication with their partner. The Multidimensional Sexual Self-Concept Questionnaire (MSSCQ) (Snell, 1995) aims to measure psychological aspects of human sexuality on 20 dimensions.

Although these instruments measure relevant aspects of sexual health, they do not incorporate the full range of elements of sexual competence and interaction competence. Furthermore, with respect to the MSSCQ, the large number of items (100) and the long time needed to complete the questionnaire (45-60 minutes) might render it less suitable for use in adolescents. Sexual competence and interaction competence have not yet been combined into one single questionnaire. To address the need for a single, short, questionnaire for male and female adolescents, we aimed to construct a short questionnaire, called the Sexual Competence and Interaction Competence in Youth (SCICY) that measures both sexual competence and interaction competence in youth. In the remainder of this paper the psychometric properties of this new instrument will be discussed. Although, the SCICY has been developed for both male and female adolescents, this first psychometric analysis has been conducted among female adolescents only. It is hypothesized that, with respect to the convergent validity, the SCICY total and subscales will have a positive association with the Partner Communication Scale (PCS; Milhausen, et al., 2007), a positive correlation with the 
positive subscales of the Multidimensional Sexual Self-Concept Questionnaire (MSSCQ; Snell, 1995), and a negative association with the negative subscales of the MSSCQ. Finally, with respect to the discriminant validity, it is hypothesized that sexually functional adolescents will have a higher score on the SCICY total and subscales than sexually dysfunctional adolescents.

\section{METHODS}

\section{Participants}

The study sample consisted of 276 female undergraduate students $(M=20.95$ years, $S D=$ 2.00). The factor structure of the SCICY was calculated on full sample data. Seventy percent of the participants were in a relationship. A subsample was used to calculate the validity and internal consistency ( $N=236 ; M=20.88$ years, $S D=1.96$ ). Sixty-eight percent of the participants were in a relationship. The test-retest reliability was also calculated in a subsample $(N=82 ; M=21.45$ years, $S D=1.74)$. Sixty-six percent of the participants were in a relationship.

\section{Measures}

\section{Sexual Competence \& Interaction Competence in Youth}

The Sexual Competence and Interaction Competence in Youth (SCICY) is a self-report questionnaire, using 5-point Likert scales, which aims to measure the sexual competence and interaction competence in adolescents. Higher scores indicate higher sexual- and interaction competence.

\section{Multidimensional Sexual Self-Concept Questionnaire}

The Multidimensional Sexual Self-Concept Questionnaire (MSSCQ; Snell, 1995) is a 100-item self-report instrument, using 5-point Likert scales, which aims to measure psychological aspects of human sexuality on the dimensions of sexual anxiety, sexual self-efficacy, sexual consciousness, motivation to avoid risky sex, chance/luck sexual control, sexual preoccupation, sexual assertiveness, sexual optimism, sexual problem self-blame, sexual monitoring, sexual motivation, sexual problem management, sexual-esteem, sexual satisfaction, power-other sexual control, sexual self-schemata, fear of sex, sexual problem prevention, sexual depression, and internal sexual control. Higher scores indicate a higher position on each dimension. The internal consistency was found adequate (Cronbach's $\alpha=$ $.72-.91 ;$ Snell, 1995).

\section{Partner Communication Scale}

The Partner Communication Scale (PCS) (Milhausen et al., 2007) is a 5-item self-report instrument, using 4-point Likert scales, which aims to measure adolescents' frequency of communicating with a partner about sexual matters. A higher score indicates more frequent 
sexual communication. The internal consistency (Cronbach's $\alpha=.87$ ) and test-retest reliability $(r=.83)$ were satisfactory (Milhausen et al., 2007).

\section{Female Sexual Function Index}

The Female Sexual Function Index (FSFI) (Rosen et al., 2000) is a 19-item self-report instrument, using 6-point Likert scales, which aims to measure female sexual functioning on the dimensions of sexual desire, arousal, lubrication, orgasm, satisfaction and pain. A higher total score indicates healthier sexual functioning. It has sound psychometric properties (ter Kuile, Brauer, \& Laan, 2006). High internal consistency was demonstrated for all subscales in sexually dysfunctional (Cronbach's $\alpha=.82-.93$ ) and healthy women (Cronbach's $\alpha=.83$ .95) (Rosen et al., 2000). The test-retest reliability was satisfactory for all subscales in both groups ( $r=.68-.80$ and $r=.77-.91$, respectively).

\section{Procedure}

The study was evaluated and approved by the Ethics Committee of the Faculty Psychology and Neuroscience of the Maastricht University. Participants were recruited using flyers and an internet-site for students who wished to apply for research participation. Adolescents interested in participating in the study sent an e-mail to the researchers. The participants were then instructed through e-mail to complete the questionnaires on a secure Internet website. To access this website, the participant had to insert a research and participant number and a separately sent password. In order to conduct the test-retest reliability we asked participants to complete the SCICY a second time after three months. As a reward for participation in this study, participants received a credit note of $€ 5$.

\section{Analysis}

First, an exploratory factor analysis on the 30-item Likert-type items was conducted in the full sample. The scree test and principal component analysis (PCA; (Field, 2009) with direct oblimin rotation and Kaiser normalization were performed. Next, reliability of the SCICY was evaluated with regard to internal consistency (Cronbach's alpha) and test-retest reliability (Pearson product-moment correlations). A 3-month interval was chosen for the test-retest reliability. This period was chosen because it was long enough to prevent that the adolescent still know the questions, but short enough that no clinical changes occurred. Convergent validity was investigated by inspecting the Pearson product-moment correlation matrix of the SCICY subscales with other measures. Discriminant validity was assessed using an ANOVA with sexual functioning as the fixed factor and $\mathrm{SCICY}$ total as the dependent variable. Two groups were created using a median split $(M=24.80, S D=8.66)$ based on the FSFI (low sexual functioning ( $N=86)$ : $M=15.46, S D=7.53$; high sexual functioning $(N=150)$ : $M=30.15, S D=2.59)$. Furthermore, a MANOVA was performed, with sexual functioning as the fixed factor and the $\mathrm{SCICY}$ subscales as the dependent variables. 


\section{RESULTS}

\section{Questionnaire development}

The Sexual Competence and Interaction Competence in Youth (SCICY) questionnaire was developed by three of the authors (AG, SE and JvL). A review of the empirical literature was conducted to ascertain domains pertinent to sexual competence and interaction competence. Items were generated in the categories of knowledge, attitude, self-efficacy, and social influence regarding sexual interaction and functioning. The items (99 in total) were compiled in a single questionnaire, which was then administered to a group of 10 male $(\mathrm{M}=21.90, \mathrm{SD}=2.60)$ and 39 female $(\mathrm{M}=21.41, \mathrm{SD}=2.22)$ undergraduate students. Besides answering every item, they gave their opinion about the understandability of each particular item and its suitability for a questionnaire addressing sexuality in adolescents (a score between 0 and 100). Based on these answers the questionnaire was revised.

Fourty-eight items were excluded because the participants found them not suitable. Furthermore, 19 items were excluded because participants were not able to understand them correctly. Finally, 2 items were excluded because every participant was found to have the highest possible score. Excluding these items resulted in a 30 -item questionnaire.

\section{Factor analysis}

A principal component analysis (PCA) was conducted on the 30 items with direct oblimin rotation. The Kaiser-Meyer-Olkin measure was used to verify the sampling adequacy for the analysis, $\mathrm{KMO}=.855$ (great according to Field, 2009). Not all KMO values for individual items were above the acceptability limit of $r=.5$ (Field, 2009). Bartlett's test of sphericity $\chi^{2}$ (435) $=3046.045, p<.001$, indicated that the inter-item correlations were sufficiently large for PCA. An initial analysis was run to obtain eigenvalues for each component in the data. A factor loading of .40 and higher was used to assign items to the different components. Eight components, that included 26-items, had eigenvalues above Kaiser's criterion of 1 and together explained $61.19 \%$ of the variance. The scree plot was slightly ambiguous and showed inflections that would justify retaining both 3 and 4 components. Even though the scree plot would suggest retaining 3 or 4 components, however, these were not optimal considering the content and interpretation of the components. Given the relatively large sample size and the evaluation of Kaiser's criterion, eight components, including 26 items, were retained in the final analysis (see Table 1). The first factor (Communication about sex) describes communication behavior that is directed at promoting Sexual hedonism and satisfaction for both oneself and the partner. The second factor (Refusing sex) describes attitudes concerning the refusal of sexual activities. The third factor (Positive sexual attitudes) describes both the positive feelings experienced after sexual contact as well as respect towards and from the sexual partner. The fourth factor (Male role in sexual interaction) describes the prejudice one can foster about the relationship between being male and aspects of sexuality. The fifth factor (Contraceptive use) describes the communication about using contraceptives to prevent STIs and unwanted pregnancy. The 
sixth factor (Not suppressing problems and desires regarding sex) describes the lack of communication about problems and wishes concerning sex. The seventh factor (Sexual assertiveness) describes the ability of the female adolescent to stand up for her own rights and desires, such as in refusing sexual contact. Finally, the eight factor (Sexual hedonism) consists of statements that represent the conditions that are required to experience sexual activities as pleasurable.

Table 1: Rotated Factor structure of the Sexual Competence \& Interaction Competence in Youth (SCICY) $(\mathrm{N}=276)$

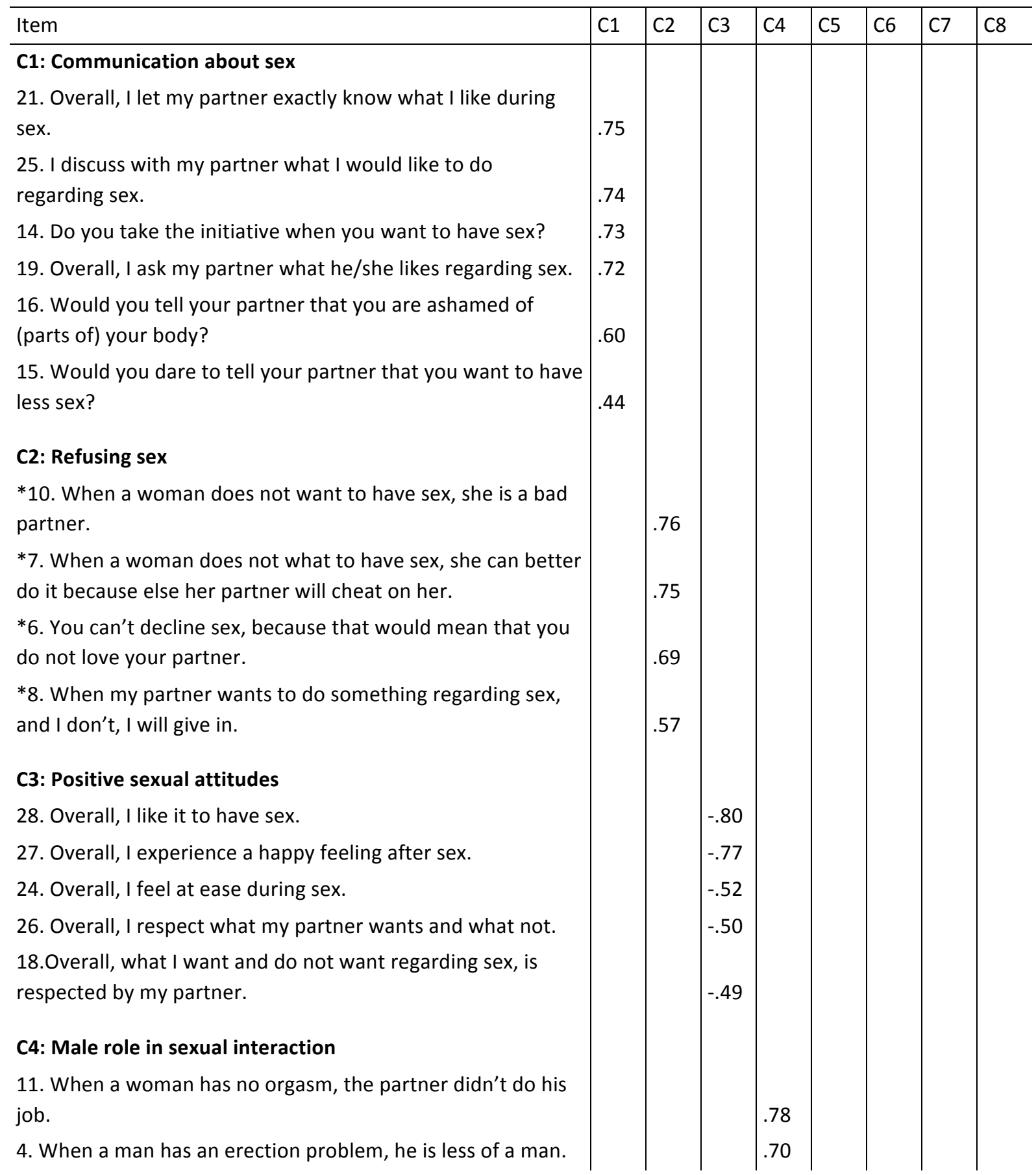




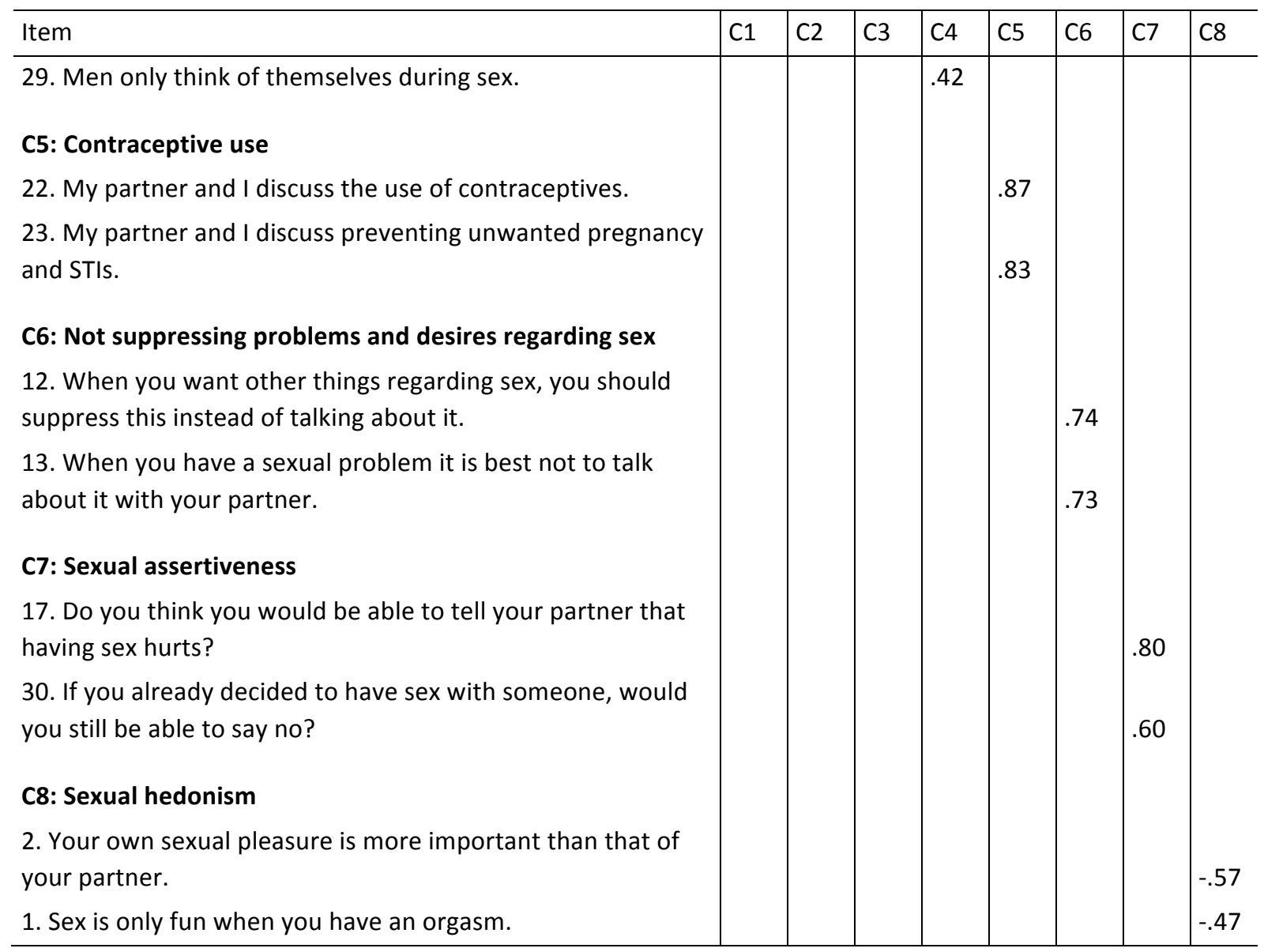

Note: Only factor loadings above .40 are reported. Loadings on the basis of which items are allocated to a component are printed in bold. ${ }^{*}=$ Items which require reverse scoring before calculating the total score. $\mathrm{C} 1$, C2, etc.: Component 1, Component 2, etc.

\section{Reliability}

This study tested both the internal consistency and test-retest reliability. The internal consistency for the SCICY total was good (Cronbach's $\alpha=.88$ ). The internal consistency of the factors Communication about sex and Contraceptive use was also good with .84 and .82 . The factors Refusing sex, Positive sexual attitudes, and Not suppressing problems and desires regarding sex had acceptable internal consistency, respectively $\alpha=.72, .77$, and .70 . Cronbach's alpha for the factors Male role in sexual interaction, Sexual assertiveness, and Sexual hedonism was poor with, respectively, $\alpha=.56, .53$, and .49 .

The test-retest reliability of the SCICY was reasonably good for the total scale $(r=.78, p<$ .001 ) and moderate to excellent for the subscales (Communication about sex: $r=.76, p<$ .001; Refusing sex: $r=.68, p<.001$; Positive sexual attitudes: $r=.54, p<.001$; Male role in sexual interaction: $r=.54, p<.001$; Contraceptive use: $r=1.00, p<.001$; Not suppressing problems and desires regarding sex: $r=1.00, p<.001$; Sexual assertiveness: $r=.52, p<.001$; Sexual hedonism: $r=.60, p<.001$ ). 


\section{Validity}

\section{Convergent validity}

Table 2 shows the correlations of the SCICY with partner communication (PCS) and sexual self-concept (MSSCQ). The total SCICY correlated significantly and positively with the PCS ( $r=$ $.31, p<.001)$. The magnitude of the relationship between the PCS total and the SCICY subscales varied. There was no significant association between the PCS total and Refusing sex and Sexual hedonism. Overall, correlations for the PCS total score were the strongest with Positive sexual attitudes and the SCICY total.

There were significant and positive correlations between the total SCICY and almost all of the positive MSSCQ subscales (e.g. sexual satisfaction). Furthermore, there were significant and negative correlations between the total SCICY and all of the negative MSSCQ subscales (e.g. sexual depression). Sexual hedonism had the fewest significant correlations with the MSSCQ subscales. Overall, correlations for the MSSCQ subscales were highest with SCICY total, Communication about sex, and Positive sexual attitudes.

\section{Discriminant validity}

An ANOVA, for the SCICY total, and a MANOVA, for the subscales separately, were used to investigate the discriminant validity. Results of the ANOVA showed that, on average, the SCICY total was higher for the high sexual functioning group $(M=34.72 ; S D=3.12)$ than for the low sexual functioning group $(M=31.31 ; S D=4.22 ; F(1,235)=50.08, p<.001)$. Female adolescents with higher levels of sexual functioning scored significantly higher on sexual and interaction competence than those with lower levels of sexual functioning.

Furthermore, MANOVA revealed a number of group differences on the $\mathrm{SCICY}$ subscales $F(1,235)=12.43, p<.001$. All subscale scores except Sexual hedonism were significant. Subscale scores on Communication about sex $(t(234)=-6.32, p<.001)$, Refusing sex $(t(234)=$ -2.85, $p<.05)$, Positive sexual attitudes $(t(234)=-8.48, p<.001)$, Male role in sexual interaction $(t(234)=-3.22, p<.05)$, Contraceptive use $(t(234)=-3.52, p<.001)$, Not suppressing problems and desires regarding $\operatorname{sex}(t(234)=-2.50, p<.05)$ and Sexual assertiveness $(t(234)=-1.78, p<.001)$ were higher for the high sexual functioning than for the low sexual functioning group. 
Sexual Competence and Interaction Competence in Youth 


\section{DISCUSSION}

The aim of the present study was to develop and test the psychometric properties of a short self-report questionnaire that can be used to assess sexual competence and interaction competence in adolescents simultaneously. Based on the exploratory factor analysis, the $\mathrm{SCICY}$ resulted in a 26-item, eight-factor, measurement instrument. The clustering of items on components suggest that component 1 represents 'Communication about sex', component 2 'Refusing sex', component 3 'Positive sexual attitudes', component 4 'Male role in sexual interaction', component 5 'Contraceptive use', component 6 'Not suppressing problems and desires regarding sex', component 7 'Sexual assertiveness' and component 8 'Sexual hedonism'.

The results of the reliability analysis of the SCICY were mixed. The internal consistencies for the SCICY total and Communication about sex and Contraceptive use were good, and they were acceptable for Refusing sex, Positive sexual attitudes, and Not suppressing problems and desires regarding sex. The internal consistencies for Male role in sexual interaction, Sexual assertiveness and Sexual hedonism, however, were unsatisfactory. One explanation for this finding may be the small number of items in each of the subscales (respectively 3 and 2 items). Furthermore, it might be the case that the content of the items in these subscales were not comparable. The test-rest reliability (with an interval of 3 months between the completion of the first and second questionnaire) of the SCICY total was reasonably good, and was moderate to excellent for the subscales.

The convergent validity of the SCICY was assessed against other instruments that measure aspects of sexual competence and interaction competence (PCS and MSSCQ. The associations of the SCICY total with the PCS and subscales of the MSSCQ were of moderate size. The associations were significant except for one subscale of the MSSCQ. This implies that the SCICY appears to measure what it was intended to, namely several aspects of sexual competence (knowledge, preventing risky behavior, psychological aspects, etc.) and communication about sex. At the subscale level, Communication about sex and Positive sexual attitudes had the strongest associations with the other two measures. The correlation of Sexual hedonism with the PCS was not significant and this subscale showed the fewest significant associations with the MSSCQ subscales. This low association could be explained by the poor internal consistency of this subscale and the low number of items $(N=2)$, or that this element is not represented by the MSSCQ Adding items that represent the content of the subscale may improve the internal consistency of this scale as well as the convergence with the other instruments. Furthermore, the association between Communication about sex and the PCS, although significant, had an unexpected low effect size. A reason for this finding may be the fact that many items of the PCS were not represented in the SCICY subscale Communication about sex. Two items of the PCS, concerning the use of contraceptives, form a separate subscale (Contraceptive use) in the SCICY. These two items also correlate significantly with the PCS. Another reason is that Communication about sex goes beyond communication about contraceptive use, and also includes expressing one's likes and dislikes regarding sex. 
Last, the discriminant validity of the SCICY was investigated. It is thought that low sexual competence and interaction competence of adolescents is associated with sexual risk behavior and sexual function problems. If the SCICY is sensitive enough to differentiate between high and low sexual functioning adolescents, this instrument could be used to prevent or early intervene in these problems. The results show that the SCICY total and all subscales, except Sexual hedonism, were significantly higher in high sexually functioning adolescents than in low sexually functioning adolescents. However, due to the low internal consistencies of the subscales Male role in sexual interaction and Sexual assertiveness, the differences on these subscales must be interpreted with caution. Furthermore, it is necessary to replicate this finding by using a patient population.

Although designed for both male and female adolescents, this study only collected data of female adolescent students between the age of 18 and 25 with a mean age of 20. This group was chosen because the prevalence of sexual dysfunctions is the highest in females. It is not certain how the SCICY will generalize to male, younger, and more diverse populations. It is possible that the factor structure and the scores on the subscales differ between these groups. Furthermore, the low internal consistencies of some of the subscales are problematic. The inclusion of more items in this subscale might be a solution here.

Notwithstanding the limitations noted, the present study gives an indication that the $\mathrm{SCICY}$ could be used as a measure of sexual competence and interaction competence in adolescent females. Furthermore, the limited number of items (26) makes this instrument suitable to use in research as well as in clinical practice. The SCICY may have particular utility in sexual health education interventions. Because of its ability to differentiate between high and low sexually functioning adolescents, a lower score on the SCICY might indicate current or future sexual problems. Especially when this is observed in younger adolescents, they might be targeted to prevent the development of sexual function problems. Furthermore, given the known relationship between communication with a sexual partner and consistent condom use (Bakker \& Vanwesenbeeck, 2006; Crosby et al., 2002; DiClemente, 1991; Widman, Welsh, McNulty, \& Little, 2006) many health education programs could incorporate this construct. The $\mathrm{SCICY}$ can be used to assess the frequency of communicating about the use of contraceptives, both pre- en post intervention, to prevent STIs and unwanted pregnancy, as well as to evaluate the efficacy of an intervention. Future research with the SCICY should include more diverse samples in terms of gender, age and sexual orientation to corroborate and extend its applicability. To address its robustness, a confirmatory factor analysis (CFA) of the SCICY has to be performed. Furthermore, the discriminant validity has to be confirmed by using clinically diagnosed adolescents with sexual dysfunctions. Finally, norm scores have to be developed for both males and females. 


\section{REFERENCES}

Bakker, F., \& Vanwesenbeeck, I. (2006). Seksuele gezondheid in Nederland 2006. Delft: Eburon.

Bouwma, J., Ranchor, A., Sanderman, R., \& Van Sonderen, E. (1995). Het meten van symptomen van depressie met de CES-D: een handleiding. Groningen: Noordelijk Centrum voor Gezondheidsvraagstukken.

Collins, W., Welsh, D., \& Furman, W. (2009). Adolescent romantic relationships. Annual Review of Psychology, 60, 631-652.

Crosby, R., DiClemente, R., Wingood, G., Cobb, B., Harrington, K., Davies, S., et al. (2002). Condom use and correlates of African American adolescent females' infrequent communication with sex partners about preventing sexually transmitted diseases and pregnancy Health Education \& Behavior, 29, 219-231.

de Beurs, E., \& Zitman, F. (2005). De Brief Symptom Inventory (BSI). De betrouwbaarheid en validiteit van een handzaam alternatief voor de SCL-90. Leiden: Leids Universitair Medisch Centrum.

de Graaf, H., Kruijer, H., van Acker, J., \& Meijer, S. (2012). Seks onder je 25e: Rutgers WPF.

de Graaf, H., Meijer, S., Vanwesenbeeck, I., \& Poelman, J. (2005). Seks onder je 25e. Seksuele gezondheid van jongeren in Nederland anno 2005. Delft: Eburon.

DiClemente, R. (1991). Predictors of HIV-preventive sexual behavior in a high-risk adolescent population: the influence of perceived peer norms and sexual communication on incarcerated adolescents' consistent use of condoms. Journal of Adolescent Health, 12, 385-390.

Evers, A., van Vliet-Mulder, J., \& Groot, C. (2000). Documentatie van tests en testresearch in Nederland, deel I en II (COTAN). Assen: van Gorcum.

Ferroni, P., \& Taffe, J. (1997). Women's emotional well-being: the importance of communicating sexual needs. Sexual and Relationship Therapy, 12, 127-138.

Field, A. (2009). Discovering statistics using SPSS. New York: Sage Publications.

Galdón, M., Durá, E., Ferrando, M., Murgui, S., Pérez, S., \& Ibañez, E. (2008). Psychometric properties of the Brief Symptom Inventory-18 in a Spanish breast cancer sample. Journal of Psychometric Research, 65, 533-539.

Guttmacher Institute. (2010). U.S. teenage pregnancies, births and abortions: National and state trends and trends by race and ethnicity.

Guttmacher Institute. (2012). Facts on American teens' sexual and reproductive health.

Hamilton, B., Martin, J., \& Ventura, S. (2010). Births: Preliminary data for 2009: National Vital Statistics Reports.

Hirst, J. (2008). Developing sexual competence? Exploring strategies for the provision of effective sexualities and relationships education. Sex Education, 8, 399-413.

Kedde, H. (2012). Seksuele disfuncties in Nederland: prevalentie en samenhangende factoren. Tijdschrift voor Seksuologie, 36(2), 98-108.

Milhausen, R., McDermott Sales, J., Wingood, G., DiClemente, R., Salazar, L., \& Crosby, R. (2007). Valdiation of a partner sexual communication scale for use in HIV/AIDS prevention interventions. Journal of HIV/AIDS Prevention in Children \& Youth, 8(1), 11-33.

Pazol, K., Zane, S., Parker, W., Hall, L., Gamble, S., Hamdan, S., et al. (2011). Abortion surveillance: United States, 2007: National Center for Chronic Disease Prevention and Health Promotion, CDC.

Rosen, R., Brown, C., Heiman, J., Leiblum, S., Meston, C., Shabsigh, R., et al. (2000). The Female Sexual Function Index (FSFI): a multidimenstional self-report instrument for the assessment of female sexual function. Journal of Sex \& Marital Therapy, 26, 191-208.

Shrier, L., Emans, J., Woods, E., \& DuRant, R. (1996). The association of sexual risk behaviors and problem drug behaviors in high school students. Journal of Adolescent Health, 20, 377-383.

Shrier, L., Harris, S., Sternberg, M., \& Beardslee, W. (2001). Associations of depression, self-esteem, and substance use with sexual risk among adolescents. Preventive Medicine, 33, 179-189.

Snell, W. (1995). The multidimensional sexual self-concept questionnaire. Downloaded from http://www4.semo.edu/snell/scales/MSSCQ.HTM

ter Kuile, M., Brauer, M., \& Laan, E. (2006). The Female Sexual Function Index (FSFI) and the Female Sexual Distress Scale (FSFD): psychometric properties within a Dutch population. Journal of Sex \& Marital Therapy, 32, 289-304. 
Wellings, K., Nanchahal, K., Macdowall, W., McManus, S., Erens, B., Mercer, C., et al. (2001). Sexual behaviour in Britain: early heterosexual experience. The Lancet, 358, 1843-1850.

Widman, L., Welsh, D., McNulty, J., \& Little, K. (2006). Sexual communication and contraceptive use in adolescent dating couples. Journal of Adolescent Health, 39, 893-899.

World Health Organization. (2002). Defining sexual health. Report of a technical consultation on sexual health. Geneva: World Health Organization.

World Health Organization. (2011). The sexual and reproductive health of young adolescents. Geneva: World Health Organization.

Zimmerman-Gernbeck, M., Siebenbruner, J., \& Collins, W. (2004). A prospective study of intraindividual and peer influences on adolescents' heterosexual romantic and sexual behavior. Archives of Sexual Behavior, 33(4), 381-394. 
Chapter 3 


\section{Chapter 4}

\section{Disgust and sexual arousal in young men and women}

A. Grauvogl, P. de Jong, M. Peters, S. Evers, \& J. van Lankveld

This chapter has been submitted for publication as:

Grauvogl, A., de Jong, P., Peters, M., Evers, S., \& van Lankveld, J. Disgust and sexual arousal in young adult men and women. 


\section{ABSTRACT}

Previous research suggested that disgust may interfere with healthy sexual functioning by demonstrating that women with sexual pain disorders are characterized by heightened disgust propensity, relatively strong (physiological and subjective) disgust responses when exposed to sexual stimuli, and relatively strong automatic sex-disgust memory associations. To broaden the understanding of the relationship between sex and disgust, this study focused on healthy adolescents, and tested the relationship between trait disgust and automatic sex-disgust associations as well as the predictive value of trait disgust propensity for participants' level of sexual arousal and disgust while watching an erotic video. The study sample consisted of 19 males and 24 females. They all completed a single target Implicit Association Task (stIAT) and self-report measures of trait disgust propensity, disgust sensitivity, and sexual functioning. Furthermore, genital and subjective sexual arousal were measured while participants were watching neutral and erotic video clips. The young adult women showed stronger sex-disgust associations and reported higher disgust propensity than men. Overall, indices of trait disgust and sex-disgust associations were not strongly associated with sexual functioning or sexual arousability. Also self-reported sexual functioning was not strongly associated with subjective or genital arousability. Unexpectedly, specifically in men, high levels of trait disgust sensitivity predicted higher levels of genital and subjective sexual arousal. Overall, no strong evidence was found to support the view that also in the non-clinical range high trait disgust or relatively strong automatic sex-disgust associations would be linked with low sexual functioning and low sexual arousal. Thus no evidence emerged to suggest that a generally enhanced disgust propensity/sensitivity or heightened sex-disgust associations are important risk factors in the development of sexual problems and dysfunctions. 


\section{INTRODUCTION}

Sexual dysfunctions are characterized by the persistent or recurrent disturbance of the sexual response to erotic stimuli. They cause distress for the individual and the partner. The current DSM-IV-TR classification differentiates between disorders of sexual desire, arousal, orgasm, and pain (American Psychiatric Association, 2000). Sexual dysfunctions are an important public health concern as approximately $40 \%$ of women and $30 \%$ of men experience sexual problems (Laumann, Paik, \& Rosen, 1999), of whom a substantial proportion also experience distress. There is considerable evidence that cognitive processes linked to fear and pain may be involved in the development of sexual problems (Barlow, 1986; Janssen \& Everaerd, 1993; Payne, Binik, Amsel, \& Khalifé, 2005). For example, men with erectile dysfunction experience performance anxiety during sexual encounters, which leads to a lack of focus on sexual stimuli, hence resulting in problems with the generation or maintenance of an erection. The anxiety will be experienced again during subsequent sexual encounters, and may result in a negative spiral of fear and avoidance of sexual activities (Barlow, 1986). Anxiety and fear of pain also play a role in theoretical accounts of sexual pain disorders (e.g., (Borg, Peters, Weijmar-Schultz, \& De Jong, 2012; Reissing, 2009). When intercourse is experienced as painful, (the anticipatory thought of) a new sexual encounter will evoke fear. The fear of pain is presumed to decrease genital sexual arousal and to increase pelvic floor muscles tension (Dewitte, van Lankveld, \& Crombez, 2011). The combination of vaginal dryness and pelvic floor muscle tension causes friction between the penis and the vagina, resulting in tissue damage, which proximally causes pain (Spano \& Lamont, 1975). However, the theoretical link between sexual dysfunctions and anxiety and fear of pain explains only part of the variability of problematic sexual functioning. For example, in sexual aversion disorder (American Psychiatric Association, 2000), the extreme aversion that is pivotal in the disorder goes beyond anxiety and fear of pain. Also, the interventions aiming at reduction of fear have shown variable efficacy in different types of sexual dysfunctions. Cognitive-behavioral therapy (CBT) for hypoactive sexual desire disorder, orgasm disorder, and vaginismus seems to yield better results than CBT for dyspareunia (ter Kuile, Both, \& van Lankveld, 2010).

Complementary explanations for sexual function and dysfunction have also been put forward. Recent evidence suggests that, next to fear and (fear of) pain, disgust can also serve to cause and maintain sexual dysfunctions (Borg, de Jong, \& Weijmar-Schultz, 2010; de Jong \& Peters, 2009; de Jong, van Overveld, Weijmar Schultz, Peters, \& Buwalda, 2009). It has been proposed that disgust has evolved as a first line of defense to protect humans from contamination by infectious agents (Oaten, Stevenson, \& Case, 2009). Because disgust elicits the urge to withdraw from the disgusting cue, it facilitates the avoidance of physical contact with pathogens. In line with such a disease-avoidance conceptualization, disgust is typically focused on the intersection between the body and the environment and concentrates on the skin and body apertures (Rozin, Nemeroff, Horowitz, Gordon, \& Voet, 1995). Sexual behavior represents an obvious threat for the transmission of disease. The close physical contact, body apertures, and exchange of bodily fluids that are implied in sexual behavior provide ample opportunity for the transmission of pathogens. Accordingly, there are many 
aspects of sexual behaviors that may promote the generation of disgust. Because of its critical features, disgust thus seems an obvious candidate for being involved in the inhibition of sexual responses. To the extent that disgust-induced sexual inhibition more chronically outbalances the propensity for sexual excitation, this may give rise to various sexual problems and promote the development of sexual dysfunctions (de Jong, Van Overveld, \& Borg, 2013). In line with the idea that disgust might be involved in sexual dysfunctions, it has been found that women with vaginismus show enhanced automatic sex-disgust associations and facial expressions of disgust (as indexed by facial muscular activity in the levator labii regions) when exposed to sex stimuli (Borg et al., 2010). Subsequent research corroborated these findings by showing that women with vaginismus are characterized by heightened disgust for sexual contaminants (van Overveld et al., 2012).

Although these earlier studies provided evidence to suggest that enhanced sexual disgust is involved in sexual dysfunctions, it remains to be tested whether i) this relationship between enhanced sexual disgust and (poor) sexual functioning represents a general phenomenon that can also be found in the non-clinical range, and ii) whether enhanced sexual disgust might indeed compromise the generation of "healthy" sexual responses. As a first step to examine the alleged inhibitory influence of disgust on sexual arousal, the present study was designed to test whether people who show relatively strong automatic disgust associations with sexual stimuli, display relatively weak sexual arousal when viewing an erotic video.

In addition, if indeed disgust were an important factor in the generation of sexual problems, individuals with enhanced trait disgust would be at risk for developing sexual problems. In this respect it is important to differentiate between a generally heightened liability to respond with the emotion of disgust (disgust propensity), and the tendency to find the emotion of disgust unpleasant (disgust sensitivity) (van Overveld, De Jong, Peters, Cavanagh, \& Davey, 2006). Both disgust propensity and sensitivity have been shown to independently affect individuals' responses to stimuli that are potentially disgust-provoking (de Jong \& Peters, 2009; de Jong et al., 2009; van Overveld et al., 2006). Consistent with the view that high disgust propensity may be considered as a latent vulnerability factor for developing sexual dysfunctions, it has been shown that women with vaginismus displayed enhanced disgust propensity compared to women without sexual problems (de Jong et al., 2009). Meanwhile, it remains to be explored whether people suffering from sexual dysfunction also show enhanced disgust sensitivity.

To further explore the alleged role of enhanced trait disgust in lowering the threshold for developing sexual problems, the present study examined whether low sexual functioning in the non-clinical range would also be associated with heightened disgust propensity. The present study included measures of both disgust propensity and disgust sensitivity, which allowed to examine to what extent disgust propensity and disgust sensitivity may be independently involved in (low) sexual functioning. From the perspective that high trait disgust would affect sexual functioning via lowering the threshold for sexual stimuli to acquire disgust-evoking properties, we also investigated whether people with relatively high trait disgust would show relatively high levels of sexual disgust as reflected in the automatic sex-disgust associations. Moreover, we tested whether participants with high levels of trait 
disgust would show less sexual arousal when watching an erotic video than individuals with relatively low levels of disgust propensity and/or disgust sensitivity.

The present study included both males and females. Previously reported studies predominantly focused on women. However, the relationship between disgust and sexual function might also contribute to erectile dysfunction and premature ejaculation in men. Furthermore, in previous research adult men and women with sexual dysfunctions were examined. To our best knowledge, empirical evidence about the relationship between disgust and sexual function in a younger and non-clinical population is absent. As a consequence, the results might be different in an adolescent population in comparison with an adult population. Germane to this, previous research has shown that disgust propensity declines with age (Fessler \& Navarrete, 2005). Furthermore, it still has to be investigated whether results found in a clinical population represent a general phenomenon that can also be found in the non-clinical range. Finally, because there is ample evidence that individuals' subjective responding may diverge from their physiological responding when exposed to erotic stimuli (e.g., Chivers, Seto, Lalumière, Laan, \& Grimbos, 2010), we measured both subjective and genital arousal as indices of sexual functioning.

All in all, the aim of this study was to investigate the association between disgust and sexual functioning in a non-clinical adolescent group, focusing on automatic sex-disgust associations and the role of disgust propensity and disgust sensitivity. We hypothesize that participants with relatively high self-reported disgust propensity or disgust sensitivity will exhibit relatively stronger automatic sex-disgust associations, lower sexual functioning and lower genital and subjective arousal during erotic stimulation.

\section{METHODS}

\section{Participants}

The study sample consisted of 19 male $(M=22.35 ; S D=1.66)$ and 24 female $(M=21.38 ; S D$ $=2.04$ ) heterosexual students at Maastricht University, the Netherlands. Participants were recruited using flyers and an internet-site for students' research participation, inviting males and females between the age of 18 and 25 to categorize words and pictures and to watch erotic video clips while their genital and subjective sexual arousal would be measured. All participants had experience with sexual intercourse.

\section{Measures}

Single target Implicit Association Test (stIAT)

To examine automatic disgust associations with sex cues, we used a single-target Implicit Association Test (stIAT) that was specifically designed for this study. This variant of the IAT (Greenwald, McGhee, \& Schwartz, 1998) is a computerized reaction time task that measures to what extent a single-target category is associated with two attribute categories (Wigboldus, Holland, \& van Knippenberg, 2005). In the current stlAT the single target 
category was sex (represented by pictures of heterosexual penetration, whereas the attribute categories were "disgust" (represented by the words sweat, stench, bad breath, excrements, garbage, and intestines) and "nice" (represented by the words ice cream, pastry, perfume, chocolate, lovely, and appealing). To get familiar with the procedure, the stIAT started with a practice run in which the participant had to categorize only the attribute words. Next, there were two blocks of 60 trials each preceded by a practice block of 30 trials. In one block sex pictures and disgust-related words were mapped on the same response key, whereas in the other block sex pictures and positive valence words shared the same response key. To prevent response bias, correct responses of the test blocks were divided equally over the two response keys (Bluemke \& Fiedler, 2009). The order of presentation of both phases was counterbalanced across participants.

Participants categorized words and pictures that appeared in the middle of a computer screen using two response keys. The labels of the categories assigned to these keys ("nice" and "disgust") were presented in the upper left and right corners of the screen. Following a correct response, the next stimulus was presented. Following an incorrect response, the word "false" appeared, and the stimulus remained on the screen until the correct response was given.

Because performance is expected to be better when the association between the target and the attribute is compatible with the participant's representational network than when this association is incompatible, one of both combinations (either the combination "sex" and "nice" or "sex" and "disgust") typically leads to faster and more accurate performance compared to the other.

To index the non-automatic (conscious, explicit) subjective evaluation of the sex pictures, a visual analogue scale ranging from -3 (not arousing) to +3 (very arousing) was used.

\section{Genital sexual arousal}

Male genital sexual arousal

To measure male genital sexual responses, an electromechanical strain gauge (Barlow, Becker, Leitenberg, \& Agras, 1970) was used. This device contains two arcs of surgical spring material joined with two mechanical strain gauges, and it produces changes in electrical resistance when the penis changes in circumference. The resistance changes are coupled, through a bridge circuit, to a BrainAmp ExG bio-amplifier (Brain Products) and an IBMcompatible computer. Participants positioned the gauge on the midsection of the penile shaft with the gauge part at the dorsal side. Calibration was performed before the beginning of every session using an oval device with six subsequent steps of 5 -mm circumference increase each, ranging from $90-125 \mathrm{~mm}$.

\section{Female genital sexual arousal}

To measure female genital sexual responses, a vaginal photoplethysmograph (Hoon, Wincze, \& Hoon, 1976; Palti \& Bercovici, 1967; Sintchak \& Geer, 1975), a clear acrylic menstrualtampon shaped plastic probe with an embedded light source illuminating the anterior vaginal wall was used. An acrylic shield on the probe's cable determined depth of insertion 
and orientation. The probe could be easily self-inserted by the participant (Geer, 1983; Laan, Everaerd, \& Evers, 1995). The AC component of the signal of the vaginal photoplethysmograph was used to measure Vaginal Pulse Amplitude (VPA; (Laan et al., 1995). Heart rate was measured to find valid peaks and troughs to be used as reference to detect VPA responses. Three disposable ECG electrodes were placed on the female participant's chest, one at the sternum, one at the left side of the body on the last rib, and one at the lower back. VPA and ECG signals were recorded using a BrainAmp ExG bioamplifier (Brain Products) and an IBM-compatible computer. The male and female genital probe disinfection procedure adhered to the pertinent local guideline.

\section{Subjective sexual arousal}

To measure subjective sexual arousal participants used a lever mounted on a small plastic box that could be moved horizontally along a sliding scale. The extreme left position on the scale represented 'not aroused' and the extreme right position 'fully aroused'. The lever position was displayed on the computer screen in front of the participant. Dots appeared incrementally (ranging from 0-10) at the bottom of the screen when the participants moved the dial to the right and disappeared when the participant moved the dial back to the left. The dots were presented just below the erotic video clip, so that the participants could keep their gaze fixed to the stimulus while they monitored their subjective sexual arousal. The lever signal was amplified using a BrainAmp ExG bio-amplifier and converted to a 0-100 scale. This task does not interfere with genital arousal, except when genital sexual arousal is very low (Wincze, Vendetti, Barlow, \& Mavissakalian, 1980).

\section{Self-report measures}

Disgust Scale-Revised

The Disgust Scale-Revised (DS-R; van Overveld, de Jong, Peters, \& Schouten, 2011) is a 25item self-report instrument, using a 5 point Likert-scale, measuring disgust propensity on the dimensions of core disgust, animal-reminder disgust, and contamination-based disgust. A high score signifies high disgust propensity. The internal consistency of core disgust and animal reminder disgust have been shown to be both satisfactory (Chronbach's $\alpha=.78$ ), whereas the internal consistency of contamination-based disgust was poor ( $\alpha=.54$ ) (van Overveld, et al., 2011).

Disgust Propensity and Sensitivity Scale-Revised

The Disgust Propensity and Sensitivity Scale-Revised (DPSS-R; Fergus \& Valentiner, 2009; van Overveld, De Jong, \& Peters, 2010) is a 12 -item self-report instrument, using a 5-point Likertscale, measuring disgust propensity and disgust sensitivity irrespective of particular disgust elicitors. Psychometric evaluation demonstrated satisfactory internal consistency ( $\alpha=.89$ for propensity and $\alpha=.87$ for sensitivity) (van Overveld, et al., 2006) and predictive validity (van Overveld et al., 2010). 


\section{Female Sexual Function Index}

The Female Sexual Function Index (FSFl; Rosen et al., 2000) is a 19-item self-report instrument, using a 6-point Likert-scale, which aims to measure sexual functioning on the dimensions of sexual desire, arousal, lubrication, orgasm, satisfaction and pain. A high score indicates healthy sexual functioning. High internal consistency was demonstrated for all subscales in sexually dysfunctional $(\alpha=.82-93$ ) and healthy women $(\alpha=.83-.95)$. Testretest reliability was satisfactory for all subscales in both groups $(r=.68-.80$ and $r=.77-$ .91 , respectively) Rosen et al., 2000).

\section{International Index of Erectile Function}

The International Index of Erectile Function (IIEF; Rosen et al., 1997) is a 15-item self-report instrument, using a 6-point Likert-scale, which aims to measure male sexual functioning on the dimensions of erectile functioning, orgasmic functioning, sexual desire, intercourse satisfaction and overall satisfaction. A high score indicates healthy erectile functioning. Erectile functioning subscale scores were selected. Internal consistency ( $\alpha=.92$ ) and testretest reliability was high ( $r=.84$; Rosen et al., 1997).

\section{Video material}

Two sets of stimuli were used, both presenting a 10-minute neutral video clip, followed by a 5 -minute erotic video clip. The neutral video clips were fragments of the BBC "Earth" series, presenting animals and flowers without any arousing content. The erotic video clips were fragments of a pornographic film, depicting petting, cunnilingus, fellatio and penile-vaginal intercourse of a male and female actor couple.

The order of the video clips was not counterbalanced. All videos were English spoken, and presented in full color with HD-resolution on a 17" TFT-monitor.

\section{Procedure}

The study was evaluated and approved by the Ethics Committee of Maastricht University. The experiment took place in a sound attenuated room, separated from the experimenter's room by a door. Upon arrival at the laboratory, participants were fully informed about the procedure of the experiment, were prompted for questions, and were reminded that they could stop with the experiment at any time. If the participant had no further questions, they were asked to read and sign an informed consent form. For female participants (because ECG electrodes were only used in women), a female researcher placed the ECG electrodes. If there were no more questions, the researcher left the room, closed the door, and further contact was continued over the intercom.

First, the participants performed the stIAT. After completion all stIAT sex pictures were rated for arousal on the VAS. Next, participants placed the genital probe in the proper position without the researcher being present. All participants then covered their lap with a towel, to make them feel more comfortable and to eliminate visual cues of their genital sexual arousal (Wincze, et al., 1980). If the probe was placed correctly the video fragments 
were started. The participants were instructed to use the lever during the erotic clips to report their subjective sexual arousal. After the last video clip, the participant removed the genital probe, and redressed before the researcher entered the room to remove the ECG electrodes. Finally, the participants completed the questionnaires on the computer. The participant was then debriefed, given the opportunity to ask remaining questions, thanked, and received $\mathrm{a} € 25$ gift voucher for participation.

\section{Data reduction and analysis}

The D600 measure, or stlAT effect, was computed according to a widely used scoring algorithm (Greenwald, Nosek, \& Banaji, 2003) that can also be used for analyzing the stlAT (Karpinski \& Steinman, 2006; Thush \& Wiers, 2007). The effect was calculated based on attribute trials only (Borg, et al., 2010). Following this algorithm all reaction times (RTs) higher than 10,000 ms were discarded. Error trials were replaced with the mean RT of the correct responses in the block in which the error occurred, plus a $600 \mathrm{~ms}$ penalty. The stIAT effect was calculated by subtracting the mean RT of the test block in which sex and nice shared the response button from the mean RT of the test block in which sex and disgust were mapped on the same key. This difference score was divided by the pooled standard deviations based on all responses of the particular blocks. Practice trials were discarded from the analyses, because we considered these trials to be truly practice. Thus the lower the stIAT effect, the stronger the automatic sex-disgust association.

Genital sexual arousal data was saved and visually inspected off-line to detect and delete movement artifacts. Male response recordings were stored after conversion from $\mathrm{mV}$ to $\mathrm{mm}$ circumference change, based on the individual pre-session calibration data. Female response recordings (VPA data) were calculated in $\mathrm{mV}$. Data were averaged per 10 s epoch. To calculate the genital response during the erotic video clip, all epochs from the onset of the erotic video clip through 300s post-onset were included and compared with the last 90 s of the preceding neutral video clip. A mean score of the two erotic video clips was calculated. To combine female and male genital sexual arousal data, Z-scores were calculated within participants, resulting in average Z-score $M=0$, with $S D=1$ for each participant (Chivers, Rieger, Latty, \& Bailey, 2004). Subjective sexual responses were averaged for both erotic video clips, and all epochs from video onset through $300 \mathrm{~ms}$ post-onset were included. Finally, a mean score of the two erotic video clips was calculated.

To answer the research questions Pearson correlations were calculated between the stIAT score and explicit ratings of the arousing quality of the pictures, genital and subjective sexual arousal, disgust propensity (based on DS-R and DPSS-R) and disgust sensitivity (DPSSR) and sexual functioning (based on FSFI and IIEF). Multiple hierarchical regression analyses were performed to examine whether the level of genital and subjective sexual arousal could be predicted by disgust propensity and disgust sensitivity (both measured with the DPSS-R), gender and the interaction between disgust propensity and disgust sensitivity on the one hand and gender on the other. 


\section{RESULTS}

Table 1 presents the mean values of the descriptive variables, both for the whole group and for men and women separately. The stIAT score was significantly higher in men than in women. This means that women showed stronger automatic sex-disgust associations than men. Furthermore, women reported a stronger disgust propensity, as measured with the DS-R, than men.

Table 1: Mean values for stIAT, arousal ratings of the stIAT pictures, subjective arousal during the erotic video clips, disgust propensity (DS-R and DPSS-R) and disgust sensitivity (DPSS-R) separately for men and women.

\begin{tabular}{lccccc}
\hline & \multicolumn{1}{c}{ Overall } & Men & Women & \multicolumn{1}{c}{$t$} \\
\cline { 2 - 6 } & & & & \multicolumn{1}{c}{$t$} \\
\cline { 2 - 6 } stIAT, mean, sd & $.13(.33)$ & $.24(.31)$ & $0.03(.33)$ & 2.13 & $.039^{*}$ \\
Arousal stIAT pictures, mean, sd & $.96(1.2)$ & $1.1(1.0)$ & $.89(1.3)$ & .456 & .651 \\
Subjective arousal erotic video, mean, sd & $53.0(21.5)$ & $69.4(11.3)$ & $39.4(18.1)$ & 6.42 & $<.001^{* *}$ \\
Disgust propensity (DS-R), mean, sd & $1.7(.42)$ & $1.6(.43)$ & $1.9(.39)$ & -2.17 & $.035^{*}$ \\
Disgust propensity (DPSS-R), mean, sd & $20.6(4.1)$ & $19.4(3.8)$ & $21.63(4.1)$ & -1.84 & .073 \\
Disgust sensitivity, mean, sd & $15.4(3.6)$ & $15.0(3.5)$ & $15.7(3.8)$ & -.639 & .526 \\
\hline
\end{tabular}

Note: ${ }^{*}=$ Difference is significant at the 0.05 level (two-tailed); ${ }^{* *}=$ Difference is significant at the 0.01 level (two-tailed)

The erotic video clips were successful in heightening sexual arousal. During the erotic clips subjective arousal was higher in men than in women. The clips were also successful in eliciting genital arousal. The level of genital sexual arousal (men: penile circumference change in $\mathrm{mm}$; women: $\mathrm{mV}$ ) was higher during the erotic video clips (men: $\mathrm{M}=43.37$; $\mathrm{SD}=$ 31.66 and women: $M=784.15 ; S D=449,83$ ) than during the neutral video clips (men: $M=$ 16.74; $S D=23.16$ and women: $M=417.13 ; S D=245.69$ ). For both men and women this difference was significant $(t(19)=8.853 ; p<0.001$ and $t(23)=6.905 ; p<0.001$, respectively).

Overall, only the relationship between disgust sensitivity and disgust propensity (as indexed by both DPSS-R and DS-R) attained significance (see Table 2).

Next, correlations were calculated separately for women (Table 3) and men (Table 4). In women, only the disgust propensity and sensitivity measures were associated. Thus there was no evidence to indicate that in the nonclinical range indices of disgust are strongly associated with sexual functioning or sexual arousability, nor that self-reported sexual functioning is strongly associated with subjective or genital arousability. 
Table 2: Bivariate correlations of the total group

\begin{tabular}{|c|c|c|c|c|c|c|c|}
\hline & stIAT & $\begin{array}{c}\text { Arousal } \\
\text { stIAT }\end{array}$ & $\begin{array}{l}\text { Genital } \\
\text { arousal }\end{array}$ & $\begin{array}{c}\text { Subjective } \\
\text { arousal }\end{array}$ & $\begin{array}{c}\text { Disgust } \\
\text { propensity } \\
\text { (DS-R) }\end{array}$ & $\begin{array}{c}\text { Disgust } \\
\text { propensity } \\
\text { (DPSS-R) }\end{array}$ & $\begin{array}{c}\text { Disgust } \\
\text { sensitivity } \\
\text { (DPSS) }\end{array}$ \\
\hline stIAT & - & & & & & & \\
\hline Arousal stlAT pictures & -.14 & - & & & & & \\
\hline Genital arousal & .28 & -.18 & - & & & & \\
\hline Subjective arousal video & .29 & .18 & .10 & - & & & \\
\hline Disgust propensity (DS-R) & -.07 & .11 & .22 & .04 & - & & \\
\hline Disgust propensity (DPSS-R) & -.13 & -.04 & .21 & .03 & $.72 * *$ & - & \\
\hline Disgust sensitivity & .01 & .27 & .18 & .14 & $.50 * *$ & $.59 * *$ & - \\
\hline Male SF & -.24 & .20 & .09 & .21 & .24 & .02 & -.13 \\
\hline Female SF & -.16 & -.12 & .34 & .10 & .03 & -.20 & -.04 \\
\hline
\end{tabular}

Note: ${ }^{*}=$ Difference is significant at the 0.05 level (two-tailed); $* *=$ Difference is significant at the 0.01 level (two-tailed); SF = Sexual functioning

Table 3: Bivariate correlations only for women

\begin{tabular}{|c|c|c|c|c|c|c|c|}
\hline & stIAT & $\begin{array}{c}\text { Arousal } \\
\text { stIAT }\end{array}$ & $\begin{array}{l}\text { Genital } \\
\text { arousal }\end{array}$ & $\begin{array}{c}\text { Subjective } \\
\text { arousal }\end{array}$ & $\begin{array}{c}\text { Disgust } \\
\text { propensity } \\
\text { (DS-R) }\end{array}$ & $\begin{array}{c}\text { Disgust } \\
\text { propensity } \\
\text { (DPSS-R) }\end{array}$ & $\begin{array}{c}\text { Disgust } \\
\text { sensitivity } \\
\text { (DPSS) }\end{array}$ \\
\hline stIAT & - & & & & & & \\
\hline Arousal ratings & -.11 & - & & & & & \\
\hline Genital arousal & .16 & -.32 & - & & & & \\
\hline Subjective arousal & .06 & .09 & -.10 & - & & & \\
\hline Disgust propensity (DS-R) & -.12 & .09 & -.04 & .34 & - & & \\
\hline Disgust propensity (DPSS-R) & -.18 & .00 & .02 & .29 & $.79 * *$ & - & \\
\hline Disgust sensitivity & -.18 & .35 & -.14 & .13 & $.52 * *$ & $.52 * *$ & - \\
\hline Female SF & -.16 & -.12 & .34 & .10 & .03 & -.20 & -.04 \\
\hline
\end{tabular}

Note: $*^{*}=$ Difference is significant at the 0.05 level (two-tailed); $* *=$ Difference is significant at the 0.01 level (two-tailed); SF = Sexual functioning

Table 4: Bivariate correlations only for men

\begin{tabular}{|c|c|c|c|c|c|c|c|}
\hline & stlAT & $\begin{array}{c}\text { Arousal } \\
\text { stIAT }\end{array}$ & $\begin{array}{l}\text { Genital } \\
\text { arousal }\end{array}$ & $\begin{array}{c}\text { Subjective } \\
\text { arousal }\end{array}$ & $\begin{array}{c}\text { Disgust } \\
\text { propensity } \\
\text { (DS-R) }\end{array}$ & $\begin{array}{c}\text { Disgust } \\
\text { propensity } \\
\text { (DPSS-R) }\end{array}$ & $\begin{array}{c}\text { Disgust } \\
\text { sensitivity } \\
\text { (DPSS) }\end{array}$ \\
\hline stIAT & - & & & & & & \\
\hline Arousal ratings & -.23 & - & & & & & \\
\hline Genital arousal & .39 & .01 & - & & & & \\
\hline Subjective arousal & .20 & .43 & $.61 * *$ & - & & & \\
\hline Disgust propensity (DS-R) & .19 & .21 & $.54 *$ & $.50 *$ & - & & \\
\hline Disgust propensity (DPSS-R) & .13 & -.05 & $.48^{*}$ & .40 & $.58 * *$ & - & \\
\hline Disgust sensitivity & .32 & .17 & $.62 * *$ & $.66^{* *}$ & $.47^{*}$ & $.69 * *$ & - \\
\hline Male SF & -.24 & .20 & .09 & .21 & .24 & .02 & -.13 \\
\hline
\end{tabular}

Note: ${ }^{*}=$ Difference is significant at the 0.05 level (two-tailed); ${ }^{* *}=$ Difference is significant at the 0.01 level (two-tailed); SF = Sexual functioning 
Also for men, there was no evidence indicating that in the nonclinical range indices of disgust are strongly associated with sexual functioning, nor that self-reported sexual functioning is strongly associated with subjective or genital arousability. However, as can be seen in Table 4, there was a significant correlation between sexual arousal during the erotic video clips (genital and subjective) and both indices of trait disgust. Yet, in contrast to our predictions, these positive correlations indicate that higher levels of trait disgust co-occurred with higher instead of lower) sexual arousal. Furthermore, there was a positive correlation between genital and subjective sexual arousal during the erotic video clips. Finally, also in men the two disgust propensity and sensitivity measures were associated.

In subsequent regression analyses we tested whether the apparent differential pattern of correlations between men and women reflected significant differences. In these analyses genital c.q. subjective arousal were the dependents whereas gender, disgust propensity, disgust sensitivity, disgust propensity $\mathrm{x}$ gender, disgust sensitivity $\mathrm{x}$ gender were the independents. In the first step, all predictor variables were entered. Next, if not significant, the interaction variables were deleted and the analysis was repeated with the variables that were left (trimmed model). For genital arousal, the gender $x$ disgust sensitivity interaction term remained in the final equation (Table 5). Thus the correlation between disgust sensitivity and genital arousal was significantly stronger for men than for women. Although the correlation between disgust propensity and genital arousal was only significant in men, the strength of the correlation did not significantly differ between both genders (gender $\mathrm{x}$ propensity did not remain in the final equation).

Table 5: Results of multiple regression analysis with genital sexual arousal

\begin{tabular}{lccccc}
\hline & B & SE B & $\beta$ & $t$ & $p$ \\
\cline { 2 - 5 } Constant & -2.64 & .936 & & -2.82 & $.007^{* *}$ \\
Gender & 3.32 & 1.25 & 1.65 & 2.60 & $.013^{*}$ \\
Disgust sensitivity & .176 & .061 & .648 & 2.89 & $.006^{* *}$ \\
Gender x Disgust sensitivity & -.214 & .079 & -1.82 & -2.70 & $.010^{* *}$ \\
\hline
\end{tabular}

Note: $\mathrm{R}^{2}=.427, \Delta \mathrm{R}^{2}=.183(\mathrm{p}=.043) ;{ }^{*}=$ Difference is significant at the 0.05 level (two-tailed); ${ }^{* *}=$ Difference is significant at the 0.01 level (two-tailed)

For subjective arousal, only gender and disgust propensity remained in the final equation indicating that overall women showed less subjective arousal during the erotic video clips, and that overall people with high disgust propensity showed enhanced subjective sexual arousal (Table 6). Since none of the interaction terms remained in the equation, the regression analysis indicated that the relationship between disgust propensity and subjective arousal was not significantly stronger for men than for women. 
Table 6: Results of multiple regression analysis with subjective sexual arousal

\begin{tabular}{lccccc}
\hline & $\mathrm{B}$ & $\mathrm{SE} \mathrm{B}$ & $\beta$ & $\mathrm{t}$ & $\mathrm{p}$ \\
\cline { 2 - 6 } Constant & 45.42 & 11.57 & & 3.93 & $<.001^{* *}$ \\
Gender & -32.72 & 4.66 & -.768 & -7.03 & $<.001^{* *}$ \\
Disgust propensity & 1.23 & .571 & .236 & 2.16 & $.037^{*}$ \\
\hline
\end{tabular}

Note: $\mathrm{R}^{2}=.547, \Delta \mathrm{R}^{2}=.547(\mathrm{p}<.001){ }^{*}=$ Difference is significant at the 0.05 level (two-tailed); ${ }^{* *}=$ Difference is significant at the 0.01 level (two-tailed)

In a final regression analysis (restricted to men) we examined whether disgust propensity and disgust sensitivity showed an (partly) independent relationship with genital c.q. subjective arousal during the erotic video clips. The analysis showed that only disgust sensitivity had independent predictive value for both genital $(\beta=.615, p=.004)$ and subjective arousal $(\beta=.664, p=.001)$. The positive beta values indicate that a higher level of disgust sensitivity was predictive of more genital and subjective arousal.

\section{DISCUSSION}

The aim of this study was to investigate the association between disgust and sexual functioning in a non-clinical group of female and male adolescents, focusing on automatic sex-disgust associations and trait disgust. We hypothesized that participants with relatively high self-reported disgust propensity or disgust sensitivity would exhibit relatively strong automatic sex-disgust associations, lower sexual functioning, and lower genital as well as subjective arousal during erotic stimulation. The main results were that: i) women showed stronger automatic sex-disgust associations (stIAT) and stronger disgust propensity (DS-R) than men; and ii) in men, higher levels of disgust sensitivity were predictive of higher levels of genital and subjective sexual arousal.

This study indicates that young women are more prone than men to experience disgust, as measured with both implicit and explicit measures. This finding is in line with previous research showing that women generally report higher levels of disgust than men, especially regarding sex (Druschel \& Sherman, 1999). Although women showed both relatively strong automatic sex-disgust associations and relatively high levels of disgust propensity, the correlational analyses indicated that both of these variables represent largely independent phenomena. Thus at least for the nonclinical range no evidence emerged to support the view that especially those with high disgust propensity would be at risk for developing (automatic) sex-disgust associations. In addition, neither for women nor for men there was a strong relationship between the indices of disgust propensity/disgust sensitivity and the gender-specific indices of sexual functioning. Thus the present study provided no evidence for a relationship between high levels of trait disgust and low sexual functioning in young adults. 
In addition, the overall correlational analysis showed no evidence for a relationship between trait disgust and the level of subjective or genital arousal that was elicited by the erotic video clips. However, when taking gender into consideration it was found that specifically for men disgust sensitivity showed independent predictive value for the level of genital and subjective arousal. Yet, the direction of this relationship was opposite to our hypothesis as relatively high disgust sensitivity was associated with relatively high instead of low levels of elicited sexual arousal. Clearly, this pattern of results does not support the view that enhanced trait disgust would be associated with lowered sexual arousability. The finding that men with relatively high disgust sensitivity scores displayed relatively strong sexual arousal might be explained by assuming that perhaps people who are highly sensitive to disgust responses are also highly sensitive to other physical sensations such as the physical responses that are involved in sexual arousal. Since the level of arousal that was elicited in women was much smaller than in men this might have reduced the sensitivity of the present study for finding a similar relationship between disgust sensitivity and sexual arousal in women. Clearly, this interpretation is post hoc and should be tested further in future research.

It also may be the case that disgust, just like performance demand and increased anxiety, has a facilitating effect in sexually functional men (Barlow, 1986). In sexually functional men, performance demand enhances sexual arousal whereas in sexually dysfunctional men it decreases sexual arousal. Disgust may have the same effect. Further research is needed to investigate this potential cause of our finding, and needs to include both sexually functional and dysfunctional men.

It has been argued that the disgusting properties of sexual stimuli may interfere with the generation of sexual arousal (de Jong et al., 2013). Following this, we anticipated that for people who show a relatively strong tendency to associate sex with disgust, sexual stimulation would elicit less sexual arousal. However, although the correlations between stIAT performance and sexual arousal were in the predicted direction, they did not reach the conventional level of significance. Thus at least in young adults without sexual problems, automatic sex-disgust associations seem no serious obstacle for the generation of sexual arousal. Perhaps this was partly due to the strength of the sexual stimulation. Previous research has shown that both in men (Stevenson, Case \& Oaten, 2011) and women (Borg \& de Jong, 2012), sexual stimulation reduces the disgusting properties of sex-relevant disgust elicitors. Accordingly, also in the present study sexual disgust may have been weakened or been taken away by the concurrently elicited sexual arousal. In line with the alleged inhibitory relationship between sexual arousal and disgust, sexual arousal may have become dominant in this group of sexually healthy individuals. It would be interesting to see in future research whether in the context of less intense stimulation the disgust eliciting properties might be more important especially in those with relatively strong automatic sex-disgust associations. 


\section{Strengths and Limitations}

The strengths of the present study are that: i) it is unique as it incorporated both female and male study participants; and ii) both implicit measures of cognitive and emotional responses (stIAT) and real-time genital and subjective sexual response measures were used.

One of the limitations of researching sexual responses and psychological associations with sex in a laboratory environment pertains to external validity. It remains questionable whether the results would be the same in real life circumstances. Also, it can be speculated that the stimuli used in the stIAT elicit more disgust responses than the sexual activities seen in the erotic video clips or in real life sexual activities, which might have influenced the results. Finally, patients with sexual dysfunctions were not included in this study, and so it remains to be determined if the results can be translated to clinical populations.

\section{Conclusions}

Young adult women showed stronger sex-disgust associations and reported higher disgust propensity than men. Overall, no strong evidence was found to support the view that high trait disgust or relatively strong automatic sex-disgust associations would be linked with low sexual functioning and low sexual arousal. Thus no evidence emerged to suggest that a generally enhanced disgust propensity/sensitivity or heightened sex-disgust associations are important risk factors in the development of sexual problems and dysfunctions. To arrive at more final conclusions in this respect it would be important to replicate this study in a larger sample and by using various (also lower) levels of erotic stimulation. 


\section{REFERENCES}

American Psychiatric Association. (2000). Diagnostic and statistical manual of mental disorders (4th, text revised ed.). Washington, DC.

Barlow, D. (1986). Causes of sexual dysfunction: The role of anxiety and cognitive interference. Journal of Consulting and Clinical Psychology, 54, 140-148.

Barlow, D., Becker, R., Leitenberg, H., \& Agras, W. (1970). A mechanical strain gauge for recording penile circumference change. Journal of Applied Behavior Analysis, 3, 73-76.

Bluemke, M., \& Fiedler, K. (2009). Base rate effects on the IAT. Consciousness and Cognition, 18, 1029-1038.

Borg, C., \& de Jong, P. (2012). Feelings of disgust and disgust-induced avoidance weaken following induced sexual arousal in women. PLoS ONE, 7: e44111.

Borg, C., de Jong, P., \& Weijmar-Schultz, W. (2010). Vaginismus and dyspareunia: Automatic vs. deliberate disgust responsivity. Journal of Sexual Medicine, 7, 2149-2157.

Borg, C., Peters, M., Weijmar-Schultz, W., \& De Jong, P. (2012). Vaginismus: Heightened harm avoidance and pain catastrophizing cognitions. Journal of Sexual Medicine, 9, 558-567.

Chivers, M., Rieger, G., Latty, E., \& Bailey, M. (2004). A sex difference in the specificity of sexual arousal. Psychological Science, 15, 736-744.

Chivers, M., Seto, M., Lalumière, Laan, E., \& Grimbos, T. (2010). Agreement of self-reported and genital measures of sexual arousal in men and women: A meta-analysis. Archives of Sexual Behavior, 39, 5-56.

de Jong, P., \& Peters, M. (2009). Sex and the sexual dysfunctions: The role of disgust and contamination sensitivity. Washington, DC: American Psychological Association.

de Jong, P., Van Overveld, M., \& Borg, C. (2013). Giving in to arousal, or staying stuck in disgust? Disgust-based mechanisms in the development of sexual dysfunctions. The Journal of Sex Research, 50, 247-462.

de Jong, P., van Overveld, M., Weijmar Schultz, W., Peters, M., \& Buwalda, F. (2009). Disgust and contamination sensitivity in vaginismus and dyspareunia. Archives of Sexual Behavior, 38, 244-252.

Dewitte, M., van Lankveld, J., \& Crombez, G. (2011). Understanding sexual pain: A cognitive-motivational account. Pain, 152, 251-253.

Fergus, T., \& Valentiner, D. (2009). The disgust propensity and sensitivity scale-revised: An examination of a reduced-item version. Journal of Anxiety Disorders, 23, 703-710.

Fessler, D., \& Navarrete, C. (2005). The effect of age on death disgust: Challenges to terror management perspectives. Evolutionary Psychology, 3, 279-296.

Fridlund, A., \& Cacioppo, J. (1986). Guidelines for human electromyographic research. Psychophysiology, 23, 567-589.

Geer, J. (1983). Measurement and methodological considerations in vaginal photometry. Paper presented at the meeting of the International Academy of Sex Research, Harriman, NY.

Geer, J., \& Fuhr, R. (1976). Cognitive factors in sexual arousal: The role of distraction. Journal of Consulting and Clinical Psychology, 44, 238-243.

Greenwald, A., Nosek, B., \& Banaji, M. (2003). Understanding and using the Implicit Association Test: An improved scoring algorithm. Journal of Personality and Social Psychology, 85, 197-216.

Hoon, P., Wincze, J., \& Hoon, E. (1976). Physiological assessment of sexual arousal in women. Psychophysiology, 19, 21-26.

Janssen, E., \& Everaerd, W. (1993). Determinants of male sexual arousal. Annual Review of Sex Research, 4, 211-245.

Karpinski, A., \& Steinman, R. (2006). The single category implicit association test as a measure of implicit social cognition. Journal of Personality and Social Psychology, 91, 16-32.

Laan, E., Everaerd, W., \& Evers, A. (1995). Assessment of female sexual arousal: Response specificity and construct validity. Psychophysiology, 32, 476-485.

Laumann, E., Paik, A., \& Rosen, R. (1999). Sexual dysfunctions in the United States: prevalence and predictions. Journal of the American Medical Association 281, 537-544.

Oaten, M., Stevenson, R., \& Case, T. (2009). Disgust as a disease-avoidance mechanism. Psychological Bulletin, $135,303-321$. 
Palti, Y., \& Bercovici, B. (1967). Photoplethysmographic study of the vaginal blood pulse. American Journal of Obstetrics and Gynecology, 97, 143-153.

Payne, K., Binik, Y., Amsel, R., \& Khalifé, S. (2005). When sex hurts, anxiety and fear orient attention towards pain. European Journal of Pain, 9, 427-436.

Reissing, E. (2009). Vaginismus: Evaluation and management. In A. Goldstein, C. Pukall \& I. Goldstein (Eds.), Female sexual pain: Evaluation and management. Oxford: Wiley-Blackwell.

Rosen, R., Brown, C., Heiman, J., Leiblum, S., Meston, C., Shabsigh, R., et al. (2000). The Female Sexual Function Index (FSFI): a multidimensional self-report instrument for the assessment of female sexual function. Journal of Sex \& Marital Therapy, 26, 191-208.

Rosen, R., Riley, A., Wagner, G., Osterloh, I., Kirkpatrick, J., \& Mishra, A. (1997). The International Index of Erectile Function (IIEF): A multidimensional scale for assessment of erectile dysfunction. Urology, 6, 822830.

Rozin, P., Nemeroff, C., Horowitz, M., Gordon, B., \& Voet, W. (1995). The borders of the self: Contamination sensitivity and potency of the mouth, other apertures and body parts. Journal of Research in Personality, 29, 318-340.

Salemink, E., \& van Lankveld, J. (2006). The effects of increasing neural distraction on sexual responding of women with and without sexual problems. Archives of Sexual Behavior, 35, 179-190.

Sintchak, G., \& Geer, J. (1975). A vaginal plethysmograph system. Psychophysiology, 12, 113-115.

Spano, L., \& Lamont, J. (1975). Dyspareunia: A symptom of female sexual dysfunction. The Canadian Nurse, 71, 22-25.

Stevenson, R., Case, T., \& Oaten, M. (2011). Effect of self-reported sexual arousal on responses to sex-related and non-sex-related disgust cues. Archives of Sexual Behavior, 40, 79-85.

ter Kuile, M., Both, S., \& van Lankveld, J. (2010). Cognitive behavioral therapy for sexual dysfunctions in women. Psychiatric Clinics of North America, 33, 595-610.

Thush, C., \& Wiers, R. (2007). Apples and oranges? Comparing indirect measures of alcohol related cognition predicting alcohol use in at-risk adolescents. Psychology of Addictive Behaviors, 21, 587-591.

van Overveld, M., De Jong, P., \& Peters, M. (2010). The disgust propensity and sensitivity scale - revised: Its predictive value for avoidance behaviour. Personality and Individual Differences, 49, 706-711.

van Overveld, M., De Jong, P., Peters, M., Cavanagh, K., \& Davey, G. (2006). Disgust propensity and disgust sensitivity: separate constructs that are differentially related to specific fears. Personality and Individual Differences, 41, 1241-1252.

van Overveld, M., De Jong, P., Peters, M., van Lankveld, J., Melles, R., \& Ter Kuile, M. (2012). The sexual disgust questionnaire: A psychometric study and first exploration in patients with sexual dysfunctions. Journal of Sexual Medicine, 10, 396-407.

Vrana, S. (1993). The psychophysiology of disgust: Differentiating negative emotional contexts with facial EMG. Psychophysiology, 30, 279-286.

Wigboldus, R., Holland, R., \& van Knippenberg, A. (2005). Single Target Implicit Associations.

Wincze, J., Vendetti, E., Barlow, D., \& Mavissakalian, M. (1980). The effects of a subjective monitoring task in the physiological measure of genital response to erotic stimulation. Archives of Sexual Behavior, 9, 533545.

Wolf, K., Mass, R., Ingenbleek, T., Kiefer, F., Naber, D., \& Wiederman, K. (2005). The facial pattern of disgust, appetence, excited joy and relaxed joy: An improved facial EMG study. Scandinavian Journal of Psychology, 46, 403-409. 
Chapter 4 


\section{Chapter 5}

\section{Clinical and cost-effectiveness of short term, cost free and anonymous sex counselling to improve sexual health: Design of a randomized control trial}

A. Grauvogl, S. Evers, K. van den Hoek, E. van der Veen, A. Franke, \& J. van Lankveld

This chapter has been published as:

Grauvogl, A., Evers, S., van den Hoek, K., van der Veen, E., Franke, A \& van Lankveld, J. (2009). Research into the efficacy and cost-effectiveness of brief, free of charge and anonymous sex counselling to improve (mental) health in youth: design of a randomized control trial. BMC Public Health, 9:459 


\section{ABSTRACT}

The capacity to form romantic relationships and sexual health of adolescents in the Netherlands are compromised by several factors, including young age of first intercourse and adolescent depression. Several thresholds like own expenses, trust and embarrassment prevent adolescents to seek help for their sexual problems. To overcome these thresholds, brief sex counselling has been developed. It has been used since 2006 within the RotterdamRijnmond Public Health Service, but there is lack of information about the (cost-) effectiveness. In the current study we will evaluate the (cost-) effectiveness of brief sex counselling for sexual problems in adolescents and young adults between 18 and 25 years of age. In a randomized controlled trial we will compare (1) brief sex counselling with (2) intensive sexual healthcare, and (3) no treatment (waiting list). Embedded in this RCT will be a trial-based economic evaluation, looking at the cost-effectiveness and cost-utility of brief sex counselling versus the two other interventions. Four hundred fifty adolescents (aged 1825) with sexual problems will be recruited among the persons who visit the Public Health Service (PHS) and through various websites. After a screening procedure, eligible participants will be randomly allocated to one of the three intervention groups. Primary outcome measure of the clinical evaluation is the severity of sexual problems. Other outcomes include psychological distress, especially depression. The economic evaluation will be performed from a societal perspective. Costs will be assessed continuously by a retrospective questionnaire covering the last 3 months. All outcome assessments (including those for the economic evaluation) will take place via the internet at baseline, and at 3, 6, 9, and 12 months after baseline. The proposed research project will be the first study to provide preliminary data about the effect and cost- effectiveness of brief sex counselling in youth in comparison with intensive sexological treatment and no treatment. It is anticipated that positive results in (cost-) effectiveness of the proposed intervention will contribute to the improvement of sexual health care for adolescents and young adults. The study has been registered at the Netherlands Trial Register, part of the Dutch Cochrane Centre (NTR1952). 


\section{INTRODUCTION}

Sexual health of adolescents has gained more attention over the last years (Brugman, Goedhart, Vogels, \& van Zessen, 1995; de Graaf, Meijer, Vanwesenbeeck, \& Poelman, 2005). Sexual health is described by the World Health Organisation (WHO) as: "... a state of physical, emotional, mental and social well- being in relation to sexuality; it is not merely the absence of disease, dysfunction or infirmity. Sexual health requires a positive and respectful approach to sexuality and sexual relationships, as well as the possibility of having pleasurable and safe sexual experiences, free of coercion, discrimination and violence. For sexual health to be attained and maintained, the sexual rights of all persons must be respected, protected and fulfilled (World Health Organization, 2002)".

The past decade has also seen a growing recognition of the existence of romantic relationships, experiences and sexual activities in adolescents (Davilla, 2008). With this attention some developments have taken place that could compromise the sexual health and romantic relationship capacities of adolescents. The first development is the increasing proportion of young people that have sexual intercourse before the age of 16 (Whight, et al., 2000). Sexual intercourse before this age is associated with increased risks (Rector, Johnson, Noyes, \& Martin, 2003). Men and women who had their first sexual encounter before the age of 16 show increased regret of this experience (Darling, Davidson, \& Passarello, 1992; Dickson, Paul, Herbison, \& Silva, 1998; Wight, et al., 2000). For both, boys and girls, the early onset of intercourse was associated with the experienced pressure by peers, and in girls this was also associated with the lack of control in the process of and during sexual intercourse (Whight, et al., 2000). Another study found increased rates of coercion to have sex in women who had their first sexual intercourse at a younger age. It is also found that the incidence of sexually transmitted diseases (STD's) was higher for the group who had their first sexual intercourse before the age of 16 (Dickson, et al., 1998; Whight, et al., 2000). Girls who began sexual activity before the age of 13 were twice as likely to become infected with an STD as girls who started sexual activity after the age of 21 . Other associations of early sexual activity were a greater likelihood of becoming a single mother, more abortions, and lower levels of personal happiness (Rector, et al., 2003). Furthermore the younger a person was at his/her first sexual intercourse the higher the likelihood was of having multiple sex partners (at least five sex partners lifetime or four sex partners during the last six months). Having multiple sex partners is associated with (sexual) risk behaviors such as unsafe sex (not using contraceptives), smoking, drug- and alcohol use (Biglan, et al., 1990; Darling, et al., 1992; Kuortti \& Kosunen, 2009; Santelli, Brener, Lowry, Bhatt, \& Zabin, 1998).

As mentioned before, unsafe sex is a common risk factor among adolescents and young adults. It has been found that only in the US, in 19 million new STD cases that occur every year, half of these are in individuals between 15 and 24 years of age (The Guttmacher Institute, 2009). Pregnancy is of course another consequence of unsafe sex. Darroch, Frost and Singh (2001) found that the US has the highest pregnancy and birth rate in women between 15 and 19 years compared to other developed countries. These higher rates arise primarily because of less, and probably less effective contraceptive use. It is well known that mood disorders, and especially major depressive disorder, are among the most common 
mental disorders in adolescence (Flemming \& Offord, 1990; Lewinsohn, Hops, Roberts, Seeley, \& Andrews, 1993; Reinherz, Giaconia, Lefkowitz, Pakiz, \& Frost, 1993). Mental disorders, including depression, play a role in the development of sexual risk behavior and sexual health problems (Shrier, Emans, Woods, \& DuRant, 1996; Stiffman, Dore, Earls, \& Cunningham, 1992). Sex- and drugs-related behavior predicts an increased likelihood of depression. Among girls, both experimental behavior patterns (experimenting with sex, drugs and alcohol) and high-risk behavior patterns (excessive drinking and/or drug use, and unprotected sexual contact) were found to increase the odds of subsequent depression. Among boys only high-risk behavior patterns increased the odds of the development of subsequent depression (Hallfors, Waller, Bauer, Ford, \& Halpern, 2005). Romantic attractions, activities (dating, kissing, more than kissing (like touching each other), etcetera) and relationships were also associated with a greater risk of depressive symptoms in adolescence (Davilla, 2008; Davilla, Steinberg, Kachadourian, Cobb, \& Fincham, 2004). Adolescents who had romantic relationships and who engaged in romantic activities, compared with adolescents who had not, reported increased depressive symptoms over time (Compain, Gowen, \& Hayward, 2004). Several models have been proposed to explain this association. For example, the attention impairment model (Joyner \& Udry, 2000), suggests that romantic activities takes attention away from other important areas of functioning and so causing impairment, which increases the risk for depressive symptoms. Impairment of romantic functioning (interpersonal skills in the romantic domain) impaired by depressive symptoms can furthermore have far reaching consequences for the relational development of adolescents (Davilla, 2008). Another study in 7th-12th grade students, age 13 to 18, found that depressive symptoms were associated with increased sexual risk. Among boys depressive symptoms were associated with non condom use at last sexual inter- course, among both boys and girls it was associated with a history of STD (Shrier, et al., 1996; Shrier, Harris, Sternberg, \& Beardslee, 2001). Thus, the relationship in adolescents and young adults between sexual behavior and sexual risk behavior on the one hand, and psychopathology, particularly depression, on the other hand, appears to be bidirectional.

In the Netherlands, adolescents are - in general - sexually healthy but there are some alarming developments. Bakker, et al. (2009) examined the sexual health of 6428 men and women between 15 and 70 years old (girls $15-18$ years old $\mathrm{N}=443$; boys $15-18$ years old $\mathrm{N}=$ 368). Of the 15 and 16 year olds, 33\% of the girls and $25 \%$ of the boys had sexual intercourse. At the age of 17-18 these percent- ages have almost doubled. Girls with a lower education level have significantly more sexual experience than higher educated girls. Of the 15 to 18 year olds, $3.8 \%$ of the boys, and $2.9 \%$ of the girls have had more than 10 sexual partners up to that point of their lives. Furthermore, $32.6 \%$ of these boys and $28.5 \%$ of these girls experienced feelings of guilt about their sexual behavior. Pregnancy and birth control were also examined in this study. Among boys, $1.1 \%$ of their female sexual partners had been pregnant and $0.4 \%$ had the baby. More of the partners of high-educated men under 26 years of age who experienced unwanted pregnancy had abortions than low educated men, but the partners of the latter more often gave childbirth. Among girls, 3.7\% had been pregnant and $0.8 \%$ had the baby. Low educated girls under 26 years of age had more (unexpected) pregnancies, children, and abortions than high-educated girls. Among boys, 
$58.9 \%$ uses no contraceptives, while this is the case for $40.9 \%$ of the girls. Sexual victimization is more common among girls than among boys ( $20.2 \%$ vs. $2.3 \%)$. Comparable results have been found in other studies in the Netherlands (Bakker \& Vanwesenbeeck, 2006; de Graaf, et al., 2005).

To improve this situation the Dutch national government has created a new service that facilitates assistance in the area of young peoples' sexual health. The core is a nation- wide network of sexual health service provision centers (called 'Sense') for young people up to 25 years of age with questions concerning or problems with sexual health. The regulation builds on the experiences of the pilot version of Sense (pilot from 2005-2008), which was situated in three areas. One of these is the southern South-Holland ( $\mathrm{sSH}$ ) region. In the pilot version of Sense sSH, the Rotterdam-Rijnmond Public Health Service (PHS) identified an omission. Referral of adolescents with sexual health problems could not be performed adequately; the threshold for referral is too high (for example too expensive, too far away, etcetera). Research has shown that not everyone who needed help or advice for sexual health issues actually sought or had access to that help. The unfamiliarity with the available resources is one factor. Furthermore, the lack of trust in the available help, the costs, and reluctance of the help-seeking person are factors that play a role (Bakker, et al., 2009). This implies that a large group of young people who need help for sexual issues have no access to the necessary care. For this reason the Rotterdam- Rijnmond PHS has, in addition to Sense, appointed a sex counsellor who helps to address the sexual problem in a maximum of three, free of charge and anonymous consultations of 45 minutes maximum. This service is called brief sex counselling. Its aim is to provide tailored and practical advice and/or reference to specialized health care, and to bridge the gap between Sense and this, more intensive, specialized help.

The earlier mentioned developments (de Graaf, et al., 2009) regarding sexual health and the related mental health problems (Shrier, et al., 1996; Stiffman, et al., 1992) form a major problem for youth in the Netherlands. Brief sex counselling might be a solution as it aims to treat the sexual problems of these adolescents in an early stage. Related mental disorders (like depression) would be less likely to develop or escalate. It is expected that brief sex counselling will prevent more serious and chronic problems in the future. However, there is no scientific evidence yet.

Goldmeier and colleagues (2004) calculated that, in 2004, the average costs of the treatment of sexual dysfunctions in the UK for women were $€ 417$ when delivered by a psychologist and $€ 896$ when delivered by a sex therapist. Potentially, a certain proportion of patients with sexual problems do not require this type of intensive and costly treatment, but can adequately and satisfactorily be treated with less intensive and lower-cost alternatives. For instance, in the Netherlands it was estimated that $14 \%$ (respectively 56,000 of the extrapolated total of 400,547 ) of the patients treated in hospital outpatient clinics for sexology and $24 \%$ (respectively 80,500 of the extrapolated total of 335,594 ) of the patients treated in mental health care centers, could be adequately treated with a cheaper, lowthreshold intervention (Bakker \& Vanwesenbeeck, 2006; Vroege, Lotgerink, van der Rhee, Tanis-Nauta, \& Weijmar-Schultz, 2007). It can be expected that brief sex counselling is a cheaper and more approachable option to treat sexual problems in adolescents than 
standard sexual health care provided in com- munity mental health services or hospital outpatient clinics for sexology.

There are two main reasons to conduct this study that are related to current policy aims to improve the sexual health in youth. First, it can be assumed that brief sex counselling for high risk groups has a preventive impact on the recurrence of their sexual condition. This would reduce, more- over, the patient flow to more expensive health care in hospitals and mental health care institutions (Bakker \& Vanwesenbeeck, 2006). Second, a secondary prevention effect of sex counselling on mental health problems, in particular depression, is predicted (Bakker \& Vanwesenbeeck, 2006; Fugl-Meyer \& Fugl-Meyer, 2002).

The objectives of the current study are threefold. The first is the development of protocols for brief sex counselling in the field of sexual health to address problems in sexual functioning in youth. Furthermore a training plan will be developed to train nurses and public health workers to implement these protocols for brief sex counselling. The second objective is to investigate the effects of brief sex counselling on somatic, mental and sexual health. The third and last aim is to investigate the cost-effectiveness of brief sex counselling. We will examine whether brief sex counselling is preferable to more intensive formats of sexual health care and no treatment in terms of costs, impact and utilities from a social perspective.

\section{METHODS}

\section{Design}

The proposed study is a prospective, randomized control trial (RCT). The subjects will be randomly allocated to one of the three conditions: (1) brief sex counselling, (2) intensive sexual healthcare, and (3) a no treatment. The trial flow of the proposed subject enrolment and randomization procedures are graphically shown in figure 1 . This study has been approved by the ethics committee academic hospital Maastricht/Maastricht University, the Netherlands. The study is registered at the Netherlands Trial Register, part of the Dutch Cochrane Centre (NTR1952).

\section{Participants}

The patient population we aim to investigate consists of adolescents with sexual problems. Patients are eligible to participate if they meet the following criteria: age between 18 and 25 years old; at least mild to moderate sexual problems (based on the International Index of Erectile Function (men) and Female Sexual Functioning Index (female) (Rosen, Brown, Heiman, Leiblum, Meston, Shabsigh, Ferguson, \& D'Agostini, 2000; Rosen et al., 1997; ter Kuile, Brauer, \& Laan, 2006); no severe psychiatric co-morbidity or relational problems, and the sexual problems are not caused by disease, medication use or physical disabilities. 


\section{Interventions}

\section{Brief sex counselling}

Brief sex counselling is a brief, free of charge and easily accessible treatment for sexual problems of people between 18 and 25 years of age. In a maximum of three sessions, of 45 minutes each, a sex counsellor attempts to solve the problems or refers to more specialized help. The treatment is aimed at people without relationship and/or psychiatric problems. The sessions include providing information, psycho-education and limited advice on behavior change. Furthermore home exercise assignments can be given, and the experiences with these exercises are discussed. The possibility for adolescents to talk about their sexuality in a non-threatening environment could initiate the problem-solving process.

\section{Treatment protocol}

The protocol that has been developed for the BSC sessions is based on the principles and practice of sexcounselling in general and on a guideline that was developed for Sense (ljff, 2006; Leusink \& Nauta, 2009). The protocol chapters address problems of sexual desire, sexual arousal, orgasm and sexual pain. First, a description of the disorder is provided. Next, specific questions are provided for sexual history taking. Furthermore, an action plan is provided, which gives an outline of the goals of the client and the elements that will be used to address the problem. The counselor evaluates which elements are useful, and in which order they should be administered. The first element that can be used is providing information. This is done to improve the client's knowledge about the cause of his or her problem and the factors that maintain it. A second element concerns cognitive and behavioral aspects. Several compromised cognitive processes and deficient coping strategies can underlie the dysfunction. During the sessions an attempt is made to identify, change and adjusted these processes and strategies. The protocol provides examples of these processes and strategies and how to deal with them. The last element concerns sensate-focus exercises. These exercises aim to help the person or couple to (re)discover sexual needs and preferences. Different exercises provided are tailored to address different sexual problems.

\section{Intensive sexual healthcare}

In a minimum of 6 treatment sessions a (Dutch Association for Sexology) certified sexologist offers an intensive form of treatment for the sexual problem(s) of the participant. This is the standard format of care for adults with sexual problems. In contrast to brief sex counselling, intensive sexological treatment also addresses the relational and/or personal psychological problems which possibly underlie the base of the sexual problems. The treatment is largely based on cognitive-behavioral therapy. In many cases homework assignments have to be carried out. The participant is taught to recognize and change thoughts which could play a negative role in their sex life.

\section{No treatment}

The active treatment conditions will be compared to a no treatment condition, which enabled to control for spontaneous recovery, and mere-measurement effects. In this 
condition, participants are requested not to engage in other types of professional help. After the waiting period, the participants who were allocated to this condition, we allowed to choose their preferred treatment (BSC or ISH).

\section{Objectives}

Both for the effectiveness study as well as for the economic evaluation study we have defined a number of research questions:

\section{Effectiveness study}

- Does BSC as envisaged, when compared to ISH and no treatment, improve the sexual and general mental health of adolescents?

- To which extent (effect size) and in what respect (which outcome dimensions)?

\section{Economic evaluation}

- Is, from a social perspective, the delivery of BSC compared to ISH and no treatment, preferable in terms of costs, effects and utilities?

- What are the (extra) costs of the delivery of BSC compared to ISH and no treatment?

- What are the (extra) effects (measured in health status and quality of life) of BSC compared to ISH and no treatment?

\section{Outcomes}

Several instruments will be used to assess the effects of BSC, ISH and NT. The endpoint variables were measured via a secure Internet link (www.emium.nl) before randomization (during initial screening), at baseline, at the end of treatment, and at 6-months follow-up. Since the duration of the study groups differed, the time points of the measurements differed. For BSC the end of treatment was measured 3 months after baseline, for ISH and NT 6 months after baseline. Furthermore, 6 months after the end of treatment there was a follow-up measurement for BSC and ISH only.

\section{Primary endpoints}

\section{Female Sexual Functional Index}

The Female Sexual Functional Index (FSFI) (Rosen, et al., 2000) is a 19-item self-report instrument, using 6-point Likert scales, which aims to measure female sexual functioning on the dimensions of sexual desire, arousal, lubrication, orgasm, satisfaction and pain. A higher score indicates healthier sexual functioning. It has sound psychometric properties (ter Kuile et al., 2006). High internal consistency was demonstrated for all subscales in sexually dysfunctional ( $\alpha=.82-93$ ) and healthy women ( $\alpha=.83-95$ ) (Rosen, et al., 2000). Test-retest reliability was satisfactory for all subscales in both groups $(r=.68-.80$ and $r=.77-.91$, respectively). 


\section{Excluded:}

- Prominent Axis I/II comorbidity

- Severe relation problems

- Sexual problems are due to disease, medication and/or physical problems
Recruitment population (adolescents (18-25) who visit Public Health Service, General Practitioner or various websites)

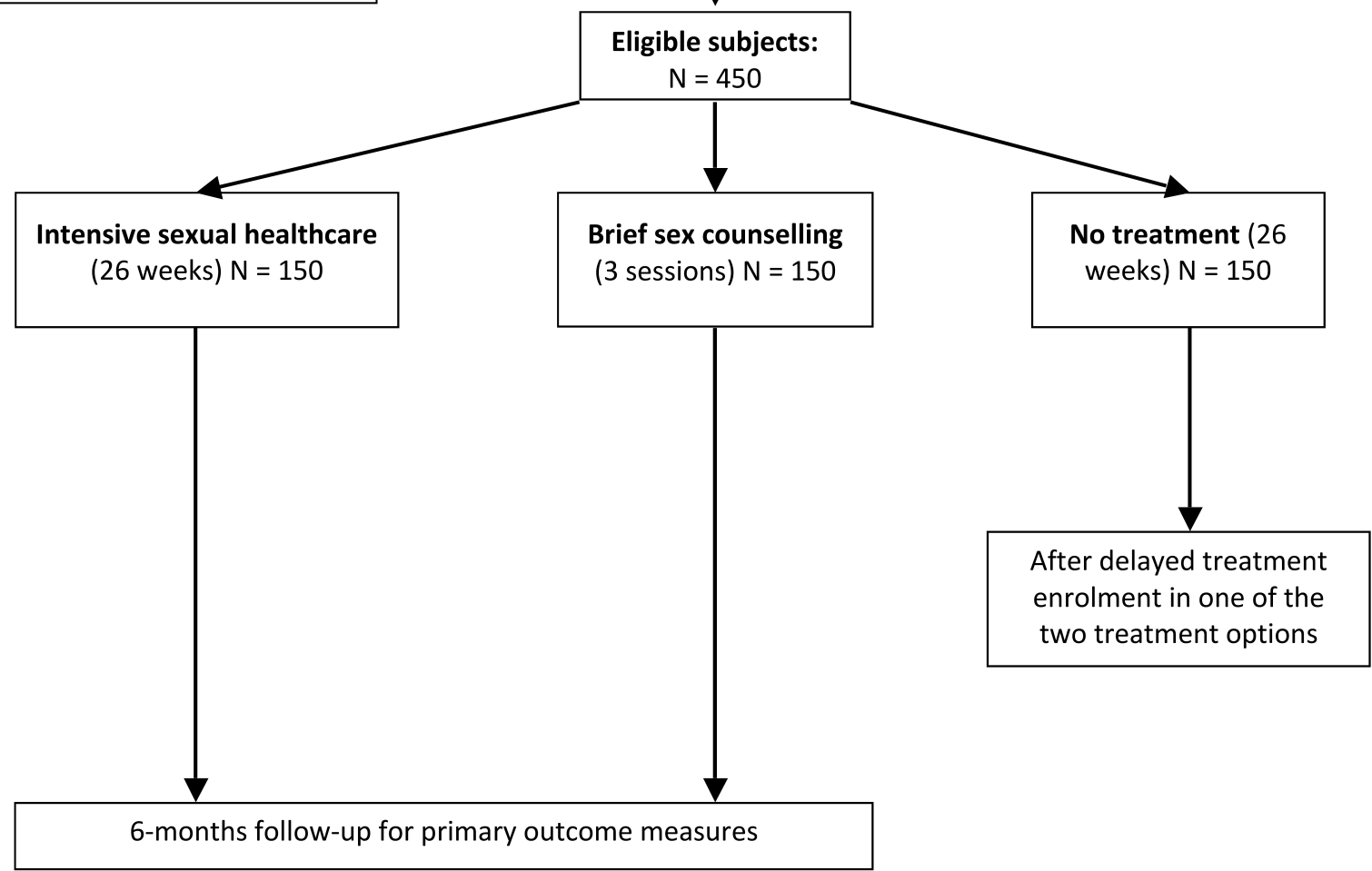

Figure 1: Trial flow proposed participant enrolment and randomization procedures.

\section{International Index of Erectile Function}

The International Index of Erectile Function (IIEF) (Rosen et al., 1997) is a 15-item self-report instrument, using 6-point Likert scales, which aims to measure male sexual functioning on the dimensions of sexual desire, erectile functioning, orgasm, intercourse satisfaction and overall satisfaction. A higher score indicates healthier erectile functioning. Its sound psychometric properties have been proven (Rosen et al., 1997). Internal consistency of this subscale was found excellent $(\alpha=.92-.96)$, and test-retest reliability was high $(\alpha=.84)$ (Rosen et al., 1997). 


\section{Center for Epidemiologic Studies Depression Scale}

The Center for Epidemiologic Studies Depression Scale (CES-D) (Bouwma, Ranchor, Sanderman, \& van Sonderen, 1995) is a 20-item self-report instrument, using 4-point Likert scales, which aims to measure depressive symptoms on the dimensions of somatic- retarded activity, depressed affect, positive affect and interpersonal affect. A higher score indicates more depressive symptoms. Its sound psychometric properties have been proven (Bouwma et al., 1995; Evers et al., 2000). Internal consistency ( $\alpha=.79-.92)$ and test-retest reliability ( $r$ $=.90$ ) is high (Bouwma et al., 1995; Evers, van Vliet-Mulder, \& Groot, 2000).

\section{Brief Symptom Inventory}

The Brief Symptom Inventory (BSI) (de Beurs \& Zitman, 2005) is a 53-item self-report instrument, using 5-point Likert scales, which aims to measure the severity of general psychological distress. A higher score indicates more severe general psychological distress. Its sound psychometric properties have been proven. Internal consistency $(\alpha=.79)$ and testretest reliability ( $r=.90$ ) is high (de Beurs \& Zitman, 2005; Galdón et al., 2008).

\section{Medical Outcomes Study 36-item Short Form Health Survey}

The Medical Outcomes Study 36-item Short Form Health Survey (SF-36) (Ware \& Sherbourn, 1992 ) is a 36-item self-report instrument, using 5-point Likert scales, which aims to measure the quality of life on the dimensions of physical functioning, role disabilities caused by physical health problems, role disabilities caused by emotional problems, pain, mental health, vitality, general health perception and social functioning. A higher score indicates a high quality of life. Its sound psychometric properties have been proven. Internal consistency $(\alpha=.84)$ and test-retest reliability $(r=.93)$ is high (Tsai, Bayliss, \& Ware, 1997; Viane, 2002).

\section{Economic evaluation}

To identify all relevant cost aspects we developed a new cost questionnaire, derived from existing questionnaires, to fit our study population (Koopmanschap et al., 2004). To identify the actual use of resources we used combined data from registrations by professionals and a cost questionnaire filled in by the participant. To identify production losses we used the patient modules of the PROductivity and DISease Questionnaire (PRODISQ) (Koopmanschap, 2005; Koopmanschap et al., 2004; Oostenbrink, Koopmanschap, \& Rutten, 2002). To calculate productivity costs we used the friction cost method, based on a mean added value of the Dutch working population. This method takes into account production losses confined to the period needed to replace a sick employee (Oostenbrink et al., 2002).

\section{Secondary endpoints}

Questionnaire for the Screening of Sexual Dysfunctions

The Questionnaire for the Screening of Sexual Dysfunctions (QSSD) (Vroege, 2003) is a 70item self-report instrument, using 5-point and a 7-point Likert scales, which aims to measure the presence, frequency and severity of sexual difficulties. A high score indicates higher frequency of the problem and higher associated distress. 
Self-Esteem and Relationship Questionnaire

The Self-Esteem and Relationship Questionnaire (SEAR) (Althof et al., 2003) is a 14-item selfreport instrument, using 5-point Likert scales, which aims to measure the sexual relationship and psychosocial factors specific for people with sexual problems on the dimensions of sexual relationship and sexual confidence. A high score indicates good functioning with regard to the participant's sexual relationship and confidence. Its sound psychometric properties have been proven. Internal consistency $(\alpha=.93)$ and test-retest reliability $(r=.93)$ is high (Althof et al., 2003).

\section{Credibility/Expectancy Questionnaire}

The Credibility/Expectancy Questionnaire (CEQ) (Borkovec \& Nau, 1972) is a 16-item selfreport instrument, using a 9-point or a 10-point Likert-scale, which aims to measure the outcome expectancy and credibility a person has regarding the therapy that will be received. A high score indicates high expectancy and credibility of the treatment. Its sound psychometric properties have been proven. Internal consistency $(\alpha=.85)$ and test-retest reliability $(r=.83)$ is high (Devilly \& Borkovec, 2000).

\section{Treatment Satisfaction Questionnaire}

The Treatment Satisfaction Questionnaire (TSQ), derived from the Erectile Dysfunction Inventory of Treatment Satisfaction (EDITS) (Althof et al., 1999), is a 15-item self-report instrument, using a 5-point Likert scale, which aims to measure the satisfaction of the treatment the participant received. A high score indicates high treatment satisfaction. The sound psychometric properties of the EDITS have been proven. Internal consistency $(\alpha=.90)$ and test-retest reliability $(r=.98)$ is high (Althof et al., 1999).

\section{Sample size}

In a repeated-measures analysis of the within-between-interaction effect, a sample size of 95 in each group has a power of $95 \%$ to detect an effect size of 0.41 using repeatedmeasures MANOVA with a 0.05 two-sided level of significance. In the absence of published controlled studies on professional care for adolescents with sexual problems, we set the desired effect size at $d=0.40$, representing the central point of the range of effect sizes that are considered as 'medium size' (Cohen, 1988). $\mathrm{N}=150$ per condition is deemed necessary to guarantee the required number of respondents, in view of the expected non-response after inclusion and later attrition (Campbell, Elbourne, \& Altman, 2004). In a repeatedmeasures analysis of the within-subjects effect, a sample size of 86 in the treated group has a power of $95 \%$ to detect an effect size of 0.25 using a repeated-measures MANOVA with a 0.05 two-sided level of significance. The before mentioned $N=150$ per condition is expected to guarantee the required number of participants. 


\section{Randomization and procedure}

For this study a block randomization procedure will be used to ascertain that each intervention runs in equally large groups. Although the order of the interventions varies randomly within each block, a person running the trial could deduce some of the next treatment allocations if they discovered the block size. In this study we use larger block sizes (30) and randomly vary in block size, which can ameliorate this problem (Campbell et al., 2004). Allocation will be performed by a researcher after getting informed consent, screening, and checking the in- and exclusion criteria, using an adaptive biased urn randomization for small strata (Schouten, 1995). This keeps randomization unpredictable up to and including the last participant on each site, while keeping the group sizes at each site in good balance (Schouten, 1995).

The questionnaires will be administered using a computer. All assessments will take place at home via Internet. Preceding an upcoming assessment point, participants will receive an email (one week before the end of the treatment and 3 months after the start of the follow-up measurement). If a participant fails to complete the assessment within one week, an email-reminder will be sent. When the participant fails to fill in the questionnaires, a phone call will be made.

\section{Statistical methods}

\section{Clinical analyses}

Our primary (base-case) analyses will be performed according to the intention-to-treat principle, including data from all participants regardless of whether they received the intervention or not. For the analyses we will use SPSS statistical software and Excel (for the bootstraps). Respondents for whom at least $75 \%$ of the data per measurement instrument are available will be included in the analysis. Missing data on item level will be handled using SPSS missing value analysis. Completely missing measurements will be handled using multiple imputation. Analysis will include comparisons of the intervention groups. The accuracy of the findings will be expressed in terms of $95 \%$ confidence intervals.

To test the main research questions, difference scores for all outcome variables will be calculated and compared between the three intervention groups using MANOVA. In the case of significant multivariate results, subsequent univariate analysis using independent groups t-tests will be conducted to assess the significance of differences pre/post intervention between control and experimental groups.

\section{Economic evaluation}

A baseline analysis will be performed to examine the comparability of groups at baseline for both costs and out- comes. If necessary methods will be applied to control for differences in baseline (Manca, Hawkins, \& Sculpher, 2005). To investigate whether data are normally distributed a Kolmogorov-Smirnov test will be performed. Despite the usual skewness in the distribution of costs, the arithmetic means will be generally considered the most appropriate measures to describe cost data (Barber \& Thompson, 2000; Ramsey et al., 2005). Therefore 
arithmetic means (and standard deviations) will be presented. In case of skewness of the cost data, non-parametric bootstrapping will be used to test for statistical differences in costs between the intervention and control group. The bootstrap replications will be used to calculate $95 \%$ confidence intervals around the costs $(95 \% \mathrm{Cl})$, based on the 2.5 th and 97.5 th percentiles. If cost data are distributed normally, t-tests will be used.

The incremental cost-effectiveness ratio (Prochaska \& Velicer, 1997) will be determined on the basis of incremental costs and effects of BSC compared to ISH and no treatment. The cost-effectiveness ratio will be stated in terms of costs per outcome rate (increase in sexual functioning, decrease of depressive- and other mental health symptoms) the cost-utility ratio will focus on the net cost per utility gained.

The robustness of the ICER will be checked by non-parametric bootstrapping. Bootstrap simulations will also be conducted in order to quantify the uncertainty around the ICER, yielding information about the joint distribution of cost and effect differences. The bootstrapped cost-effectiveness ratios will be subsequently plotted in a cost-effectiveness plane. The choice of treatment depends on the maximum amount of money that society is prepared to pay for a gain in effectiveness, which is called the ceiling ratio. Therefore, the bootstrapped ICERs will also be depicted in a cost-effectiveness acceptability curve showing the probability that BSC is cost-effective using a range of ceiling ratios. Additionally, to demonstrate the robustness of our base-case findings, multi-way sensitivity analyses will be performed (Briggs, Wonderling, \& Mooney, 1997).

\section{Collaboration}

The current study will be conducted in collaboration with several disciplines. The PHS Rotterdam-Rijnmond, Northern-Netherlands and Limburg (southern part of the Netherlands) will be involved in the development and implementation of BSC. PsyQ Rotterdam, NorthernNetherlands and Limburg (specialized mental health institute) will be involved in the development and implementation of the ISH. Furthermore, there is collaboration between the Dutch-Flemish research school Experimental Psychopathology (EPP) and the Care and Public Health Research Institute (Caphri).

\section{DISCUSSION}

There are some alarming developments regarding sexual health in adolescents. To overcome the threshold in the treatment of sexual dysfunctions, BSC has been developed. It has been used successively since 2006, but research evaluating this intervention is necessary. Therefore, in the current study we will evaluate the (cost-) effectiveness of BSC for sexual dysfunctions of adolescents up and till the age of 25 years of age. We shall compare BSC with ISH and no treatment. 


\section{Methodological considerations}

BSC is a relatively new intervention with which the experience in practice is restricted. The intervention is carried out in the - also relatively new - setting of adjuvant sexuality consultations for adolescents. However, on the basis of the experiences between 2006 and 2008 (pilot version of Sense), the research group is convinced that it is important to start with this intervention because it may reveal sexual health problems that cannot be solved within the regular setting. The threshold for ISH might prove to be too high for some groups, who may suffer severe health consequences in later life. Furthermore, this is one of the first economic evaluation studies and the SF-36 does not take into account a sexual dimension. Finally, the questionnaires are administered among a relative young population.

\section{Conclusion}

BSC is a new treatment with interesting possibilities. It might lower the threshold to seek professional help for sexual health problems, and could prevent health consequences in later life. The current study contributes to the growing literature on sexual health in adolescents. 


\section{REFERENCES}

Althof, S., Cappelleri, J., Shpilsky, A., Stecher, V., Diuguid, C., Sweeny, M., et al. (2003). Treatment responsiveness of the Self-Esteem and Relationship questionnaire in erectile dysfunction. Urology, 888892.

Althof, S., Corty, E., Levine, S., Levine, F., Burnett, A., McVary, K., et al. (1999). EDITS: development of questionnaires for evaluating satisfaction with treatments for erectile dysfunction. Adult Urology, 53, 793799.

Bakker, F., de Graaf, H., de Haas, S., Kedde, H., Kruijer, H., \& Wijsen, C. (2009). Seksuele gezondheid in Nederland 2009. Utrecht: Rutgers Nisso Group.

Bakker, F., \& Vanwesenbeeck, I. (2006). Seksuele gezondheid in Nederland 2006. Delft: Eburon.

Barber, J., \& Thompson, S. (2000). Analysis of cost data in randomized trials. Statistical Medicine, 19, 32193236.

Biglan, A., Metzler, C., Wirt, R., Ary, D., Noell, J., Ochs, L., French, C., \& Hood, D. (1990). Social and behavioral factors associated with high-risk sexual behavior among adolescents. Journal of Behavioral Medicine, 13, 245-261.

Borkovec, T., \& Nau, S. (1972). Credibility of analogue therapy rationales. Journal of Behavior Therapy and Experimental Psychiatry, 3, 257-260.

Bouwma, J., Ranchor, A., Sanderman, R., \& van Sonderen, E. (1995). Het meten van symptomen van depressie met de CES-D: een handleiding. Groningen: Noordelijk Centrum voor Gezondheidsvraagstukken.

Brugman, E., Goedhart, H., Vogels, T., \& van Zessen, G. (1995). Jeugd en Seks 95. Resultaten van het nationale scholierenonderzoek. Utrecht: SWP.

Briggs, A., Wonderling, D., \& Mooney, C. (1997). Pulling cost-effectiveness analysis up by its bootstraps: a nonparametric approach to confidence interval estimation. Econometrics and Health Economics, 6, 327-340.

Campbell, M., Elbourne, D., \& Altman, D. (2004). CONSORT statement: extension to cluster randomised trials. British Medical Journal, 328, 702-708.

Cohen, J. (1988). Statistical power analysis for the behavioral sciences (Second edition ed.). Hillsdale, New Jersey: Lawrence Erlbaum Associates.

Compain, L., Gowen, L., \& Hayward, C. (2004). Peripubertal girls' romantic and platonic involvement with boys: associations with body image and depression symptoms. Journal of Research on Adolescence, 14, 23-47.

Darling, C., Davidson, J., \& Passarello, L. (1992). The mystique of first intercourse among college youth: the role of partners, contraceptive practices, and psychological reactions. Journal of Youth and Adolescence, 21, 97-117.

Darroch, J., Frost, J., \& Singh, S. (2001). Teenage sexual and reproductive behavior in developed countries. Can more progress be made? New York \& Washington: The Alan Guttmacher Institute.

Davila, J. (2008). Depressive symptoms and adolescent romance: theory, research, and implications. Child Development Perspectives, 2, 26-31.

Davila, J., Steinberg, S., Kachadourian, L., Cobb, R., \& Fincham, F. (2004). Romantic involvement and depressive symptoms in early and late adolescence: the role of a preoccupied relational style. Personal Relationships, 11, 161-178.

de Beurs, E., \& Zitman, F. (2005). De Brief Symptom Inventory (BSI). De betrouwbaarheid en validiteit van een handzaam alternatief voor de SCL-90. Leiden: Leids Universitair Medisch Centrum.

de Graaf, H., Meijer, S., Vanwesenbeeck, I., \& Poelman, J. (2005). Seks onder je 25e: Seksuele gezondheid van jongeren in Nederland anno 2005. Delft: Eburon.

Devilly, G., \& Borkovec, T. (2000). Psychometric properties of the credibility/expectancy questionnaire. Journal of Behavior Therapy and Experimental Psychiatry, 31, 73-86.

Dickson, N., Paul, C., Herbison, P., \& Silva, P. (1998). First sexual intercourse: age, coercion, and later regrets reported by a birth cohort. British Medical Journal, 316, 29-33.

Evers, A., van Vliet-Mulder, J., \& Groot, C. (2000). Documentatie van tests en testresearch in Nederland, deel I en II (COTAN). Assen: van Gorcum. 
Flemming, J,. \& Offord, D. (1990). Epidemiology of childhood depressive disorders: a critical review. Journal of the American Academy of Child \& Adolescent Psychiatry, 29, 571-580.

Fugl-Meyer, K., \& Fugl-Meyer, A. (2002). Sexual disabilities are not singularities. International Journal of Impotence Research 2002, 14:487-493.

Galdón, M., Durá, E., Ferrando, M., Murgui, S., Pérez, S., \& Ibañez, E. (2008). Psychometric properties of the Brief Symptom Inventory-18 in a Spanish breast cancer sample. Journal of Psychometric Research, 65, 533-539.

Guttmacher Institute. (2009). Facts on sexually transmitted infections in the United States.

Goldmeier, D., Malik, F., \& Green, J. (2004). Cost implications of sexual dysfunction: the female picture. International Journal of Impotence Research, 16, 130-134.

Hallfors, D., Waller, M., Bauer, D., Ford, C., \& Halpern, C. (2005). Which comes first in adolescence sex and drugs or depression? American Journal of Preventive Medicine, 29, 163-170.

ljff, M. (2006). Sexcounseling. Handleiding voor seksuologische hulpverlening. Assen: Van Gorcum.

Joyner, K., \& Udry, J. (2000). You don't bring me anything but down: adolescent romance and depression. Journal of Health and Social Behaviour, 41, 369-391.

Koopmanschap, M. (2005). PRODISQ: a modular questionnaire on productivity and disease for economic evaluation studies. Expert review of Pharmacoeconomics and Outcome research, 5, 23-28.

Koopmanschap, M., Meerding, W., Evers, S., Severens, J., Burdorf, A., \& Brouwer, W. (2004). Handleiding voor het gebruik van PRODISQ. Een modulaire vragenlijst over de relatie tussen ziekte en productiviteitskosten. Toepasbaar bij economische evaluaties van gezondheidszorgprogramma's voor patiënten en werknemers. Rotterdam/Maastricht: Erasmus Universiteit Rotterdam/Erasmus Medisch Centrum/Universiteit Maastricht.

Kuortti, M., \& Kosunen, E. (2009): Risk-taking behaviour is more frequent in teenage girls with multiple sexual partners. Scandinavian Journal of Primary Health Care, 27, 47-52.

Leusink, P., \& Nauta, M. (2009). Seksuele Gezondheidszorg. Deel 2 Handboek Seksualiteit en reproductie. Bilthoven: RIVM.

Lewinsohn, P., Hops, H., Roberts, R., Seeley, J., \& Andrews, J. (1993). Adolescent psychopathology: I. Prevalence and incidence of depression and other DSM-III-R disorders in high school students. Journal of Abnormal Psychology, 1, 133-144.

Manca, A., Hawkins, N., \& Sculpher, M. (2005). Estimating mean QALY's in trial-based cost-effectiveness analysis: the importance of controlling for baseline utility. Health Economics, 14, 487-496.

Oostenbrink, J., Koopmanschap, M., \& Rutten, F. (2002). Standardisation of costs. The Dutch manual for costing in economic evaluations. Pharmacoeconomics, 20, 443-454.

Ramsey, S., Willke, R., Briggs, A., Brown, R., Buxton, M., Chawla, A., et al. (2005). Good research practices for cost-effectiveness analysis alongside clinical trials: the ISPOR RCT-CEA task force report. Value in Health, 8, 521-533.

Rector, R., Johnson, K., Noyes, L., \& Martin, S. (2003). The harmful effects of early sexual activity and multiple sexual partners among women: a book of charts. Washington: The Heritage Foundation.

Reinherz, H., Giaconia, R., Lefkowitz, E., Pakiz, B., \& Frost, A. (1993). Prevalence of psychiatric disorders in a community population of older adolescents. Journal of the American Academy of Child \& Adolescent Psychiatry, 32, 369-377.

Rosen, R., Brown, C., Heiman, J., Leiblum, S., Meston, C., Shabsigh, R., et al. (2000). The Female Sexual Function Index (FSFI): a multidimensional self-report instrument for the assessment of female sexual function. Journal of Sex \& Marital Therapy, 26, 191-208.

Rosen, R., Riley, A., Wagner, G., Osterloh, I., Kirkpatrick, J., \& Mishra, A. (1997). The International Index of Erectile Function (IIEF): a multidimensional scale for assessment of erectile dysfunction. Urology, 6, 822830.

Santelli, J., Brener, N., Lowry, R., Bhatt, A., \& Zabin, L. (1998). Multiple sexual partners among US adolescents and young adults. Family Planning Perspectives, 30, 271-275.

Schouten, H. (1995). Adaptive biased urn randomization in small strata. Biometrics, 51, 1529-1535.

Shrier, L., Emans, J., Woods, E., \& DuRant, R. (1996). The association of sexual risk behaviors and problem drug behaviors in high school students. Journal of Adolescent Health, 20, 377-383. 
Shrier, L., Harris, S., Sternberg, M., \& Beardslee, W. (2001). Associations of depression, self-esteem, and substance use with sexual risk among adolescents. Preventive Medicine, 33, 179-189.

Stiffman, A., Dore, P., Earls, F., \& Cunningham, R. (1992). The influence of mental health problems on AIDSrelated risk behaviors in young adults. The Journal of Nervous and Mental Disease, 20, 377-383.

ter Kuile, M., Brauer, M., \& Laan, E. (2006). The Female Sexual Function Index (FSFI) and the Female Sexual Distress Scale (FSFD): psychometric properties within a Dutch population. Journal of Sex \& Marital Therapy, 32, 289-304.

Tsai, C., Bayliss, M., \& Ware, J. (1997). SF-36 survey annotated bibliography: 1996 supplement. Boston: New England medical center.

Viane, I. (2002). MOS 36-item Short Form Health Survey (MOS SF-36): Ghent University.

Vroege, J. (2003). De vragenlijst voor het signaleren van seksuele disfuncties (VSD): bruikbaarheid in de klinische praktijk. Delft: Eburon.

Vroege, J., Lotgerink, H., van der Rhee, K., Tanis-Nauta, M., \& Weijmar Schultz, W. (2007). Behandeling van seksuele problemen in de eerstelijn, de tweedelijns somatische gezondheidszorg of de tweedelijns GGZ? Tijdschrift voor Seksuologie, 31, 80-84.

Vroege, J., Zeijlemaker, B., \& Scheers, M. (1998). Sexual functioning of adult patients born with meningomeylocele: a pilot study. European Urology, 34, 25-29.

Ware, J., \& Sherbourn, C. (1992). MOS 36-item Short Form Health Survey (MOS-SF-36): Ghent University.

Wight, D., Henderson, M., Raab, G., Abraham, C., Buston, K., Scott, S., \& Hart, G. (2000). Extent of regretted sexual intercourse among young teenagers in Scotland: a cross sectional survey. British Medical Journal, 320, 1243-1244.

World Health Organization. (2002). Defining sexual health. Report of a technical consultation on sexual health. Geneva: World Health Organization. 
Chapter 5 


\section{Chapter 6}

\section{The clinical effectiveness of brief sex counselling for sexually dysfunctional adolescents}

A. Grauvogl, S. Evers, M. Peters, \& J. van Lankveld

This chapter has been submitted for publication as:

Grauvogl, A., Evers, S., Peters, M., \& van Lankveld, J. The clinical effectiveness of brief sex counselling for sexually dysfunctional adolescents. 


\section{ABSTRACT}

Sexual function problems among Dutch adolescents are not uncommon. However, referral of adolescents with a sexual dysfunction to intensive sexual healthcare is problematic. Brief sex counselling, a brief, anonymous and cost-free treatment might offer a solution. The aim of this study was to compare the clinical effectiveness of brief sex counselling (BSC), intensive sexual healthcare (ISH) and no treatment (NT) for adolescents with a sexual dysfunction. In this multi-center randomized controlled trial, 71 male and female adolescents between the age of 18 and 25 with a sexual dysfunction were randomly allocated to BSC, ISH or NT. Primary outcome measures were the improvement in sexual functioning and psychological wellbeing. Secondary outcome measures were quality of life, sexual confidence and relationship quality, and treatment satisfaction. Results show that there were no significant differences in outcome between the three study options. Brief sex counselling could not be identified as a superior treatment option for adolescents with a sexual dysfunction. 


\section{INTRODUCTION}

Sexual health research among adolescents has focused primarily on sexual risk behavior, such as unwanted or unplanned pregnancy, teenage childbirth and STls (Guttmacher Institute, 2010, 2012; Hamilton, Martin, \& Ventura, 2010; Pazol et al., 2011), while neglecting other aspects of sexual health. De Graaf, Kruijer, van Acker and Meijer (2012) explored sexual health problems among approximately 8,000 adolescents, aged 12 to 25, and revealed that several sexual themes still need attention of policy makers and sexual health care providers, including lowering the rates of unwanted sexual behaviors (e.g., physical violence, force, etcetera), improving the preparation and planning of the first sexual intercourse, increasing knowledge about sexuality, and reducing problems with regard to sexual functioning. Adolescents in the Netherlands experience substantial rates of problems with sexual desire, sexual arousal, orgasm and pain during sexual encounters (De Graaf et al., 2012). Especially girls report these problems. More recently, Kedde (2012) explored sexual dysfunctions among 608 adolescent girls and 459 adolescent boys, aged 15 to 24, in the Netherlands. Among the adolescent females, $43.4 \%$ experienced at least one sexual dysfunction. Among the adolescent males, $27.3 \%$ experienced at least one sexual dysfunction. These findings can be taken to imply that sexual function problems in adolescents indeed warrant attention.

Experiencing sexual function problems can significantly impact one's emotional and social wellbeing. Men with erectile dysfunction experience considerable psychological distress and negative social consequences (Althof, 2002). Men with premature ejaculation report lower levels of sexual satisfaction in addition to higher levels of personal distress and interpersonal difficulties (Rowland, Patrick, Rothman, \& Gagnon, 2007), while women with sexual dysfunctions are particularly at risk for secondary problems, such as depression and relationship problems (Hallfors, Waller, Bauer, Ford, \& Halpern, 2005; Shrier, Emans, Woods, \& DuRant, 1996; Stiffman, Dore, Earls, \& Cunningham, 1992). Only one third of the adult women with sexual function problems in need of help actually receive such help. In men only four percent of those in need actually receive help (Bakker \& Vanwesenbeeck, 2006).

To improve the overall sexual health of adolescents in the Netherlands, the Dutch government created a new service in 2005 to facilitate professional assistance in the area of sexual health. The core element of this service is a nationwide network of sexual health care centers (called 'Sense') offering professional help for adolescents up to 25 years of age who have questions concerning sexuality or sexual health problems. The assistance offered by Sense comprises two sessions of 25 minutes each. The main goal of Sense is to give information and tips and tricks about sexual functioning and dysfunction. In the pilot version of Sense, the Rotterdam-Rijnmond Public Health Service (PHS) identified a weak spot in this service. Adolescents who presented more severe sexual function problems would normally be referred to more specialized intensive sexual healthcare, however, this could not be done adequately, due to loss of anonymity, financial costs, lack of familiarity with, and lack of confidence in the available healthcare services (Akre, Michaud, \& Suris, 2010; Bakker et al., 2009; Bakker \& Vanwesenbeeck, 2006). This implies that a large group of adolescents in need of help is deprived of access to the necessary care. 
To overcome these obstacles, the Rotterdam-Rijnmond PHS has, in addition to Sense, developed a new intervention, termed brief sex counselling (BSC). A sex counsellor provides three consultations of 45 minutes each for adolescents with sexual function problems. This service is free of charge and anonymous. It aims to provide tailored and practical advice. BSC is intended to offer a more accessible and affordable service to help adolescents with sexual function problems.

The aim of this study is to investigate the efficacy of BSC compared with intensive sexual healthcare and no treatment. It is expected that BSC will result in better sexual and general mental health of adolescents with sexual function problems than no treatment. Furthermore, it is expected that intensive sexual healthcare will show superior outcome compared to BSC, since it is more intensive and longer of duration.

\section{METHODS}

\section{Participants}

Participants were included if they met the following criteria: age between 18 and 25 years old; at least mild to moderate sexual function problems; no severe psychiatric co-morbidity or relational problems; and the sexual function problems were not caused by disease, medication/drug use or physical disabilities (based on a problem history questionnaire). Participants were recruited through referrals from the PHS Rotterdam-Rijnmond, NorthernNetherlands and Limburg (southern part of the Netherlands), Sense, and various websites (www.sexcounselling.eu, www.sense.info). Participants received their treatment in one of these three regions in the Netherlands (Rotterdam, Northern-Netherlands and Limburg).

\section{Interventions}

\section{Brief sex counselling}

Brief sex counselling (BSC) is a brief, free of charge, and low-threshold treatment for adolescents between 18 and 25 years of age who experience sexual function problems. In a maximum of three sessions, of 45 minutes each, spread over a 3-month period, a sex counsellor provides treatment. The sex counsellor is a nurse who works at Sense and who received a supplementary training provided by a sexologist. The sessions include providing information (psycho-education), and cognitive restructuring. Instructions for home-based exercises, following the principles of sensate-focus exercises of Masters and Johnson (Masters \& Johnson, 1970) are also provided during the sessions.

The treatment manual that has been developed for the BSC sessions (Grauvogl, 2009) is based on the general principles and practice of sex counseling, and on a guideline that was developed for Sense (ljff, 2006; Leusink \& Nauta, 2009). The manual contains instructions for the sex counselor to address problems of sexual desire, sexual arousal, orgasm, and sexual pain. In the first session, specific questions regarding sexual functioning and the overall sexual history are discussed. Furthermore, an action plan is established, which gives an 
outline of the adolescent's treatment goals and the elements that will be used to alleviate the problem. The counselor evaluates which elements are useful for the client, and in which order they are administered. Several therapeutic techniques are offered in session two and three. Information can be given to improve the adolescent's knowledge about the cause of the problem and the factors that maintain it. During the sessions the counselor attempts to identify, change and adjust compromised cognitive processes and deficient coping strategies. Instructions for sensate-focus exercises (Masters \& Johnson, 1970) can be given to help the adolescent to (re)discover sexual needs and preferences and to practice sensual and erotic touching, while avoiding performance pressure.

The brief duration of the intervention was expected to render BSC unsuitable to treat individuals with sexual dysfunctions with comorbid relationship and/or psychiatric problems.

\section{Intensive sexual healthcare}

In the intensive sexual healthcare (ISH) condition, participants receive more intensive psychological treatment. During a minimum of 6 sessions, spread over a 6-month period, a certified sexologist offers sexological treatment based on cognitive-behavior therapy principles. The sessions are scheduled weekly. Often the adolescent will receive instructions for exercises that are performed at home. These exercises concern writing exercises or more body-related exercises, following the sensate-focus format. In the next session the experiences regarding the exercises are discussed. Furthermore, in contrast to BSC, the therapist in intensive sexual healthcare also addresses the psychological problems of the participant, which may be the cause of the sexual function problem.

\section{No treatment}

The active treatment conditions were compared to a no treatment (NT) condition, which enabled to control for spontaneous recovery and mere measurement effects. In this condition, participants were requested not to engage in other types of professional help, for a 6-month period. After the waiting period, the participants who were allocated to this condition could choose their preferred treatment (BSC or ISH).

\section{Outcomes}

\section{Primary endpoints}

Female Sexual Functional Index

The Female Sexual Functional Index (FSFI) (Rosen et al., 2000) is a 19-item self-report instrument, using 5-point (range 1-5; 4 items) and 6-point Likert scales (range 1-6; 15 items; minimum total score 2, maximum total score 36 ), which aims to measure female sexual functioning on the dimensions of sexual desire, arousal, lubrication, orgasm, satisfaction and pain. A higher total score indicates healthier sexual functioning. It has good psychometric properties (ter Kuile et al., 2006). High internal consistency was demonstrated for all subscales in sexually dysfunctional $(\alpha=.82-.93)$ and healthy women $(\alpha=.83-.95)$ (Rosen et al., 2000). The test-retest reliability was satisfactory for all subscales in both groups $(r=.68$ .80 and $r=.77-.91$, respectively). 
International Index of Erectile Function

The International Index of Erectile Function (IIEF) (Rosen et al., 1997) is a 15-item self-report instrument, using 5-point (range 1-5; 5 items) and 6-point Likert scales (range 0-5; 10 items; minimum total score 5 maximum total score 75 ), which aims to measure male sexual functioning on the dimensions of sexual desire, erectile functioning, orgasm, intercourse satisfaction, and overall satisfaction. A higher total score indicates healthier erectile functioning. The internal consistency is excellent $(\alpha=.92-.96)$, and test-retest reliability is high $(r=.84)$ (Rosen et al., 1997).

\section{Center for Epidemiologic Studies Depression Scale}

The Center for Epidemiologic Studies Depression Scale (CES-D) (Bouwma et al., 1995) is a 20item self-report instrument, using 4-point Likert scales (ranging 0-3; minimum total score 0, maximum total score 60 ), which aims to measure depressive symptoms. A higher total score indicates more depressive symptoms. The internal consistency ( $\alpha=.79-.92)$ and test-retest reliability $(r=.90)$ are high (Bouwma et al., 1995; Evers, van Vliet-Mulder, \& Groot, 2000).

\section{Brief Symptom Inventory}

The Brief Symptom Inventory (BSI) (de Beurs \& Zitman, 2005) is a 53-item self-report instrument, using 5-point Likert scales (ranging 0-4; minimum total score 0 , maximum total score 4), which aims to measure the severity of general psychological distress. A higher total score indicates more severe general psychological distress. The internal consistency $(\alpha=.79)$ and test-retest reliability $(r=.90)$ are high (de Beurs \& Zitman, 2005; Galdón et al., 2008).

\section{Secondary endpoints}

Questionnaire for the Screening of Sexual Dysfunctions

The Questionnaire for the Screening of Sexual Dysfunctions (QSSD) (Vroege, 2003) is a 70item self-report instrument, using 5-point and 7-point Likert scales (ranging 1-5 and 1-7; minimum score 0 , maximum score 12 ), which aims to measure the presence, frequency and severity of sexual difficulties. It has 4 different versions, differentiating between gender and partner status, including versions for women and men, with male of female partners, or without steady partner. In this study only the satisfaction score was used, which is only measured for participants with a steady partner (2 5-point Likert scales, ranging from 0-4; minimum score 0 , maximum score 8 ). Higher scores indicate higher relational and sexual satisfaction. There are no psychometric properties available, however this is a questionnaire that is frequently used by clinicians.

\section{SF-6D}

The SF-6D a utility instrument based on the health-related quality of life questionnaire Medical Outcomes Study 36-item Short Form Health Survey (SF-36) (Ware \& Sherbourn, 1992). The utility score is derived from 11 items of the SF-36 and is composed of six dimension of health (physical functioning, role disabilities caused by physical health problems, role disabilities caused by emotional problems, pain, mental health, vitality, general health perception and social functioning), and calculated using preferences elicited 
from a general population from the UK, the so-called Brazier algorithm (Brazier, Roberts, \& Deverill, 2002).

\section{Self-Esteem and Relationship Questionnaire}

The Self-Esteem and Relationship Questionnaire (SEAR) (Althof et al., 2003) is a 14-item selfreport instrument, using 5-point Likert scales (ranging 1-5; minimum total score 0 , maximum total score 0.7), which aims to measure sexual relationship and psychosocial factors specifically for people with sexual problems. A high score indicates good functioning with regard to the participant's sexual relationship and confidence. The internal consistency ( $\alpha=$ .93 ) and test-retest reliability ( $r=.93$ ) are high (Althof et al., 2003).

\section{Credibility/Expectancy Questionnaire}

The Credibility/Expectancy Questionnaire (CEQ) (Borkovec \& Nau, 1972) is a 6-item selfreport instrument, using VAS scales ranging from 0 ( $0 \%$ credible or expected) to 100 (100\% credible or expected), which aims to measure the outcome expectancy and credibility a person attributes to the therapy that he will receive. The internal consistency $(\alpha=.85)$ and test-retest reliability $(r=.83)$ are high (Devilly \& Borkovec, 2000).

\section{Treatment Satisfaction Questionnaire}

The Treatment Satisfaction Questionnaire (TSQ), derived from the Erectile Dysfunction Inventory of Treatment Satisfaction (EDITS) (Althof et al., 1999), is a 15-item self-report instrument, using a 5-point Likert scale (range 1-5; minimum total score 15, maximum total score 75), which aims to measure the satisfaction with the treatment that the participant received. A low score indicates high treatment satisfaction. The internal consistency $(\alpha=.90)$ and test-retest reliability $(r=.98)$ of the original EDITS are high (Althof et al., 1999).

\section{Procedure}

The endpoint variables were measured via a secure Internet link (www.emium.nl) before randomization (during initial screening), at baseline, at the end of treatment, and at 6months follow-up. Since the duration of the study groups differed, the time points of the measurements differed. For BSC the outcome of treatment was measured 3 months after baseline, for ISH and NT outcome was measured 6 months after baseline. Furthermore, 6 months after the end of treatment there was a follow-up measurement for BSC and ISH, not for NT.

\section{Randomization}

We used a block randomization procedure to ascertain that each intervention runs in equally large groups. Allocation was performed by a researcher after informed consent and screening data were received, and after in- and exclusion criteria were checked, and the applicant was deemed eligible, using an adaptive biased urn randomization for small strata 
(Schouten, 1995). This keeps randomization unpredictable up to and including the last participant, while keeping the group sizes in good balance.

\section{Statistical methods}

Our primary analyses were performed according to the intention-to-treat principle, including data from all participants regardless of whether they completed the measurements or not. Only intermittent missing data were imputed, and calculated using the mean values of the previous and subsequent time point. Missing data due to lost to follow-up were not replaced by imputed values. For the analyses we used SPSS 20.0 statistical software. First, a baseline analysis, using ANOVA F-tests or non-parametric Chi Square tests, was performed to examine the comparability of groups at baseline. To test the main hypotheses, repeatedmeasures analyses of variance (ANOVAs) were performed, using the total scores of the selected instruments. With respect to sexual functioning, standardized values of the FSFI and IIEF total scores were used to render data of male and female adolescents comparable on the same scale. Study group (ISH, BSC and NT) was entered as between subject's factor, and to correct for baseline differences, the baseline SEAR score was entered as a covariate. The improvement effect sizes for sexual functioning of female adolescents for end of treatment and 6-month follow-up according to Cohen's d statistic were computed, defined as Timepoint0-Timepointk) / sd(Timepoint0-Timepointk). Between-group effect sizes were determined by subtracting the improvement effect sizes of one group from the other.

\section{RESULTS}

\section{Flowchart and comparison of baseline characteristics}

The study was conducted between November 2009 and July 2013. The participant flow is presented in Figure 1. 580 adolescents applied to participate in the study and received the information letter and informed consent. 157 adolescents returned their informed consent form, of whom 130 completed the screening procedure. 44 adolescents did not meet the inclusion criteria, 27 adolescents did not fill in the screening questionnaires and could not be reached, 11 adolescents were not willing to participate after all and 1 adolescent had no more complaints. In total, 71 adolescents were randomized (23 to intensive sexual healthcare (ISH), 27 to brief sex counselling (BSC) and 21 to no treatment (NT). With respect to the choice of treatment after the no treatment option, 4 participants chose BSC, 2 participants chose ISH, 5 participants had no further interest in a treatment and 9 participants could not be reached.

Although the inclusion period was longer than originally intended, inclusion progressed too slow. Many adolescents were reluctant to participate because of the risk that they would be randomized into the no treatment group. They were not willing to wait 6 months before treatment would start. Furthermore, many adolescents were not willing to complete 
questionnaires after the treatment ended, thus resulting in an even lower number of participants at 6-month follow-up.

Missing data per group between baseline and end of the treatment ranged from $4.8 \%$ to 21.7\% (1 NT, $2 \mathrm{BSC}, 5 \mathrm{ISH}$,). At six months of follow-up, missing data per group ranged from $29.6 \%$ to $30.4 \%$ (7 ISH, 8 BSC). Characteristics of the completers were compared with the non-completers. Completers had a significantly higher sexual confidence and relationship quality (SEAR) level at baseline than non-completers, $F(62,1)=4.948, p=.03$. There were no differences with respect to gender, age, study group, education, occupation, relation status, amount of children or the other primary and secondary measures.

Baseline characteristics and treatment history of all participants are shown in Table 1. Randomization was successful, as the baseline characteristics of the three groups were not significantly different, except for sexual confidence and relationship quality (SEAR). The mean SEAR score was significantly higher for the BSC group than for the ISH group, $F(62,2)=$ $5.513, p=.006$, indicating higher sexual confidence and relationship quality.

\section{Treatment outcomes}

Table 2 shows the means and standard deviations of the clinical outcomes at baseline, posttreatment, and follow-up for both primary and secondary endpoint measures. First, a $2 \times 3$ (baseline and end of treatment $x$ three study groups; BSC, ISH and NT) repeated-measures ANOVA was performed. Second, a $3 \times 2$ (baseline, end of treatment and 6-month follow-up $x$ two study groups; BSC and ISH) repeated-measures ANOVA was performed. Significant effects of Time with respect to overall psychological problems and depressive symptoms were found. Overall, psychological problems $(F(1,49)=6.65, p=.013)$ and depressive symptoms $(F(1,49)=6.45, p=.014)$ increased between the beginning and end of treatment. There was also an effect of Time at 6-month follow-up with respect to sexual functioning; sexual functioning increased between baseline and 6 months after the end of treatment $(F(2,36)=4.91, p=.044)$. The interaction of Time and Group was not significant. Thus with respect to the primary outcome measures no differences could be identified between groups.

Also for the secondary endpoints, first, a $2 \times 3$ (baseline and end of treatment $x$ three study groups; BSC, ISH and NT) repeated-measures ANOVA was performed. Second, a $3 \times 2$ (baseline, end of treatment and 6-month follow-up $x$ two study groups; BSC and ISH) repeated-measures ANOVA was performed. With respect to the secondary endpoint measures, a significant Time effect at post-treatment was found for sexual satisfaction, sexual confidence and relationship quality $(\operatorname{SEAR} F(1,41)=6.30, p=.016)$. All participants across study conditions reported higher sexual self-confidence and relationship quality at treatment termination or waiting period. A significant Time by Group interaction at posttreatment was found with regard to sexual self-confidence and relationship satisfaction (SEAR; $F(2,41)=6.35, p=.004)$, however, no significant group differences could be identified.

Because there were outcome differences between the study groups, post hoc analyses were performed comparing the administration of any treatment (combination of ISH and 
BSC) versus no treatment (NT). Again no significant group differences could be identified for both primary and secondary outcome measures. With respect to the effect of Time, psychological wellbeing decreased and sexual satisfaction, sexual confidence and relationship quality improved, for both the treatment and no treatment group.

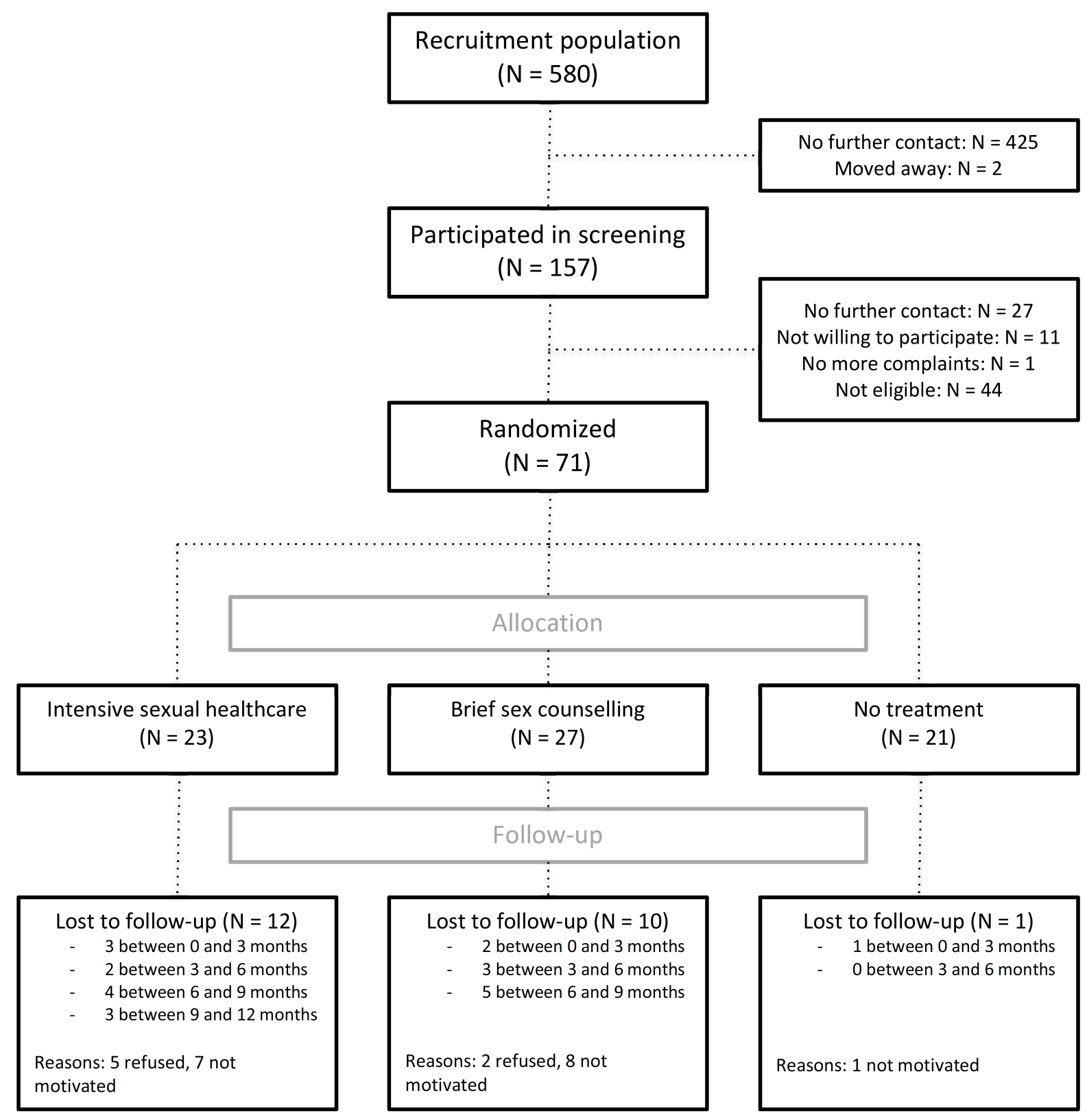

Figure 1: Flow of the participants 
Table 1: Baseline characteristics

\begin{tabular}{|c|c|c|c|c|c|c|c|}
\hline \multirow[b]{2}{*}{ Age, mean (sd) } & \multicolumn{2}{|c|}{ ISH (N=23) } & \multicolumn{2}{|c|}{ BSC (N=27) } & \multicolumn{2}{|c|}{ NT $(\mathrm{N}=21)$} & \multirow{2}{*}{$\begin{array}{r}\text { P-Value } \\
.159^{\mathrm{a}}\end{array}$} \\
\hline & 22.30 & $(1.89)$ & 21.41 & $(1.86)$ & 21.38 & $(1.77)$ & \\
\hline Female sex, $\mathrm{nr}(\%)$ & 19 & $(82.6)$ & 25 & $(86.2)$ & 18 & $(85.7)$ & $.909^{\mathrm{b}}$ \\
\hline Partner, n (\%) & & & & & & & $.636^{\mathrm{b}}$ \\
\hline No & 8 & $(34.8)$ & 4 & $(13.8)$ & 4 & (19) & \\
\hline Yes, a man & 14 & $(60.9)$ & 22 & (75.9) & 16 & $(76.2)$ & \\
\hline Yes, a woman & 1 & $(4.3)$ & 3 & $(10.3)$ & 1 & $(4.8)$ & \\
\hline Children, n (\%) & & & & & & & $.657^{\mathrm{b}}$ \\
\hline None & 22 & $(95.7)$ & 28 & $(96.6)$ & 21 & $(100)$ & \\
\hline One & 1 & $(4.3)$ & 1 & $(3.4)$ & & & \\
\hline Education, n (\%) & & & & & & & $.471^{b}$ \\
\hline Primary school & 6 & $(26.1)$ & 14 & $(48.3)$ & 13 & $(61.9)$ & \\
\hline Middle secondary education & 5 & $(21.7)$ & 8 & $(27.6)$ & 3 & $(14.3)$ & \\
\hline Higher secondary education & 8 & $(34.8)$ & 4 & $(13.8)$ & 3 & $(14.3)$ & \\
\hline Academic education & 4 & $(17.4)$ & 3 & $(10.3)$ & 2 & $(9.5)$ & \\
\hline Work, yes (\%) & 15 & $(65.2)$ & 22 & (75.9) & 15 & $(71.4)$ & $.583^{b}$ \\
\hline BSI, mean (sd) & .30 & $(.30)$ & .29 & $(.19)$ & .27 & $(.25)$ & $.727^{c}$ \\
\hline CES-D, mean (sd) & 8.09 & $(6.84)$ & 5.81 & $(4.24)$ & 4.7 & $(4.30)$ & $.097^{\mathrm{a}}$ \\
\hline Sexual functioning, mean $(s d)^{d}$ & -.24 & $(.93)$ & .14 & (.99) & .09 & $(1.06)$ & $.369^{\mathrm{a}}$ \\
\hline \multicolumn{8}{|l|}{ QSSD, mean (sd) } \\
\hline Satisfaction & 1.57 & $(2.57)$ & 2.19 & (2.09) & 2.14 & $(1.80)$ & $.201^{\mathrm{c}}$ \\
\hline \multicolumn{8}{|l|}{ Quality of life, mean (sd) } \\
\hline SF-6D, UK Brazier-tariff & .592 & $(.052)$ & .581 & $(.059)$ & .601 & $(.039)$ & $.187^{\mathrm{a}}$ \\
\hline SEAR, mean (sd) & .22 & $(.19)$ & .40 & $(.17)$ & .34 & $(.18)$ & $.006^{a^{*}}$ \\
\hline CEQ, mean (sd) & 62.93 & $(16.25)$ & 62.67 & $(17.76)$ & & & $.864^{\mathrm{a}}$ \\
\hline
\end{tabular}

Note: $\mathrm{a}=\mathrm{P}$-value calculated with ANOVA F-test; $\mathrm{b}=\mathrm{P}$-value calculated with Pearson Chi Square test; $\mathrm{c}=\mathrm{P}$-value calculated with Kruskal-Wallis test; $d=z$-score of the Female Sexual Functional Index and the International Index of Erectile Function; ${ }^{*}=$ significant at $\mathrm{p}<0.05$; ISH = Intensive sexual healthcare; $\mathrm{BSC}=\mathrm{Brief}$ sex counselling; NT = No treatment; $\mathrm{BSI}=$ Brief Symptom Inventory; CES-D = Center for Epidemiological Studies Depression scale; QSSD = Questionnaire for the Screening of Sexual Dysfunctions SEAR = Self-Esteem and Relationship Questionnaire; CEQ = Credibility and Expectancy Questionnaire 
Chapter 6 


\section{Effect sizes}

The effect sizes were only calculated for sexual functioning in female adolescents due to the small number of male participants $(N=7)$. In female adolescents, difference scores (baseline to post-treatment; baseline to 6-month follow-up) in all three groups had only marginal effect sizes (range -.37 - .09). The directions of the effects were as expected; negative effect sizes were found for ISH and BSC participants (representing higher sexual functioning) and positive effect sizes for the NT participants (representing lower sexual functioning). Between-group effect sizes ranged from marginal to moderate improvement (see Table 3).

Comparable results were found when comparing the combination of ISH and BSC $(d=-$ .27) versus NT ( $d=.09)$, indicating better sexual functioning when any actual treatment was received compared with no treatment.

Table 3: Improvement effect size and between-group effect size of sexual functioning in women based on the FSFI in the intention-to-treat population

\begin{tabular}{lcccccc}
\hline & \multicolumn{3}{c}{ Improvement effect size } & \multicolumn{3}{c}{ Between-group effect size } \\
& $\mathrm{ISH}(\mathrm{N}=29)$ & $\mathrm{BSC}(\mathrm{N}=23)$ & $\mathrm{NT}(\mathrm{N}=18)$ & $\mathrm{BSC}$ vs ISH & $\mathrm{BSC}$ vs NT & ISH vs NT \\
End of treatment & -.28 & -.26 & .46 & .02 & -.72 & -.74 \\
6-month follow-up & -.27 & -.37 & & -.10 & & \\
\hline
\end{tabular}

Note: ISH = Intensive sexual healthcare; BSC = Brief sex counselling; NT = No treatment; Improvement effect size $=($ Timepoint 0 -Timepoint $k) / \mathrm{sd}$ (Timepoint0-Timepoint $k) ;$ Between-group effect size $=$ Difference in improvement effect size between groups; FSFI = Female Sexual Functional Index

\section{DISCUSSION}

The aim of this study was to investigate whether brief sex counselling (BSC) was superior to no treatment (NT) in improving sexual and mental health of adolescents with sexual function problems. This study was, to our knowledge, the first to examine the effect of BSC and ISH in a group of adolescents with sexual dysfunctions. A standardized treatment manual for the BSC was designed and all treatment providers were trained to work with this protocol. The present study included both male and female adolescents including both adolescents with an autochthonous and non-autochthonous demographic background.

There was a significant increase in overall psychological wellbeing and depression between baseline and post-treatment in all study groups. Furthermore, sexual functioning increased between baseline and 6-month follow-up. With respect to the secondary outcome measures, sexual confidence and relationship quality (SEAR) significantly increased between baseline and end of treatment in all study groups. With respect to either primary or secondary outcome measures no group differences could be identified. Finally, in female adolescents, small improvement effect sizes were found regarding sexual functioning after brief sex counselling (BSC) and intensive sexual healthcare (ISH). 
This study was not able to differentiate between BSC, ISH and NT with respect to the improvement of sexual functioning at the end of treatment. Although sexual functioning increased for BSC and ISH and decreased for NT, the limited statistical power due to the small number of participants per group might explain the lack of significant differences between groups.

Factors that play a role in the development and maintenance of sexual dysfunctions could provide an explanation of the initial absence of improvement in sexual functioning. Theories addressing the etiology of sexual dysfunctions predominantly state that sexual dysfunctions are not caused by one single factor, but that such problems are the result of a synthesis between biological, psychological, and social factors (Barlow, 1986; Everaerd \& Moors, 1995). In the treatment, biological aspects (e.g. function of the body during sexual activity), but most of all, psychological aspects (e.g. fear and anxiety) and social aspects (e.g. communication with partner) are discussed. With respect to social aspects improvement in all groups between pre- and post-treatment could be identified, as can be seen in the improvement of sexual confidence and relationship quality (as measured with the SEAR). It might be the case that, in adolescents, it is necessary that social aspects (e.g. relationship quality and sexual confidence) are satisfactory in order to alleviate the sexual problems. The results might suggest that a treatment for adolescents with a sexual dysfunction should focus on creating an environment in which sexual activities are experienced as pleasant, and as a consequence the distress and frequency of the sexual problems might decrease. The results indicate that it might take a while to reduce the distress and frequency of the problems, hence the fact there were no significant results between pre- and post-treatment on overall sexual functioning. This is supported by the finding that, for both BSC and ISH, sexual functioning significantly improved between baseline and 6-month follow-up. However, because there was no 6-month follow-up measurement for the no-treatment group, the improvement in sexual functioning could also be a result of spontaneous recovery, and not due to the effect of a treatment.

The initial increase in psychological problems and depressive symptoms for all groups at the first follow-up measurement is not uncommon in psychological treatment (studies), and this increase in psychological problems and depressive symptoms might explain the lack of a significant improvement in sexual functioning between baseline and end of treatment (Hesse, 2009). One can imagine that when dealing with or trying to resolve sexual problems, a person is confronted with several aspects of life (problems regarding the relationship, problems regarding oneself, etcetera) that are problematic or difficult. This confrontation can cause an increase in psychological distress, hence the increase in psychological and depressive problems. However, since the questionnaires that measure these characteristics also include aspects such as eating and sleeping behavior, it might be the case that these problems increased and that this not necessarily means that adolescents have severe psychological problems. 


\section{Limitations}

It was not possible to include the intended number of participants in each treatment group, and it was not possible to retain all participants. Many adolescents were reluctant to participate because of the risk they ran to be assigned to the delayed treatment group. They were not willing to wait 6 months before treatment would start. Furthermore, many adolescent were not willing to fill in the questionnaires after the treatment ended, resulting in an even lower number of participants at 6-month follow-up.

The enrolment of participants was a large obstacle in this study. Motivating adolescents to participate proved very difficult. Nurses did not have enough time to discuss sexual functioning with the adolescents and when they identified a possible problem the adolescent was overwhelmed with a lot of information concerning the study. To overcome this problem, later on, only an email address during the consultation was noted and the researcher would contact the adolescent afterwards. It could also be the case that some adolescents were not motivated to participate because they were not in a state of mind to change their problems at that time point. Other factors like problems at home, money problems, problems with school/work, might be more important than resolving their sexual problem. The resulting low numbers of participants created a power problem to detect smaller effects, and reduced the possibility to generalize study findings to the entire population of adolescents with sexual problems.

Furthermore, only a small number of male adolescents were enrolled in this study. This might have been due to the lower prevalence of sexual dysfunctions in male adolescents compared with female adolescents (Kedde, 2012), maybe help-seeking behavior might also be more prevalent in women than in men.

\section{Conclusions}

The present study was not able to differentiate between brief sex counselling, intensive sexual healthcare and no treatment. We were not able to demonstrate the benefits of a psychological treatment for adolescents with sexual problems. Therefore, it is currently not warranted, based on the present analysis of clinical efficacy, to recommend any of these treatment options for adolescents with a sexual dysfunction. It might be best to assess the knowledge and skill level of adolescents, give them tips and tricks to prevent or deal with minor problems, and to start treatment only when they are motivated to deal with their problems. Especially the level of motivation, or the need, to change might have been a problem in this study. The fact that almost half of the adolescents that were in the notreatment condition could not be contacted after the waiting period ended, might indicate this lack of motivation or need for treatment. Further research needs to pay more attention to the level of motivation to change in adolescents with a sexual dysfunction. 


\section{REFERENCES}

Akre, C., Michaud, P. A., \& Suris, J. C. (2010). "I'll look it up on the web first": Barriers and overcoming barriers to consult for sexual dysfunction among young men. Swiss Medical Weekly, 140, 348-353.

Althof, S., Cappelleri, J., Shpilsky, A., Stecher, V., Diuguid, C., Sweeny, M., et al. (2003). Treatment responsiveness of the Self-Esteem and Relationship questionnaire in erectile dysfunction. Urology, 888892.

Althof, S., Corty, E., Levine, S., Levine, F., Burnett, A., McVary, K., et al. (1999). EDITS: development of questionnaires for evaluating satisfaction with treatments for erectile dysfunction. Adult Urology, 53, 793799.

Althof, S. E. (2002). Quality of life and erectile dysfunction. Urology, 59, 803-810.

Bakker, F., de Graaf, H., De Haas, S., Kedde, H., Kruijer, H., \& Wijsen, C. (2009). Seksuele gezondheid in Nederland 2009. Utrecht: Rutgers Nisso Group.

Bakker, F., \& Vanwesenbeeck, I. (2006). Seksuele gezondheid in Nederland 2006. Delft: Eburon.

Barlow, D. (1986). Causes of sexual dysfunction: The role of anxiety and cognitive interference. Journal of Consulting and Clinical Psychology, 54, 140-148.

Borkovec, T., \& Nau, S. (1972). Credibility of analogue therapy rationales. Journal of Behavior Therapy and Experimental Psychiatry, 3, 257-260.

Bouwma, J., Ranchor, A., Sanderman, R., \& Van Sonderen, E. (1995). Het meten van symptomen van depressie met de CES-D: een handleiding. Groningen: Noordelijk Centrum voor Gezondheidsvraagstukken.

Cohen, J. (1988). Statistical power analysis for the behavioral sciences (Second edition ed.). Hillsdale, New Jersey: Lawrence Erlbaum Associates.

de Beurs, E., \& Zitman, F. (2005). De Brief Symptom Inventory (BSI). De betrouwbaarheid en validiteit van een handzaam alternatief voor de SCL-90. Leiden: Leids Universitair Medisch Centrum.

de Graaf, H., Kruijer, H., van Acker, J., \& Meijer, S. (2012). Seks onder je 25e: Rutgers WPF.

Devilly, G., \& Borkovec, T. (2000). Psychometric properties of the credibility/expectancy questionnaire. Journal of Behavior Therapy and Experimental Psychiatry, 31, 73-86.

Doering, S., \& et al. (2007). Validation of the assessment of DSM-IV personality disorders (ADP-IV) questionnaire. Zeitschrift für Psychosomatische Medizin und Psychotherapy, 53, 111-128.

Everaerd, W., \& Moors, J. (1995). De biopsychosociale benadering van seksualiteit. In K. Slob, C. Vink, J. Moors \& W. Everaerd (Eds.), Seksuologie voor de arts. Houten: Bohn Stafleu van Loghum.

Evers, A., van Vliet-Mulder, J., \& Groot, C. (2000). Documentatie van tests en testresearch in Nederland, deel I en II (COTAN). Assen: van Gorcum.

Galdón, M., Durá, E., Ferrando, M., Murgui, S., Pérez, S., \& Ibañez, E. (2008). Psychometric properties of the Brief Symptom Inventory-18 in a Spanish breast cancer sample. Journal of Psychometric Research, 65, 533-539.

Grauvogl, A, \& van Lankveld, J. (2009). Protocol Brief sex counselling. Unpublished manual.

Goldmeier, D., Malik, F., \& Green, J. (2004). Cost implications of sexual dysfunction: the female picture. International Journal of Impotence Research, 16, 130-134.

Guttmacher Institute. (2010). U.S. teenage pregnancies, births and abortions: National and state trends and trends by race and ethnicity.

Guttmacher Institute. (2012). Facts on American teens' sexual and reproductive health.

Hallfors, D., Waller, M., Bauer, D., Ford, C., \& Halpern, C. (2005). Which comes first in adolescence - sex and drugs or depression? American Journal of Preventive Medicine, 29, 163-170.

Hamilton, B., Martin, J., \& Ventura, S. (2010). Births: Preliminary data for 2009: National Vital Statistics Reports. ljff, M. (2006). Sexcounseling. Handleiding voor seksuologische hulpverlening. Assen: Van Gorcum.

Kedde, H. (2012). Seksuele disfuncties in Nederland: prevalentie en samenhangende factoren. Tijdschrift voor Seksuologie, 36, 98-108.

Koopmanschap, M. (2005). PRODISQ: a modular questionnaire on productivity and disease for economic evaluation studies. Expert review of Pharmacoeconomics and Outcome research, 5, 23-28. 
Koopmanschap, M., Meerding, W., Evers, S., Severens, J., Burdorf, A., \& Brouwer, W. (2004). Handleiding voor het gebruik van PRODISQ. Een modulaire vragenlijst over de relatie tussen ziekte en productiviteitskosten. Toepasbaar bij economische evaluaties van gezondheidszorgprogramma's voor patiënten en werknemers. Rotterdam/Maastricht: Erasmus Universiteit Rotterdam/Erasmus Medisch Centrum/Universiteit Maastricht.

Leusink, P., \& Nauta, M. (2009). Seksuele Gezondheidszorg. Deel 2 Handboek Seksualiteit en reproductie. Bilthoven: RIVM.

Masters, W., \& Johnson, V. (1970). Human sexual respons. Boston: Little, Brown \& Co.

Oostenbrink, J., Koopmanschap, M., \& Rutten, F. (2002). Standardisation of costs. The Dutch manual for costing in economic evaluations. Pharmacoeconomics, 20, 443-454.

Pazol, K., Zane, S., Parker, W., Hall, L., Gamble, S., Hamdan, S., et al. (2011). Abortion surveillance: United States, 2007: National Center for Chronic Disease Prevention and Health Promotion, CDC.

Rosen, R., Brown, C., Heiman, J., Leiblum, S., Meston, C., Shabsigh, R., et al. (2000). The Female Sexual Function Index (FSFI): a multidimensional self-report instrument for the assessment of female sexual function. Journal of Sex \& Marital Therapy, 26, 191-208.

Rosen, R., Riley, A., Wagner, G., Osterloh, I., Kirkpatrick, J., \& Mishra, A. (1997). The International Index of Erectile Function (IIEF): a multidimensional scale for assessment of erectile dysfunction. Urology, 6, 822830.

Rowland, D. L., Patrick, D. L., Rothman, M., \& Gagnon, D. D. (2007). The psychological burden of premature ejaculation. The Journal of Urology, 177, 1065-1070.

Schotte, C., \& de Doncker, D. (1994). ADAP-IV Questionnaire. Antwerpen: Universiteitsziekenhuis Antwerpen.

Schouten, H. (1995). Adaptive biased urn randomization in small strata. Biometrics, 51, 1529-1535.

Shrier, L., Emans, J., Woods, E., \& DuRant, R. (1996). The association of sexual risk behaviors and problem drug behaviors in high school students. Journal of Adolescent Health, 20, 377-383.

Stiffman, A., Dore, P., Earls, F., \& Cunningham, R. (1992). The influence of mental health problems on AIDSrelated risk behaviors in young adults. The Journal of Nervous and Mental Disease, 20, 377-383.

ter Kuile, M., Brauer, M., \& Laan, E. (2006). The Female Sexual Function Index (FSFI) and the Female Sexual Distress Scale (FSFD): psychometric properties within a Dutch population. Journal of Sex \& Marital Therapy, 32, 289-304.

Tsai, C., Bayliss, M., \& Ware, J. (1997). SF-36 survey annotated bibliography: 1996 supplement. Boston: New England medical center.

Viane, I. (2002). MOS 36-item Short Form Health Survey (MOS SF-36): Ghent University.

Vroege, J. (2003). De vragenlijst voor het signaleren van seksuele disfuncties (VSD): bruikbaarheid in de klinische praktijk. Delft: Eburon.

Vroege, J., Lotgerink, H., van der Rhee, K., Tanis-Nauta, M., \& Weijmar Schultz, W. (2007). Behandeling van seksuele problemen in de eerstelijn, de tweedelijns somatische gezondheidszorg of de tweedelijns GGZ? Tijdschrift voor Seksuologie, 31, 80-84.

Ware, J., \& Sherbourn, C. (1992). MOS 36-item Short Form Health Survey (MOS-SF-36): Universiteit Gent.

World Health Organization. (2002). Defining sexual health. Report of a technical consultation on sexual health. Geneva: World Health Organization. 
Chapter 6 


\section{Chapter 7}

\section{Economic evaluation of brief sex counselling for sexually dysfunctional adolescents}

A. Grauvogl, S. Evers, M. Peters, \& J. van Lankveld

This chapter has been submitted for publication as:

Grauvogl, A., Evers, S., Peters, M., \& van Lankveld, J. Economic evaluation of brief sex counselling for sexually dysfunctional adolescents. 


\section{ABSTRACT}

In a randomized controlled trial brief sex counselling (BSC), intensive sexual healthcare (ISH) and no treatment (NT) for adolescents with a sexual dysfunction were compared. The aim of this study was to assess the cost-effectiveness and cost-utility of BSC versus ISH and NT from a societal perspective. Costs, sexual functioning and quality of life were measured during 6 months. Primary outcome measures were measured with the Female Sexual Functional Index, the International Index of Erectile Function and the utilities reflecting Quality of Life based on the SF-36. Uncertainty was dealt with by using bootstrap replications and sensitivity analyses. Results show that the societal costs were the highest for ISH followed by NT and BSC. The difference in costs between ISH compared to NT and BSC was significant. Furthermore, there were no significant group differences in sexual functioning or quality of life. With respect to the cost-effectiveness and cost-utility, BSC can be considered to be a suitable treatment for adolescents with a sexual dysfunction. Due to the lack of a significant difference in clinical effect, it can be concluded that BSC is the cheapest treatment option for adolescents with a sexual dysfunction. 


\section{INTRODUCTION}

Although Dutch adolescents are considered as being sexually healthy (Bakker \& Vanwesenbeeck, 2006), Kedde (2012) reported that substantial numbers of adolescents in the Netherlands experience problems with sexual desire, sexual arousal, orgasm and pain during sexual encounters. Especially female adolescents report these problems. Among girls, 43.4\% experience at least one sexual dysfunction. Orgasmic disorders are the most frequently reported sexual dysfunction (20.3\%). Among boys, $27.3 \%$ experience at least one sexual dysfunction. Premature ejaculation is the most frequently reported sexual dysfunction (12.6\%). These findings can be taken to imply that sexual function problems in adolescents warrant attention of researchers, professionals and policy makers.

When adolescents acknowledge that they experience a sexual problem, finding and receiving adequate care is often problematic. The loss of anonymity, financial costs of intensive sexual healthcare, limited familiarity with and lack of confidence in the healthcare services available can be a problem (Akre et al., 2010; Bakker et al., 2009; Bakker \& Vanwesenbeeck, 2006). Goldmeier, Malik and Green (2004) calculated that the average costs of a treatment delivered by a sex therapist in the United Kingdom is approximately $€ 900(\$ 1,200)$. Given these costs, it is essential from a societal perspective that cost-effective treatment options are developed and evaluated. There are indications that this is possible for the treatment of sexual dysfunctions. For instance, $14 \%$ of the patients treated in outpatient clinics for sexology and $24 \%$ of the patients treated in mental health care centers, could be adequately treated with a less costly, low-threshold intervention (Bakker \& Vanwesenbeeck, 2006; Vroege et al., 2007). However, the cost-effectiveness of these lowthreshold interventions need to be examined first in order to the get the required financial support. There are published economic evaluations concerning HIV care, showing that brief behavioral interventions to reduce the incidence of HIV and other sexually transmitted infections are cost-effective (Burgos, Gaebler, Strathdee, Lozada, Staines, \& Patterson, 2010; Zaric, Bayoumi, Brandeau, \& Owens, 2005). However, to our knowledge, full economic evaluations concerning treatment options for adolescents who experience sexual dysfunctions are lacking.

In this study we focus on 'Brief sex counselling'. Brief sex counselling is a new treatment, developed by the Rotterdam-Rijnmond Public Health Service (PHS) and Maastricht University (UM) in the Netherlands, that could provide a more cost-effective treatment for adolescents with sexual dysfunctions.

In a randomized controlled trial we examined the cost-effectiveness and the cost-utility of brief sex counselling (BSC), compared with intensive sexual healthcare (ISH) and no treatment (NT), focusing on the following research question: Is BSC, compared with ISH and NT, preferable for the treatment of adolescents with sexual dysfunctions in terms of costeffectiveness from a societal perspective? 


\section{METHODS}

\section{Participants}

Participants were included if they met the following criteria: age between 18 and 25 years old; at least mild to moderate sexual function problems; no severe psychiatric co-morbidity or relational problems; the sexual function problems were not caused by disease, medication/drug use, or physical disabilities (based on a problem history questionnaire). Participants were recruited through referrals from the PHS in Rotterdam-Rijnmond, in Northern-Netherlands and in Limburg (southern part of the Netherlands), the website Sense, and various websites (www.sexcounselling.eu, www.sense.info). After randomization participants received their treatment in one of these three regions in the Netherlands (Rotterdam, Northern-Netherlands, and Limburg).

\section{Procedure}

This economic evaluation is embedded in a trial based economic evaluation with a time horizon of 6 months. Details of the study are described in the design article (Grauvogl, et al. 2009). After informed consent was obtained and participants completed an online screening questionnaire, participants were randomly allocated to: i): BSC, ii) ISH, iii) and NT. The outcomes and costs were measured, via a secure Internet link (www.emium.nl), before randomisation (during initial screening), at baseline and three, six, and additionally only for ISH and BSC, 9 months after baseline. To reduce the period that the respondents in the NT group are denied treatment, the last follow-up in this group was after 6 months. As a result there was no 9-month follow-up measurement for NT, because participants were enrolled in one of the treatment groups, or found treatment elsewhere. Preceding an upcoming assessment point, participants received an email (one week before the end of the treatment and 3- and 6 months after the end of the treatment). If a participant failed to complete the assessment within one week, a reminder was sent through email.

\section{Interventions}

\section{Brief sex counselling}

Brief sex counselling (BSC) is a brief, free of charge, and low-threshold treatment for adolescents between 18 and 25 years of age who experience sexual function problems. In a maximum of three sessions, of 45 minutes each, spread over a 3-month period, a sex counsellor provides treatment. The sex counsellor is a nurse who works at Sense and who received a supplementary training provided by a sexologist. The sessions include providing information (psycho-education), and cognitive restructuring. Instructions for home-based exercises, following the principles of sensate-focus exercises of Masters and Johnson (Masters \& Johnson, 1970), are also provided during the sessions.

The treatment manual that has been developed for the BSC sessions (Grauvogl, 2009) is based on the general principles and practice of sex counseling, and on a guideline that was 
developed for Sense (Ijff, 2006; Leusink \& Nauta, 2009). The manual contains instructions for the sex counselor to address problems of sexual desire, sexual arousal, orgasm, and sexual pain. In the first session, specific questions regarding sexual functioning and the overall sexual history are discussed. Furthermore, an action plan is established, which gives an outline of the adolescent's treatment goals and the elements that will be used to alleviate the problem. The counselor evaluates which elements are useful for the client, and in which order they are administered. Several therapeutic techniques are offered in session two and three. Information can be given to improve the adolescent's knowledge about the cause of the problem and the factors that maintain it. During the sessions the counselor attempts to identify, change and adjust compromised cognitive processes and deficient coping strategies. Instructions for sensate-focus exercises (Masters \& Johnson, 1970) can be given to help the adolescent to (re)discover sexual needs and preferences and to practice sensual and erotic touching, while avoiding performance pressure.

The brief duration of the intervention was expected to render BSC unsuitable to treat individuals with sexual dysfunctions with comorbid relationship and/or psychiatric problems.

\section{Intensive sexual healthcare}

In the intensive sexual healthcare (ISH) condition, participants receive more intensive psychological treatment. During a minimum of 6 sessions, spread over a 6 -month period, a certified sexologist offers sexological treatment based on cognitive-behavior therapy principles. The sessions are scheduled weekly. Often the adolescent will receive instructions for exercises that are performed at home. These exercises concern writing exercises or more body-related exercises, following the sensate-focus format. In the next session the experiences regarding the exercises are discussed. Furthermore, in contrast to BSC, the therapist in intensive sexual healthcare also addresses the psychological problems of the participant, which may be the cause of the sexual function problem.

\section{No treatment}

The active treatment conditions were compared to a no treatment (NT) condition, which enabled to control for spontaneous recovery and mere measurement effects. In this condition, participants were requested not to engage in other types of professional help, for a 6-month period. After the waiting period, the participants who were allocated to this condition could choose their preferred treatment (BSC or ISH).

\section{Cost measures and valuation}

This economic evaluation was performed from a societal perspective, which implies that all relevant costs and outcomes will be taken into account. As several countries have a more limited perspective, an additional analysis from a healthcare perspective was performed. Total costs were estimated using a bottom-up approach, where information on each element of service is multiplied by an appropriate unit cost, and summed to provide an overall total cost (Drummond, Sculpher, Torrance, O'Brien, \& Stoddart, 2005). We assessed intervention costs, healthcare costs, patient and family costs, and costs in other sectors. For 
this study we developed a cost questionnaire for this group, based on existing questionnaires (Hakkaart-van Roijen, van Straten, Donker, \& Tiemens, 2002; Koopmanschap et al., 2004), which identified all relevant costs aspects.

To measure the actual use of resources, data were obtained using combined sources (registrations by professionals and the cost questionnaire). Resources used relating to the interventions were based on the registered number of sessions all professionals spent on the treatment. All use of resources by the adolescent in and outside the health sector, was measured by means of the cost questionnaire.

The valuation of healthcare costs and patient and family costs were based on the updated Dutch manual for cost analysis in health-care research (Hakkaart-van Roijen, Tan \& Bouwmans, 2010). This manual recommends using standardized cost prices. Costs in other sectors, and especially productivity costs, were calculated by means of the friction cost method, based on a mean added value of the Dutch working population. The friction cost method takes into account production losses confined to the period needed (usually 90 days) to replace a sick employee. Absenteeism from school was calculated using the number of days the adolescents was absent from school. Cost prices are presented in 2012 euros (Hakkaart-van Roijen, et al., 2010).

\section{Outcome measures}

Several instruments were used to assess the outcomes of the economic evaluation. The primary outcome measures were sexual functioning as measured in women using the Female Sexual Function Index (FSFI) (Rosen, Brown, Heiman, Leiblum, Meston, Shabsigh, Ferguson, \& D'Agostini, 2000), and in men using the International Index of Erectile Function (IIEF) (Rosen et al., 1997). High scores indicate healthy sexual functioning. In order to combine female and male sexual functioning data, Z-scores were calculated within the female and male subgroup, resulting in average Z-score $M=0$, with $S D=1$ for each participant.

Within the cost-utility analysis, utilities were derived using the SF-6D, which is a utility instrument based on the health-related quality of life questionnaire Medical Outcomes Study 36-item Short Form Health Survey (SF-36) (Ware \& Sherbourn, 1992). The utility score is derived from 11 items of the SF-36 and is composed of six dimensions of health (physical functioning, role disabilities caused by physical health problems, role disabilities caused by emotional problems, pain, mental health, vitality, general health perception and social functioning), and was calculated using preferences elicited from a general population in the UK, the so-called Brazier algorithm (Brazier, Roberts, \& Deverill, 2002). The utility values derived from the Brazier algorithm were used to compute the Quality Adjusted Life Year (QALY) metric, by using the area under the curve method (Drummond, et al., 2005). The results will be a gain of 0.5 QALY, since there was a measurement period of only 6 months. 


\section{Statistical methods}

All primary analyses were performed according to the intention-to-treat principle, including data from all participants regardless of whether they completed the measurements or not. Intermittent missing data were imputed by calculating the mean values of the previous and subsequent time point. 1 participant missed 1 intermittent measurement. Missing data due to lost to follow-up (32\%) were replaced by imputed values, using the last observation carried forward technique. For the analyses SPSS 20.0 statistical software and Excel (for the bootstraps) were used.

To describe the cost data arithmetic means were used. The incremental costeffectiveness ratio (Prochaska \& Velicer, 1997) was determined based on the incremental costs and effects of BSC compared to the intensive sexual healthcare and no treatment. The incremental cost-effectiveness ratio (ICER) was stated in terms of incremental costs per outcome rate (increase in sexual functioning), the cost-utility ratio focused on the incremental cost per QALY gained.

Group differences in clinical effect (proportion of recovery) and quality of life were analyzed with non-parametric Kruskall-Wallis tests with a $p<.05$ significance level. Because costs were not normally distributed, we performed 5,000 bootstrap simulations.

The economic evaluation included a base-case cost-effectiveness and utility analysis, and several sensitivity analyses. In the base-case, the primary outcome measure for the costeffectiveness analysis was change from baseline score of sexual functioning measured by using standardized results of both the FSFI and IIEF at 6 months, and for cost-utility analysis the QALY at 6 months based on the SF-6D using the UK Brazier-tariff. Non-parametric bootstrap simulations were used in order to quantify the uncertainty around the ICERs, yielding information about the joint distribution of cost and effect differences. The bootstrapped ICERs will be subsequently plotted in a cost-effectiveness plane, in which the vertical line reflects the difference in costs and the horizontal line reflects the difference in effectiveness. The choice of treatment depends on the maximum amount of money that society is prepared to pay for a gain in effectiveness, which is called the ceiling ratio. To present the probability that either intervention (ISH, BSC and NT) is cost-effective the bootstrapped ICERs are also be depicted in a cost-effectiveness acceptability curve (CEAC) using a range of ceiling ratios. To determine the cost-utility we used a willingness to pay per QALY between 1,000 and 11,000 Euro. This threshold was calculated with information provided by the Counsel for Public Health and Health Care. This report provides the results of the societies willingness to pay per QALY for several sexual health treatment options. Since there were no results specifically addressing sexual healthcare for adolescents with a sexual problem, we combined the results for several other sexual healthcare measurements (€11,000 per QALY for antiviral therapy for HIV, €1,050 per QALY for HIV prevention and $€ 5,100$ per QALY for Viagra for erectile dysfunction; Counsel for Public Health and Health Care, 2006). Furthermore, since there is no guideline on the threshold value per point improvement of sexual functioning, the threshold value was set up to 11,000 Euro using the information of other sexual health treatment strategies (Counsel for Public Health and Health Care, 2006). 
Several sensitivity analyses were performed to test for the robustness of the findings. Except for the first sensitivity analysis (where only study completers were included), all analyses were executed using the base-case data set where missing data were imputed. All analyses used non-parametric bootstrap resampling techniques to explore the uncertainty around estimates of cost-effectiveness and cost-utility. First, participants who missed no single measurement were analyzed (17 ISH, 19 BSC, 19 NT). Second, cost-effectiveness was calculated for male and female adolescents separately, since the results could be different when using the original questionnaires and not a standardized version. Third, since the physical components of the SF-36 might not be accurate for adolescents with a sexual dysfunction, cost-utility was calculated using only the mental status related components of the SF-36. Fourth, cost-effectiveness and cost-utility were calculated from a healthcare perspective (i.e. only using the total healthcare costs in the analyses). Fifth, to account for any baseline differences, both cost-effectiveness and cost-utility analysis were calculated with a correction for baseline differences in costs. For this baseline correction we used the delta adjustment method (van Asselt, et al., 2009). Finally and sixth, cost-effectiveness was calculated using a longer time horizon of 9 months for the intervention group ISH and BSC, for NT these data were not available. In the final analysis the time horizon was extended to 9 months after baseline to include the longer follow-up effect of both ISH and BSC.

\section{RESULTS}

\section{Baseline characteristics}

In total, 71 adolescents were randomized to intensive sexual healthcare (ISH) ( $N=23)$, brief sex counselling (BSC) $(N=27)$ and no treatment $(N T)(N=21)$. The study sample consisted of 11 male $(M=21.91, S D=1.97)$ and 60 female $(M=21.72, S D=1.85)$ adolescents with a sexual dysfunction. Every participant that was randomized in the study survived.

In Table 1 baseline characteristics of the three groups are described. There were no differences in demographic (age, gender, relationship status, number of children, education and employment status), or diagnostic (sexual functioning based on FSFI and IIEF) baseline characteristics. Furthermore, there were no significant differences in costs between the three treatment groups at the start of the trial.

\section{Costs}

Table 2 presents the volumes of healthcare use during the 6-month follow-up period for each group. Furthermore, table 3 presents the uncorrected costs of the different cost items. Costs were bootstrapped and stratified per group. Societal costs were the highest for ISH $(€ 2,469.02)$, followed by NT (€738.68) and BSC (€559.66). The difference between ISH on the one hand and NT and BSC on the other was significant $(U(2)=28.17, p=0.001)$. Healthcare costs account for $78 \%$ of the total costs. Healthcare costs and patient and family costs are the highest for ISH (€2,153; €106), followed by NT (€390; €48) and BSC (€378; €33). Costs in 
other sectors are the highest for NT (€301), followed by ISH (€210) and BSC (€149). It can be concluded that the costs for the BSC group were the lowest in every sector.

Table 1: Baseline characteristics

\begin{tabular}{|c|c|c|c|c|c|c|c|}
\hline \multirow[b]{2}{*}{ Age, mean (sd) } & \multicolumn{2}{|c|}{ ISH $(N=23)$} & \multicolumn{2}{|c|}{ BSC $(N=27)$} & \multicolumn{2}{|c|}{ NT $(\mathrm{N}=21)$} & \multirow{2}{*}{$\begin{array}{c}\mathbf{P} \\
.159^{\mathrm{a}}\end{array}$} \\
\hline & 22.30 & $(1.89)$ & 21.41 & $(1.86)$ & 21.38 & $(1.77)$ & \\
\hline Female sex, $\mathrm{nr}(\%)$ & 19 & $(82.6)$ & 25 & $(86.2)$ & 18 & $(85.7)$ & $.909^{\mathrm{b}}$ \\
\hline Partner, n (\%) & & & & & & & $.636^{\mathrm{b}}$ \\
\hline No & 8 & (34.8) & 4 & $(13.8)$ & 4 & (19) & \\
\hline Yes, a man & 14 & $(60.9)$ & 22 & (75.9) & 16 & $(76.2)$ & \\
\hline Yes, a woman & 1 & $(4.3)$ & 3 & $(10.3)$ & 1 & $(4.8)$ & \\
\hline Children, $\mathrm{n}(\%)$ & & & & & & & $.657^{b}$ \\
\hline None & 22 & $(95.7)$ & 28 & $(96.6)$ & 21 & $(100)$ & \\
\hline One & 1 & $(4.3)$ & 1 & (3.4) & & & \\
\hline Education, n (\%) & & & & & & & $.471^{\mathrm{b}}$ \\
\hline Primary school & 6 & $(26.1)$ & 14 & $(48.3)$ & 13 & (61.9) & \\
\hline Middle sec. education & 5 & $(21.7)$ & 8 & $(27.6)$ & 3 & $(14.3)$ & \\
\hline Higher sec. education & 8 & $(34.8)$ & 4 & (13.8) & 3 & $(14.3)$ & \\
\hline Academic education & 4 & (17.4) & 3 & $(10.3)$ & 2 & (9.5) & \\
\hline Work, yes (\%) & 15 & $(65.2)$ & 22 & (75.9) & 15 & $(71.4)$ & $.583^{b}$ \\
\hline BSI, mean (sd) & .30 & $(.30)$ & .29 & (.19) & .27 & $(.25)$ & $.727^{c}$ \\
\hline CES-D, mean (sd) & 8.09 & $(6.84)$ & 5.81 & $(4.24)$ & 4.7 & $(4.30)$ & $.097^{\mathrm{a}}$ \\
\hline Sexual function, mean (sd) ${ }^{d}$ & -.24 & $(.93)$ & .14 & (.99) & .09 & $(1.06)$ & $.369^{\mathrm{a}}$ \\
\hline \multicolumn{8}{|l|}{ QSSD, mean (sd) } \\
\hline Satisfaction & 1.57 & (2.57) & 2.19 & (2.09) & 2.14 & $(1.80)$ & $.201^{\mathrm{c}}$ \\
\hline \multicolumn{8}{|l|}{ Quality of life, mean (sd) } \\
\hline SF-6D, UK Brazier-tariff & .592 & $(.052)$ & .581 & $(.059)$ & .601 & $(.039)$ & $.187^{\mathrm{a}}$ \\
\hline SEAR, mean (sd) & .22 & (.19) & .40 & (.17) & .34 & (.18) & $.006^{* a}$ \\
\hline CEQ, mean (sd) & 62.93 & $(16.25)$ & 62.67 & $(17.76)$ & & & $.864^{\mathrm{a}}$ \\
\hline \multicolumn{8}{|l|}{ Costs, mean, $95 \% \mathrm{Cl}$} \\
\hline Healthcare costs & \multicolumn{2}{|c|}{$258.31[96.5 ; 420.2]$} & \multicolumn{2}{|c|}{$102.60[38.1 ; 167.1]$} & \multicolumn{2}{|c|}{$178.72[-17.7 ; 375.1]$} & $.371^{c}$ \\
\hline Patient and family costs & \multicolumn{2}{|c|}{$25.93[.28 ; 51.6]$} & \multicolumn{2}{|c|}{$15.94[-.25 ; 32.1]$} & \multicolumn{2}{|c|}{$7.37[2.8 ; 11.9]$} & $.256^{c}$ \\
\hline Productivity costs & \multicolumn{2}{|c|}{$138.66[-51.3 ; 328.6]$} & \multicolumn{2}{|c|}{$43.59[8.7 ; 78.5]$} & \multicolumn{2}{|c|}{$158.70[-140.4 ; 457.7]$} & $.471^{c}$ \\
\hline Societal costs & \multicolumn{2}{|c|}{$422.92[174.7 ; 671.1]$} & \multicolumn{2}{|c|}{$162.1[69.6 ; 254.6]$} & \multicolumn{2}{|c|}{$344.75[-14.3 ; 703.8]$} & $.09^{c}$ \\
\hline
\end{tabular}

Note: $\mathrm{a}=\mathrm{P}$-value calculated with ANOVA F-test; $\mathrm{b}=\mathrm{P}$-value calculated with Pearson Chie Square test; $\mathrm{c}=\mathrm{P}$ value calculated with Kruskal-Wallis test; $d=z$-score of the Female Sexual Functional Index and the International Index of Erectile Function; ${ }^{*}=$ significant at $p<0.05 ; \mathrm{ISH}=$ Intensive sexual healthcare; BSC $=$ Brief sex counselling; NT = No treatment; $B S I=$ Brief Symptom Inventory; $C E S-D=$ Center for Epidemiological Studies Depression scale; FSFI = Female Sexual Functional Index; IIEF = International Index of Erectile Function 
Chapter 7 
Table 3: Total mean costs in euros per cost item at 6 months after baseline $(N=71)$

\begin{tabular}{lccc}
\hline Cost type & ISH $(\mathrm{N}=23)$ & $\mathrm{BSC}(\mathrm{N}=27)$ & $\mathrm{NT}(\mathrm{N}=21)$ \\
Health care costs [95\% Cl]* & $2153[1508.0 ; 3068.8]$ & $378[295.3 ; 478.8]$ & $390[203.9 ; 658.7]$ \\
Mental healthcare & $1727.05(401.59)$ & $265.71(38.70)$ & $70.96(26.43)$ \\
$\quad$ Intervention & $1673.12(403.84)$ & $240.81(117.57)$ & $49.03(18.18)$ \\
Other mental healthcare & $53.93(22.92)$ & $24.90(15.85)$ & $21.93(21.93)$ \\
General practitioner & $81.45(17.04)$ & $61.87(14.05)$ & $65.73(12.87)$ \\
Medical specialist & $91.06(42.43)$ & $30.60(14.65)$ & $68.84(25.37)$ \\
Company welfare worker & $58.55(16.75)$ & $.00(.00)$ & $.00(.00)$ \\
Social worker & $13.15(13.15)$ & $.00(.00)$ & $10.36(10.36)$ \\
Center for Alcohol and Drugs & $3.29(3.29)$ & $8.29(8.29)$ & $.00(.00)$ \\
Hospital day treatment & $63.49(51.73)$ & $.00(.00)$ & $.00(.00)$ \\
Hospital stay & $69.36(69.36)$ & $.00(.00)$ & $121.38(98.84)$ \\
Self-help group & $1.90(.88)$ & $.00(.00)$ & $.00(.00)$ \\
Medication & $42.06(27.37)$ & $12.95(4.24)$ & $52.93(19.60)$ \\
Patient and family costs [95\% CI]* & $106.3[71.2 ; 148.9]$ & $32.7[17.9 ; 53.8]$ & $47.7[17.1 ; 86.8]$ \\
Travelling & $105.64(19.66)$ & $30.04(8.84)$ & $31.05(13.52)$ \\
Informal care & $.63(.63)$ & $2.66(2.66)$ & $16.60(13.51)$ \\
Costs in other sectors [95\% Cl]* & $210.0[52.7 ; 479.1]$ & $149.0[64.4 ; 250.6]$ & $300.8[80.5 ; 649.6]$ \\
Productivity costs & $70.83(29.54)$ & $106.47(44.02)$ & $183.97(77.72)$ \\
Absenteeism from study & $139.12(101.08)$ & $42.49(21.02)$ & $116.86(85.70)$ \\
Societal costs [95\% CI]* & $2469.0[1750.8 ; 3410.6]$ & $559.7[418.0 ; 720.5]$ & $738.8[396.6 ; 1165.6]$ \\
\hline
\end{tabular}

Note: $\mathrm{ISH}=$ Intensive sexual healthcare; $\mathrm{BSC}=$ Brief sex counselling; NT = No treatment; ${ }^{*}=$ The upper and lower confidence limits are the $2.5^{\text {th }}$ and $97.5^{\text {th }}$ percentile based on 5000 bootstrap replications

Table 4: QALY and effectiveness outcomes and group differences at 6 months after baseline

\begin{tabular}{lccccccc}
\hline & \multicolumn{3}{c}{ ISH (N=23) } & \multicolumn{3}{c}{ BSC (N=27) } & \multicolumn{2}{c}{ NT (N=21) } & P-Value \\
\cline { 2 - 8 } Sexual functioning, mean (sd) & -.24 & $(1.02)$ & .12 & $(.78)$ & .11 & $(1.05)$ & $.20^{a}$ \\
FSFI, mean (sd) & 20.2 & $(9.48)$ & 22.8 & $(7.03)$ & 22.4 & $(8.87)$ & $.57^{a}$ \\
IIEF, mean (sd) & 27.0 & $(4.55)$ & 36.7 & $(23.6)$ & 48.7 & $(29.2)$ & $.43^{a}$ \\
QALY, mean (sd) & .32 & $(.05)$ & .31 & $(.04)$ & .31 & $(.05)$ & $.68^{a}$ \\
\hline
\end{tabular}

Note: $a=$ P-value calculated with ANOVA F-test; $b=z$-score of the Female Sexual Functional Index and the International Index of Erectile Function; ISH = Intensive sexual healthcare; BSC = Brief sex counselling; NT = No treatment; FSFI = Female Sexual Functional Index; IIEF = International Index of Erectile Function

\section{Effects}

\section{Clinical effectiveness and QALYS}

In the base-case analysis, the results show a mean sexual functioning of -.024 for ISH, .12 for BSC and .11 for NT. There were no significant group differences $(F(1,70)=1.665, p=.20)$. With respect to male and female adolescents separately, it was found that in male adolescents, both treatment groups (ISH and BSC) had improvement effect sizes that were not as expected. Sexual functioning, as measured with the IIEF, was found to be deteriorated after treatment instead of better. With respect to NT, sexual functioning - counter to 
intuitive expectations - improved. In female adolescents, both treatment groups yielded marginal effect sizes. Sexual functioning, as measured with the FSFI, was found to be improved after treatment. As expected, sexual functioning of female adolescents in the NT group further deteriorated. Finally, every participant survived.

Furthermore, the results show a mean QALY of .32 for ISH, .31 for BSC and .31 for NT. There were no significant differences between the groups in $\operatorname{QALYS}(F(1,70)=.395, p=.68)$ (see table 4).

\section{Cost-effectiveness and cost-utility}

The costs and level of sexual functioning of BSC vs ISH and BSC vs NT separately are plotted in cost effectiveness planes (figure 1a). BSC tends to be more effective and has less costs than ISH (90\% of the bootstrapped pairs are lying in the cost-effective south-east quadrant). When looking at BSC versus NT, the majority of the replications (45\%) also lie in the southeast quadrant, thus meaning that BSC is more effective and has less costs than NT.

With respect to the costs and effects of cost per QALY (figure 1b), the results show that BSC is more cost effective than ISH (55\% of the bootstrapped pairs are lying in the costeffective south-east quadrant). With respect to the comparison between BSC and NT, the results show that the majority of the replications lie in the south-west quadrant $(47 \%)$, indicating that BSC has less costs but is also less effective than NT. However, still $39 \%$ of the replications lie in the dominant (south-east) quadrant.

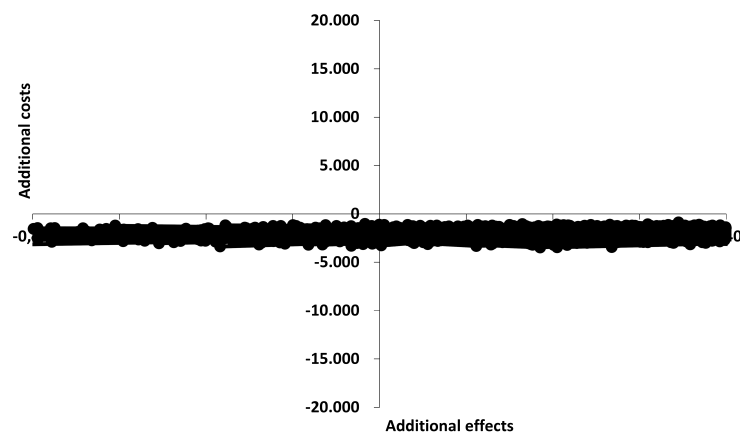

Figure 1a: BSC versus ISH - sexual functioning

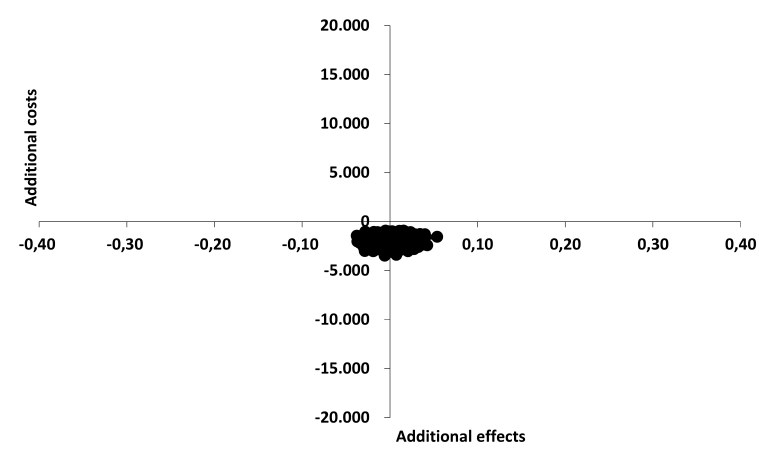

Figure 1b: BSC versus ISH - QALY

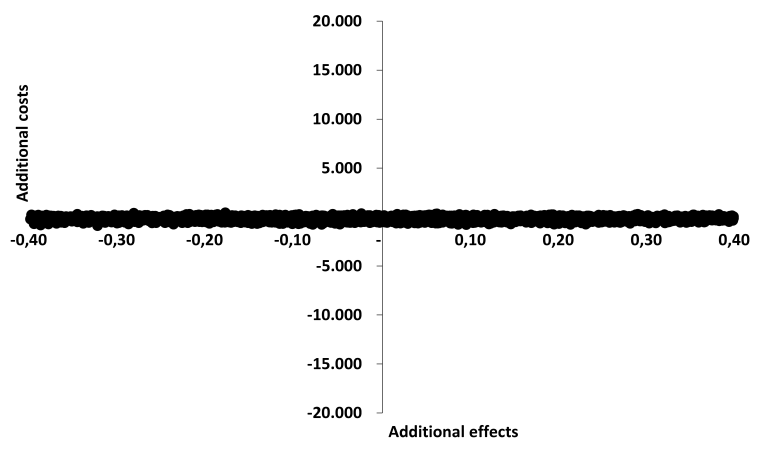

Figure 1a: BSC versus NT - sexual functioning

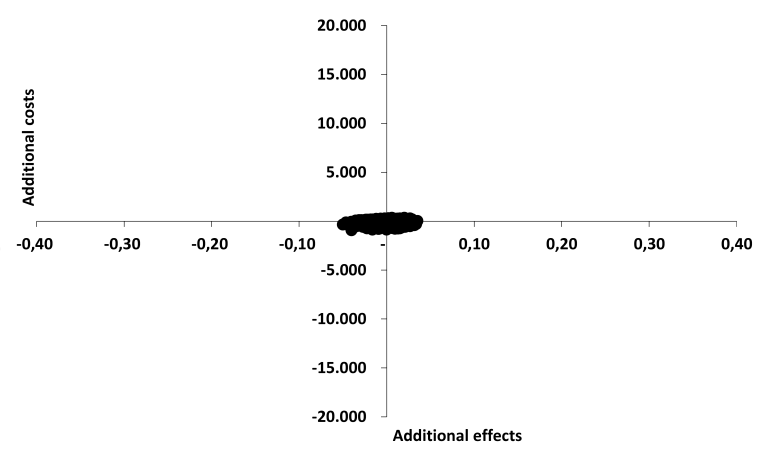

Figure 1b: BSC versus NT - QALY 
Furthermore, the base-case cost-effectiveness analysis with the bootstrapped societal costs at 6 months and sexual functioning (standardized values of the FSFI and IIEF) as outcome is presented in Figure 2. BSC has a higher probability of being cost-effective than the other 2 comparisons (ISH and NT) up to a willingness to pay of 35,000 Euro, varying from a probability of $79 \%$ at a cost-effectiveness threshold of 0 Euro to $34 \%$ at a cost-effectiveness threshold of 32,500 Euro. When considering the threshold value of 11,000 Euro, BSC has a probability of $42 \%$ of being the most optimal treatment option, followed by NT with $38 \%$ and ISH with $20 \%$. It should be noted that the difference between BSC and NT becomes indifferent after this point. The choice between the three study options becomes indifferent, as all curves approach a probability of 33\%, when the threshold is higher than 35,000 Euro.

The base-case cost-utility analysis with the bootstrapped societal costs at 6 months and the SF-6D as outcome is presented in Figure 3. With an $81 \%$ probability of being the most optimal treatment option at a threshold value of $€ 0$ per gained QALY, and a probability of $75 \%$ at a threshold value of 11,000 Euro per gained QALY, BSC tends to be superior when compared to ISH and NT. The probability of being the most optimal treatment option increases for NT when the willingness to pay increases. However, up to a willingness to pay of $€ 50,000$ per gained QALY, BSC has the highest probability to be the most optimal treatment option.

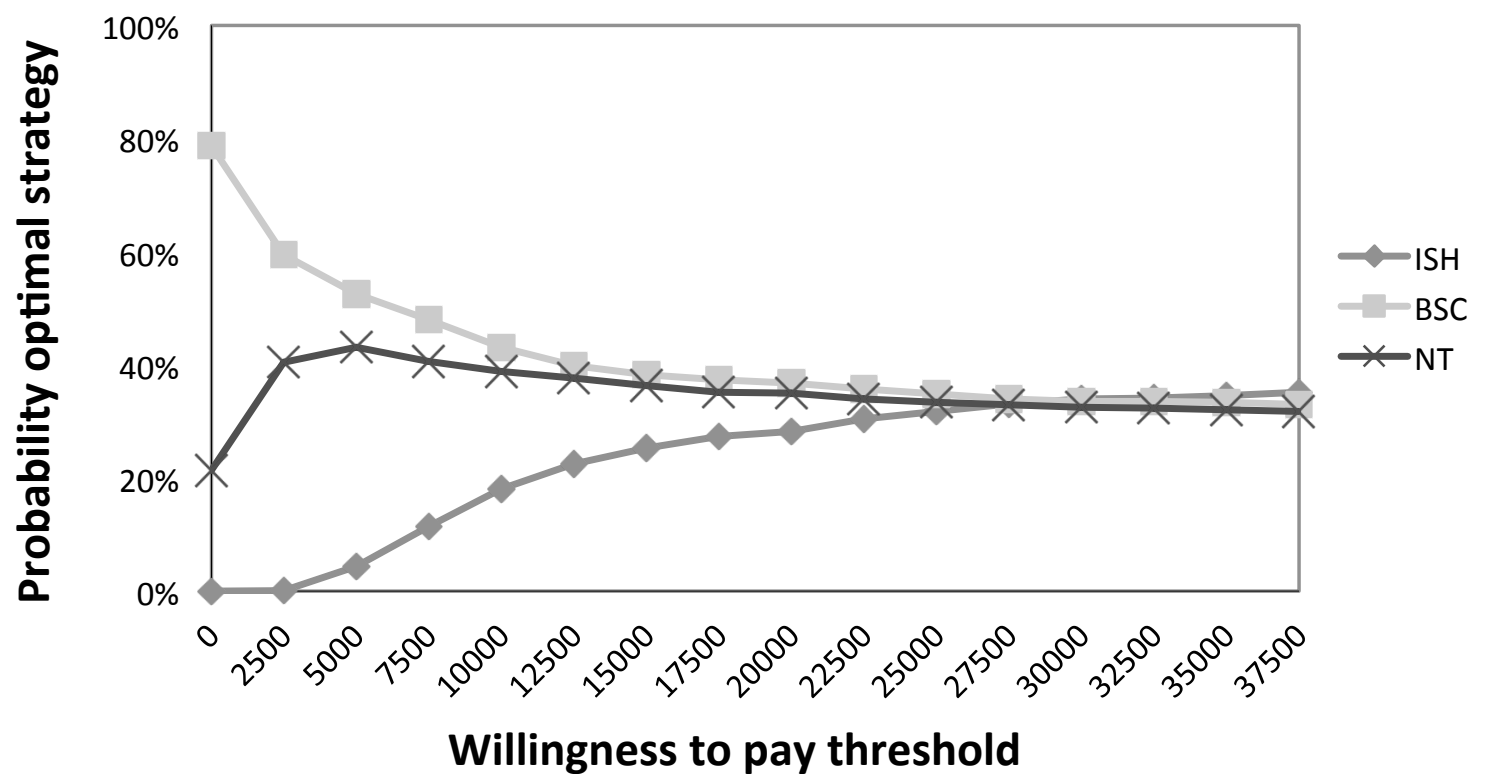

Figure 2: Cost-effectiveness acceptability curves looking at sexual functioning at 6 months after baseline Note: $\mathrm{ISH}=$ Intensive sexual healthcare; $\mathrm{BSC}=$ Brief sex counselling; NT = No treatment 


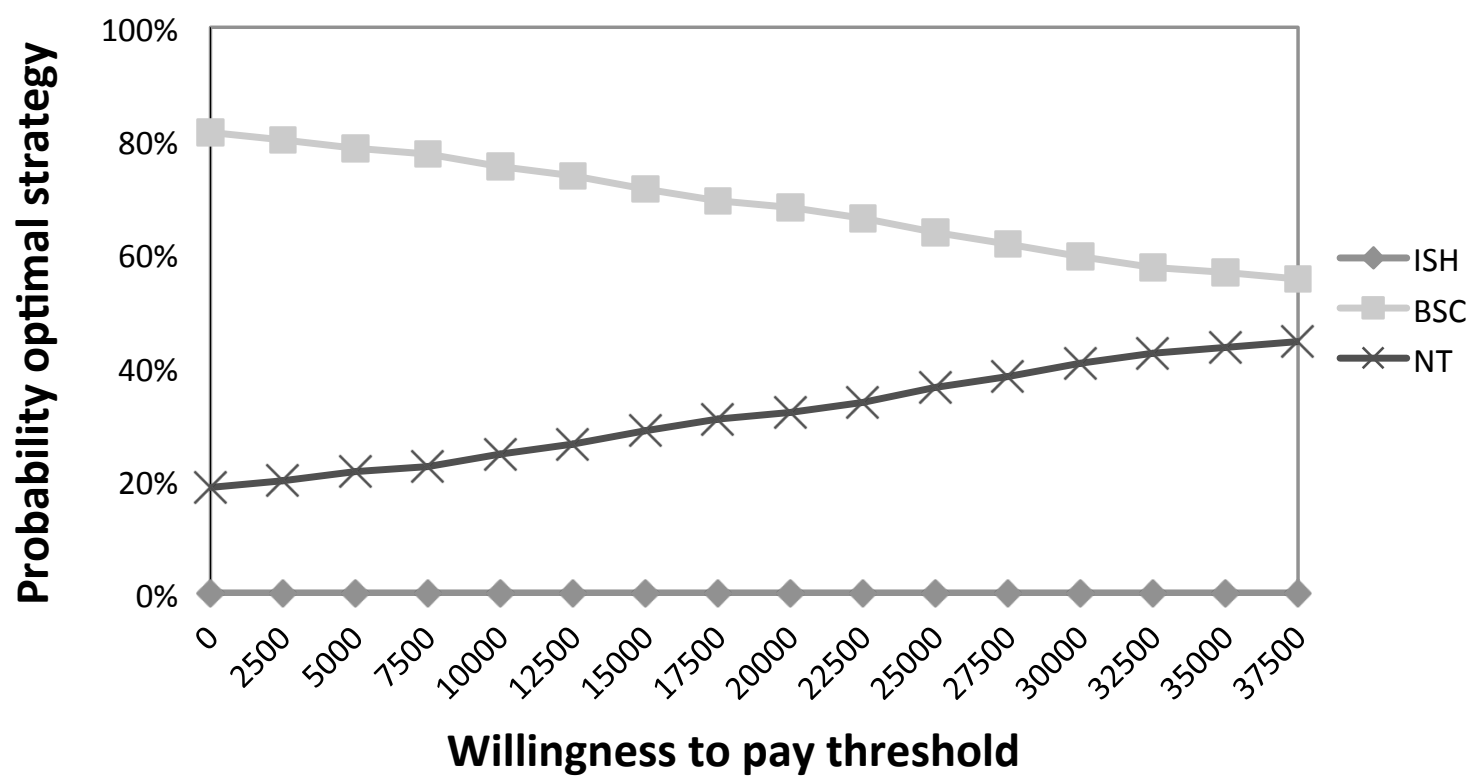

Figure 3: Cost-effectiveness acceptability curves looking at QALY at 6 months after baseline Note: $\mathrm{ISH}=$ Intensive sexual healthcare; $\mathrm{BSC}=$ Brief sex counselling; NT = No treatment

\section{Sensitivity analyses}

\section{1) Study completers only}

In this scenario data were used of study completers only. Results of the cost-effectiveness analysis (figure 4a) were comparable to the base-case analysis. Also here, BSC tends to be the most optimal treatment option when compared to ISH and NT, however the difference between BSC and ISH is more prominent in favor of BSC. Whatever threshold BSC has a higher probability of being cost-effective than the other 2 comparisons (ISH and NT). Overall, these results support the robustness of the base-case analysis. With respect to the costutility analysis (figure 4b), BSC has the highest probability of being the most optimal treatment option up to a willingness to pay of 17,500 Euro.

\section{2) Comparison of sexual functioning between male and female adolescents}

In this scenario sexual functioning are calculated for male (figure 4c) and female (figure 4d) adolescents separately. With respect to sexual functioning in female adolescents, the results are comparable with the base-case analysis. BSC is considered to be the best treatment option irrespective of the willingness to pay threshold. With respect to sexual functioning in male adolescents, NT is considered to be superior over BSC and ISH. These results indicate that the results of the base-case analysis might be influenced by a gender effect.

\section{3) Mental status related components of the SF-36}

In this scenario only the mental properties of the SF-36 (figure 4e) were used since these aspects are thought to better reflect sexual problems. The results suggest BSC to be the most optimal treatment option, up to a willingness to pay of 17,500 Euro. 


\section{4) Analyses based on a healthcare perspective}

In this scenario only healthcare costs were included in the analyses. Both cost-effectiveness (figure 4g) and cost-utility (figure 4h) were comparable to the base-case analyses. However, the difference between BSC and NT is only very limited, suggesting that when only considering healthcare costs, BSC and NT are comparable treatment strategies.

\section{5) Correction for baseline costs}

In this scenario the total costs were corrected for differences in baseline costs. Both costeffectiveness (figure $4 \mathrm{i}$ ) and cost-utility (figure $4 \mathrm{j}$ ) were comparable to the base-case analyses. The difference in cost-effectiveness between BSC and NT is only very limited, suggesting that when correcting for baseline costs, BSC and NT are comparable treatment strategies. However, the preference of BSC over NT is more prominent with respect to costutility.

\section{6) Cost-effectiveness at 9 months}

In this scenario a 9-month follow-up period (figure 4f) after baseline was used to compare ISH and BSC. Cost-effectiveness analysis was comparable to the base-case analysis. BSC remains the most optimal treatment strategy. These results suggest that the effect remains stable even after a longer follow-up period.

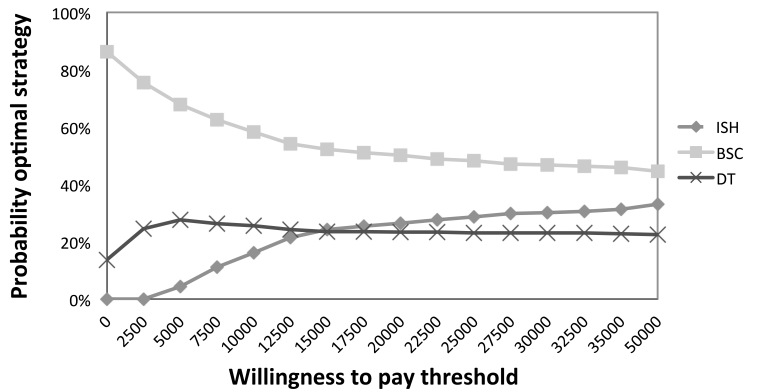

Figure 4a: Cost-effectiveness study completers

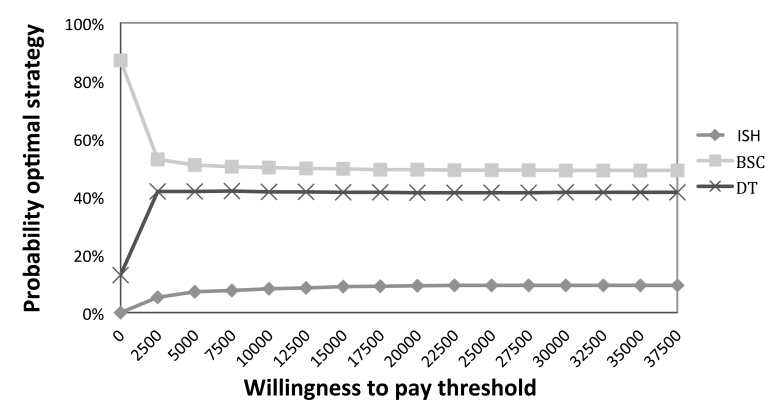

Figure 4c: Cost-effectiveness female adolescents

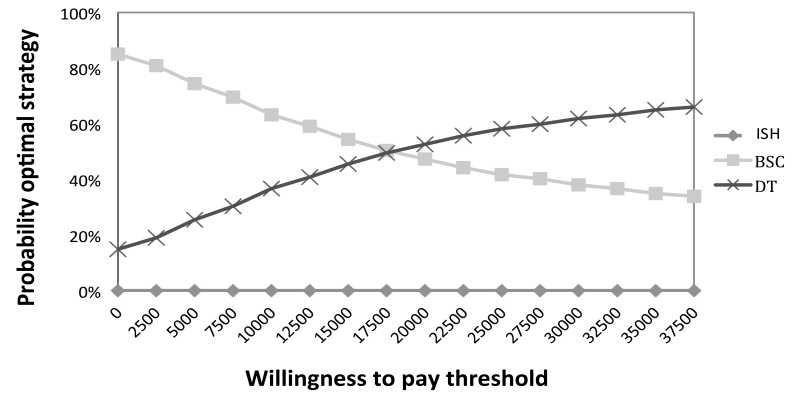

Figure 4b: Cost-utility study completers

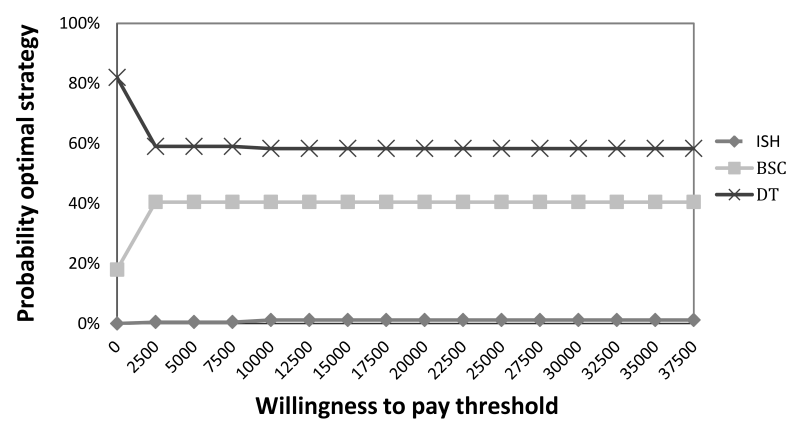

Figure 4d: Cost-effectiveness male adolescents 


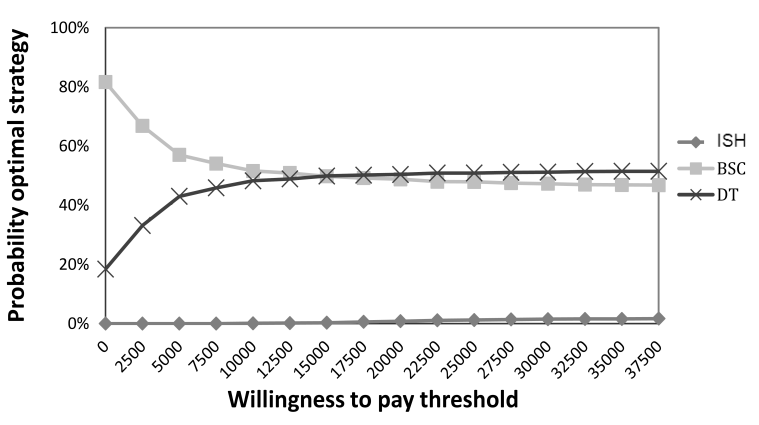

Figure 4e: SF-36 mental aspects

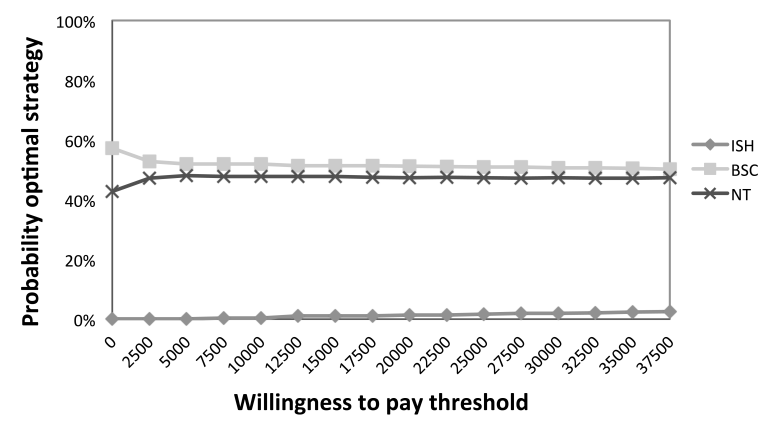

Figure 4g: Cost-effectiveness healthcare perspective

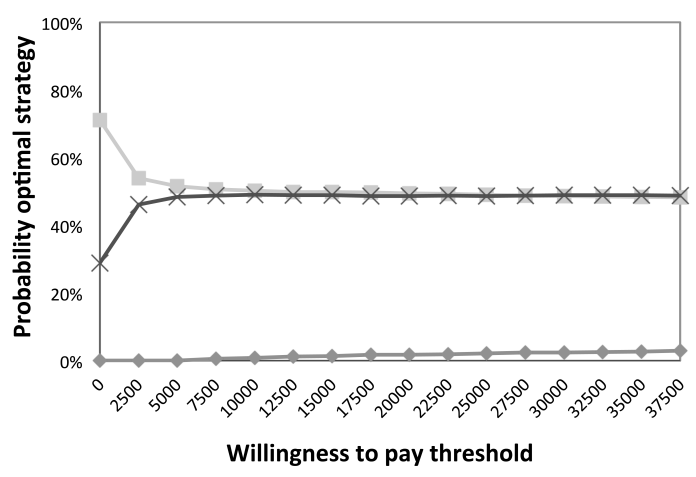

Figure 4i: Cost-effectiveness correction baseline

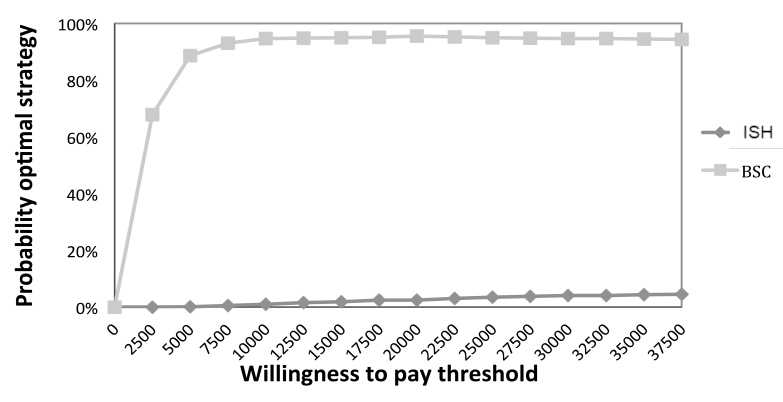

Figure 4f: Cost-effectiveness 9-month follow-up

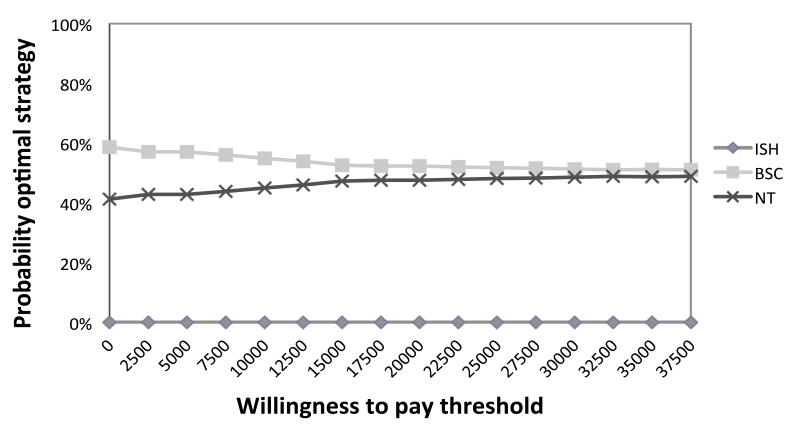

Figure 4h: Cost-utility healthcare perspective

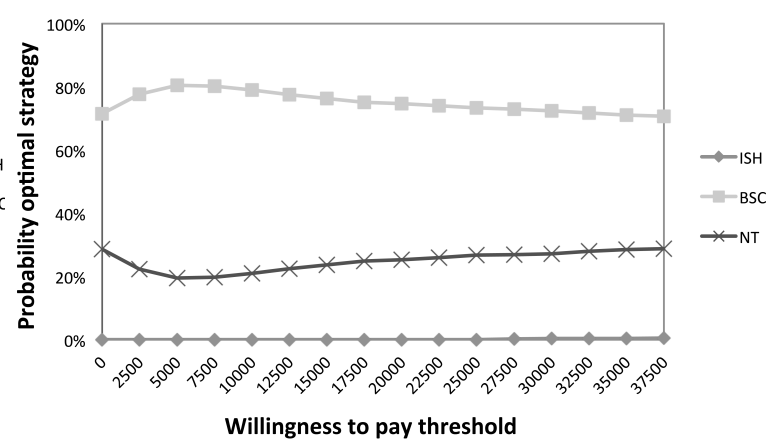

Figure 4j: Cost-utility correction baseline

\section{DISCUSSION}

The aim of the present study was to examine the cost-effectiveness and cost-utility of BSC for adolescents with a sexual dysfunction. BSC was compared with ISH and NT. Based on both the cost-effectiveness and cost-utility analyses, BSC is a suitable treatment option for adolescents with a sexual dysfunction.

The results of the cost-effectiveness analysis indicate BSC as the most optimal treatment option, up to a willingness to pay of 35,000 Euro. Although there were no significant differences in clinical effectiveness between the three groups, results show that in female adolescents sexual functioning increases for BSC and ISH and decreases for NT. The lack of a 
significant difference in clinical effect indicates that this result is mainly caused by the difference in costs, not effect.

In the cost-utility analysis BSC was the most optimal treatment option. When closely looking at the division of costs it can be concluded that societal costs are significantly higher for ISH than for BSC and NT. Mental health-care costs, especially intervention costs, are relatively high in ISH. Furthermore, costs in other sectors were higher for NT, followed by ISH and BSC. The lack of guidance during the waiting period and the fact that their problems are not resolved might cause the higher absenteeism from school and work in this group.

Results of the sensitivity analyses, except the results of the comparison between males and females, overall confirmed the robustness of the base-case analyses. The most important difference was the higher probability of BSC to be preferred over ISH and NT when only the data of study completers were analyzed. From a healthcare perspective and when correcting for baseline costs, the difference in cost-effectiveness between BSC and NT is less prominent. Furthermore, results show that when using the mental properties of the SF-36 only, the difference between BSC and ISH and NT is less conclusive than when the total SF-36 is used. An explanation for this finding could be that the SF-36 measures both physical aspects and mental aspects, and that the mental aspects do not cover only psychological distress. This instrument might be less sensitive and responsive for adolescents with a sexual dysfunction (Wiebe, Guyatt, Weaver, Matijevic, \& Sidwell, 2003). The best solution would be to develop a utility measure that also is suitable for people with sexual dysfunctions. The results of this study point out that a generic utility measure makes it more difficult to examine the cost-utility for a specific mental disorder. Furthermore, this indicates that costutility analyses might be less suitable than cost-effectiveness analyses for adolescents with a sexual dysfunction, due to the lack of a sexual component in the cost-utility analyses.

\section{Methodological considerations}

Several methodological considerations concerning this study should be taken into account. First of all, this study had to deal with a substantial amount of missing values (32\%). The dropout of participants could be explained by two factors. First, due to the time between the measurements (3-months) it could be difficult for the participants to remember what had happened over the last three months and because of this they were not motivated to fill in the questionnaires. Furthermore, $65 \%$ of the participants dropped out after their treatment had finished. This could indicate that adolescents are motivated to complete questionnaires as long as it might be of interest for the treatment they receive. In adult populations the dropout after treatment termination is not as high (de Graaf, et al., 2009; Bamelis, Evers, Spinhoven, \& Arntz, 2013). This suggests that, when including adolescent participants in randomized controlled trials, extra incentives should be provided in the follow-up period to ensure that they continue to complete questionnaires.

Second, there was a difference in the procedure of recording the data of the costs between the intervention costs and other costs. All costs were recorded using self-report data from the participants. With respect to intervention costs we used the data received from the treatment centers, yielding the actual number of sessions that the participant 
received. The number of sessions reported by the treatment centered did not always correspond with the number of treatment sessions reported by the adolescents. It might be possible that the self-reported costs are over- or underestimated, and as a consequence might have influenced the results.

Furthermore, there is no previous research that examines the effect of a sexological treatment for adolescents with a sexual dysfunction, and, consequently, there is no previous scientific data that provides information about the ceiling value of the willingness to pay. In previous research various ceiling values per gained QALY have been mentioned, ranging from values of $€ 3,600$ up to $€ 147,250$ (Counsel for Public Health and Health Care, 2006; Gyrd-Hansen, 2003; King, Tsevat, Lave, \& Roberts, 2005). Thus, despite the absence of a clear guideline, it can be expected that the used ceiling value up to $€ 11,000$ is sufficient.

\section{Conclusion and recommendations}

To our knowledge, this study is the first that explored the cost-effectiveness and cost-utility of sexological treatment of adolescents with a sexual dysfunction in general, and more specifically the effect of brief sex counseling (BSC). The results of both the cost-effectiveness and cost-utility analyses suggest that BSC has the highest probability of being the most optimal treatment option. Despite the lack of a significant clinical difference between BSC on the one hand and ISH and NT on the other, based on the cost-effectiveness and cost-utility, BSC might be considered to be a suitable treatment option for adolescents with a sexual dysfunction. However, it should be noted that the cost-effectiveness is due to the difference in costs, not effect. Since the results of a single study are not sufficient, it is advised to further investigate the effect of BSC. Furthermore, the effect of BSC might also be examined in adults with a sexual dysfunction. 


\section{REFERENCES}

Akre, C., Michaud, P. A., \& Suris, J. C. (2010). "I'll look it up on the web first": Barriers and overcoming barriers to consult for sexual dysfunction among young men. Swiss Medical Weekly, 140, 348-353.

Bakker, F., de Graaf, H., de Haas, S., Kedde, H., Kruijer, H., \& Wijsen, C. (2009). Seksuele gezondheid in Nederland 2009. Utrecht: Rutgers Nisso Group.

Bakker, F., \& Vanwesenbeeck, I. (2006). Seksuele gezondheid in Nederland 2006. Delft: Eburon.

Bamelis, L., Evers, S., Spinhoven, P., \& Arntz, A. (2013). Results of a multicentered randomized controlled trial on the clinical effectiveness of schema therapy for personality disorders. Unpublished article.

Bouwma, J., Ranchor, A., Sanderman, R., \& van Sonderen, E. (1995). Het meten van symptomen van depressie met de CES-D: een handleiding. Groningen: Noordelijk Centrum voor Gezondheidsvraagstukken.

Brazier, J., Roberts, J., \& Deverill, M. (2002). The estimation of a preference-based measure of health from the SF-36. Journal of Health Economics, 21, 271-292.

Burgos J, Gaebler J, Strathdee S, Lozada R, Staines H, Patterson T. (2010). Cost-Effectiveness of an Intervention to Reduce HIV/STI Incidence and Promote Condom Use among Female Sex Workers in the Mexico-US Border Region. PLoS One, 5, e11413.

de Beurs, E., \& Zitman, F. (2005). De Brief Symptom Inventory (BSI). De betrouwbaarheid en validiteit van een handzaam alternatief voor de SCL-90. Leiden: Leids Universitair Medisch Centrum.

de Graaf, L., Gerhards, S., Arntz, A., Riper, H., Metsemakers, J., Evers, S., Severens, J., Widdershoven, G., \& Huibers, M. (2009). Clinical effectiveness of online computerised cognitive behavioural therapy without support for depression in primary care: a radomised trial. British Journal of Psychiatry, 195, 73 - 80.

de Graaf, H., Kruijer, H., van Acker, J., \& Meijer, S. (2012). Seks onder je 25e: Rutgers WPF.

Drummond, M., Sculpher, M., Torrance, G., O'Brien, B., \& Stoddart. (2005). Methods for economic evaluation of health care programmes (Third ed.). New York: Oxford University Press.

Grauvogl, A, \& van Lankveld, J. (2009). Protocol Brief sex counselling. Unpublished manual

Grauvogl, A., Evers, S., van den Hoek, K., van der Veen, E., Franke, A., \& van Lankveld, J. (2009). Research into the efficacy and cost-effectiveness of brief, free of charge and anonymous sex counselling to improve (mental) health in youth: Design of a randomised controlled trial. BMC Public Health, 9, 459.

Goldmeier, D., Malik, F., \& Green, J. (2004). Cost implications of sexual dysfunction: the female picture. International Journal of Impotence Research, 16, 130-134.

Gyrd-Hansen, D. (2003). Willingness to pay for a QALY. Health Economics, 12, 1049-1060.

Hakkaart-van Roijen, L., Tan, S., \& Bouwmans, C. (2010). Handleiding voor kostenonderzoek: Methoden en standaard kostprijzen voor economische evaluaties in de gezondheidszorg (Geactualiseerde versie 2010) [Dutch manual for costing: Methods and standard costs for economic evaluations in health care (actualized version 2010)]. Diemen: College voor Zorgverzekeringen, 2010

Hakkaart-van Roijen, L., van Straten, A., Donker, M., \& Tiemens, B. (2002). Trimbos/iMTA questionnaire for Costs associated with Psychiatric Illness (TIC-P). Rotterdam: Erasmus University Rotterdam.

Kedde, H. (2012). Seksuele disfuncties in Nederland: prevalentie en samenhangende factoren. Tijdschrift voor Seksuologie, 36, 98-108.

King, J., Tsevat, J., Lave, J., \& Roberts, M. (2005). Willingness to pay for a quality-adjusted life year: Implications for societal health care resource allocation. Medical Decision Making, 25, 667-677.

Koopmanschap, M., Meerding, W., Evers, S., Severens, J., Burdorf, A., \& Brouwer, W. (2004). Handleiding voor het gebruik van PRODISQ. Een modulaire vragenlijst over de relatie tussen ziekte en productiviteitskosten. Toepasbaar bij economische evaluaties van gezondheidszorgprogramma's voor patiënten en werknemers. Rotterdam/Maastricht: Erasmus Universiteit Rotterdam/Erasmus Medisch Centrum/Universiteit Maastricht.

Masters, W., \& Johnson, V. (1970). Human sexual response. Boston: Little, Brown \& Co.

Prochaska, J. O., \& Velicer, W. F. (1997). The transtheoretical model of health behavior change. American Journal of Health Promotion, 12, 38-48.

Raad voor de Volksgezondheid en Zorg. Zinnige en duurzame zorg [Sensible and Sustainable Care]. Zoetermeer, 2006. 
Rosen, R., Brown, C., Heiman, J., Leiblum, S., Meston, C., Shabsigh, R., et al. (2000). The Female Sexual Function Index (FSFI): a multidimensional self-report instrument for the assessment of female sexual function. Journal of Sex \& Marital Therapy, 26, 191-208.

Rosen, R., Riley, A., Wagner, G., Osterloh, I., Kirkpatrick, J., \& Mishra, A. (1997). The International Index of Erectile Function (IIEF): a multidimensional scale for assessment of erectile dysfunction. Urology, 6, 822830.

Van Asselt, A., van Mastrigt, G., Dirksen, C., Arntz, A., Severens, J., \& Kessels, A. (2009). How to deal with cost differences at baseline. Pharmacoeconomics, 27, 519-528.

Vroege, J., Lotgerink, H., van der Rhee, K., Tanis-Nauta, M., \& Weijmar Schultz, W. (2007). Behandeling van seksuele problemen in de eerstelijn, de tweedelijns somatische gezondheidszorg of de tweedelijns GGZ? Tijdschrift voor Seksuologie, 31, 80-84.

Ware, J., \& Sherbourn, C. (1992). MOS 36-item Short Form Health Survey (MOS-SF-36): Universiteit Gent.

Wiebe, S., Guyatt, G., Weaver, B., Matijevic, S., \& Sidwell, C. (2003). Comparative responsiveness of generic and specific quality-of-life instruments. Journal of Clinical Epidemiology, 56, 52-60

Zaric G, Brandeau M, Bayoumi A, Owens D. (1998). The effect of protease inhibitors on the spread of HIV and the development of drug resistance: a simulation study. Simulation, 71, 262-75. 
Chapter 8

Summary and general discussion 


\section{INTRODUCTION}

In the present dissertation several aspects of sexuality and sexual health of adolescents were addressed. Previous research of adolescent sexual health predominantly focused on the prevention of sexual transmitted infections (STIS), HIV/AIDS and unwanted pregnancy. When sexual health is approached from this point of view, Dutch adolescents are considered to be sexually healthy. However, with respect to another aspect of sexual health, such as sexual dysfunction, the situation is less optimistic. Only little is known thus far about sexual dysfunction among adolescents. The aim of this dissertation was to add to the existing knowledge of sexual dysfunction ant its treatment among adolescents.

First of all, the perceptions of adolescents about sexuality, sexual health and sexual problems were investigated (Chapter 2). Furthermore, the validation of a new instrument concerning sexual competence and interaction competence in youth was described (Chapter 3 ). With regard to the causes of sexual dysfunction in adolescents, the role of disgust was investigated (Chapter 4). Finally, the clinical (Chapter 6) and cost-effectiveness and costutility (Chapter 7) of a new treatment for adolescents with a sexual dysfunction, brief sex counselling, were explored.

\section{SUMMARY OF THE FINDINGS}

In the exploratory qualitative study, as described in Chapter 2, we set out to identify adolescents' perceptions of sexual health and sexual health problems. Since education and prevention programs primarily focus on STIs, HIV/AIDS and unwanted pregnancy, and considering the relatively small literature on sexual dysfunctions in adolescents, we considered this study to be imperative to gain greater insight regarding adolescents' perceptions of sexual health. Furthermore, it served as important input for the development and implementation, or adaptation, of a new treatment that matched the expressed needs of the target population. In this study we interviewed 22 male and female adolescents between the age of 13 and 25 years old.

First of all, we wanted to know more about the perspectives adolescents have on sexuality and sexual health. When we asked adolescents to describe the meanings that sex and sexuality had for them, most of them associated it with sexual intercourse, STIs, pregnancy prevention, and sexual orientation. Emotional aspects played only a minor role. Additionally, psychological, social or interactional functions of sexuality were not mentioned at all. Furthermore, schools, parents, and culture were identified as influential determinants of the perception of sexual health by adolescents. For example, adolescents with an Islamic background had more conservative values concerning sex and sexuality than non-Islamic, Dutch adolescents.

Second, we addressed communication issues between sexual partners during the interviews. The results suggest that being in a long-term relationship improves the willingness and capacity to communicate about sexuality and sexual preferences. 
Finally, we addressed sexual health problems and care needs for these problems. In line with their description of sexuality and sexual health, sexual health problems that were seen as relevant by adolescents were associated with medical problems such as STIs and unwanted pregnancy. They had no knowledge about sexual dysfunctions. Consequently, they did not know where to go for treatment when they would experience such problems.

Taken together, this study suggests that adolescents can improve their knowledge about other aspects of sexual health, including emotional and relationship aspects and sexual dysfunction.

The qualitative study indicated that the knowledge of adolescents about all aspects of sexual health is very limited. A lack of knowledge about emotional, social and interactional aspects of sexual activities can play a role in the development and maintenance of sexual dysfunctions. That is why we thought it was important to develop a questionnaire that incorporates several aspects of sexual health, and not, like what has been done for other measurement instruments, only a single aspect. In Chapter 3 we described the psychometric investigation of a questionnaire that was developed to measure sexual competence and interaction competence in youth (SCICY). The total study sample consisted of 276 female undergraduate students between the age of 18 and 25 . We examined the factor structure ( $N$ $=276)$, internal consistency and validity $(N=236)$, and test-retest reliability $(N=82)$.

First, an exploratory factor analysis was conducted that suggested an eight-factor structure (Communication about sex, Refusing sex, Positive sexual attitudes, Male role in sexual interaction, Contraceptive use, Not suppressing problems and desires regarding sex, Sexual assertiveness and Sexual hedonism). Using these factors, the psychometric properties of the SCICY were explored. All factors had moderate to good internal consistencies. The test-retest reliability was good for the total scale and moderate to excellent for the subscales. Furthermore, we explored the convergent and discriminant validity. The SCICY was found to correlate well with instruments that measured communication between partners and overall aspects of sexuality, indicating good convergent validity. With respect to discriminant validity, the SCICY was able to differentiate between adolescents scoring high or low on sexual functioning.

This study can be taken to suggest that the SCICY is a valid and reliable instrument to measure sexual competence and interaction competence in female adolescents. The psychometrics of the instrument in male adolescents remains to be examined.

Until a few years ago, anxiety and fear of pain were the main psychological factors that were associated with the development and maintenance of sexual dysfunctions (de Jong \& Peters, 2009). Recently, the role that disgust might have in sexual dysfunctions has begun to be explored. Elevated levels of disgust propensity (the heightened propensity to react to a certain stimuli with the emotion of disgust) and disgust sensitivity (evaluating this emotion of disgust as something negative) have been found in women with dyspareunia and vaginismus (van Overveld, de Jong, Peters, Cavanagh, \& Davey, 2006; Borg, de Jong, Weijmar-Schultz, 2010). However, these studies focused on the comparison of healthy 
women and sexually dysfunctional women, and did not study men. Furthermore, these studies did not employ direct measurements of genital and subjective sexual arousal.

The study described in Chapter 4 addressed the association between sex and disgust in a non-clinical participant group, including male and female adolescents $(N=43)$, and using both implicit (single target Implicit Association Task; stIAT and genital sexual arousal) and explicit measures (subjective sexual arousal and questionnaires). It was expected that adolescents with higher levels of disgust propensity and disgust sensitivity would experience lower levels of sexual functioning.

We found that female adolescents showed stronger sex-disgust associations and reported higher disgust propensity than men. Unexpectedly, and only in male adolescents, higher levels of disgust sensitivity were found to be associated with higher levels of genital and subjective sexual arousal in response to erotic video clips. The current study can be considered as a starting point for future research into the role of disgust in sexual dysfunction.

The last part of this dissertation dealt with the treatment for adolescents with sexual dysfunctions. Until now, no empirically validated interventions were available for adolescents with sexual dysfunctions. It was noticed (de Graaf, Meijer, Vanwesenbeeck, \& Poelman, 2005) that adolescents with sexual dysfunctions could not adequately be referred to intensive sexual healthcare. Adolescents found it too costly, it was not anonymous, they had no confidence in the treatment, and they disliked that they had to go to a psychologist. The result was that adolescents with a need for help did not receive help, and that consequently, problems got worse or secondary problems such as depression and relationship problems occurred. To amend the finding that regular, adult-oriented, sexual healthcare was not an option for adolescents, a new intervention, called 'brief sex counselling' was designed. With this brief and cost free treatment, that adolescents could access anonymously, we hoped to lower the threshold for seeking treatment, and to prevent the escalation of problems. In Chapters 5 to 7, the design and results of an RCT of the effects of brief sex counselling, intensive sexual healthcare and no treatment were described. In this study, 71 adolescents with a sexual dysfunction between the age of 18 and 25 years old were included. After screening for eligibility, the participants were randomized into one of the three groups; brief sex counselling (BSC), intensive sexual healthcare (ISH), and no treatment (NT). The aim of this study was to investigate the clinical (Chapter 6 ) and cost(Chapter 7) effectiveness of BSC, versus ISH and NT. The first research question concerned the clinical effectiveness of BSC, compared to ISH and NT. There were no significant differences between the groups with respect to both primary and secondary outcome measures.

The results suggest that overall psychological problems and depressive symptoms increased between the beginning and end of treatment for all groups. There was an effect of Time at 6-months follow-up with respect to sexual functioning for BSC and ISH. Sexual functioning increased between baseline and 6 months after the end of treatment. Finally, there was a significant improvement between baseline and the end of treatment with respect to sexual confidence and relationship aspects for all groups. 
The results of the economic evaluation can be taken to suggest that the societal costs (healthcare costs, patient and family costs, and other costs) are significantly higher for ISH than for BSC and NT. Results of the cost-effectiveness analysis show that BSC has the highest probability of being cost-effective in treating adolescents with a sexual dysfunction, up to a willingness to pay $€ 35,000$. However, due to the lack of a significant difference in clinical effect between the three groups, this results is mainly caused by the difference in costs. With respect to the cost-utility analysis, thus using quality of life as a measure of effect, BSC has the highest likelihood of being cost-effective over NT and ISH regardless of the willingness to pay.

Based on the economic evaluation BSC can be considered to be a suitable treatment strategy for adolescents with sexual dysfunctions.

\section{GENERAL DISCUSSION OF THE FINDINGS}

\section{Role of knowledge}

As has been shown in Chapter 2, adolescents have limited knowledge about sexual health factors other than STI and HIV/Aids. The lack of knowledge, the belief in myths and irrational beliefs with regard to sex can be seen as important factors in the development and maintenance of sexual dysfunctions and are dealt with at the beginning of every psychological treatment (van Lunsen, Weijenborg, Vroege, \& Meinhart, 2009). Adolescents appear to have little or no knowledge of sexual dysfunctions or psychological aspects of sexual dysfunctions. Parents and schools may be a key factor in improving adolescents' knowledge about sexual dysfunctions.

Parents play an important role in the sexual development of their child. By talking about sexuality, parents teach their child to make healthy and responsible decisions. Sometimes parents are embarrassed to talk about sex, do not know what to talk about, or have beliefs about sexuality (e.g. 'no sexual intercourse before marriage' or 'sex education only stimulates my child to engage in exactly those sexual activities that the child learns to know'), that discourage them. Furthermore, from a certain age onward, adolescents do not want to talk intimately with their parents about sex. So parents need to know when, how and what they should talk about. The Rutgers Nisso Groep (2007) (now RutgersWPF) advises parents to inform themselves about phases that their children will go through and which problems or insecurities might occur. Furthermore, adolescents should be informed about both the more negative or difficult aspects of sexuality as well as the positive. They should choose the right moment and ask open and inviting questions. Most importantly parents should let their children know that, whatever the problem or question is, they are available for their child.

School also plays an important role in the sexual development of children. In many cases sex education in schools in the Netherlands is very biological oriented and directed at preventing STIs, and this is not different from other countries (Wellings \& Parker, 2006; Fagen, Stacks, Hutter, \& Syster, 2010). However, an educational program is available that 
deals with a larger variety of sexual health aspects. 'Long live love' (in Dutch: Lang leve de liefde) is a sexual educational program that was developed in 1990, and it is currently at its fourth version. Until the third version of this program, 'long live love' was designed for 2 nd and 3 th year students enrolled in lower secondary education, reaching approximately $60 \%$ of the Dutch adolescents. Adolescents are offered 6 lessons in which they are trained in skills such as discussing and negotiating about relationships and safe sex, how to use condoms and other contraceptives and sexual diversity (e.g. hetero- vs. homo- and bisexual). The goal is to improve interaction competence and safe $(r)$ sexual activities. Research on the effectiveness of the third version suggests that adolescents, after having received this education, have significantly more knowledge about sexual risks, possess more skills such as being able to buy condoms, and are more assertive to use condoms in sexual contacts (Poelman, 2008). However, this research suggested that sexual dysfunctions needed more attention, and that sexual health education was not only needed for adolescents with lower educational levels, but for all adolescents. This suggestion resulted in the launch of the fourth version of 'long live love' in September 2012. The program is available for all education levels. Furthermore, the lessons also include information about sexual functioning, sexual dysfunctions, and what to do when adolescents experience these problems (www.langlevedeliefde.nl).

\section{Role of disgust}

The goal of the study presented in Chapter 4 was to give more insight into the relationship between sexual functioning and disgust.

It was expected that adolescents who had strong implicit sex-disgust associations, and higher levels of disgust propensity and sensitivity would have lower levels of genital or subjective sexual arousal. The expectation that higher levels of disgust sensitivity would be associated with lower levels of sexual arousal was not confirmed. Instead we found that male adolescents with higher levels of disgust sensitivity experienced higher levels of sexual arousal. Some ideas were proposed that could explain these results. One option has to do with the transfer of emotions between two different stimuli, in this case the stIAT stimuli and erotic video clips. The positive association between disgust sensitivity and genital and subjective sexual arousal might be explained by an excitation-transfer effect (Cantor, Zillmann, \& Bryant, 1975; Meston, 2000; Meston \& Frohlich, 2003; Meston \& Gorzalka, $1995,1996)$, an effect that has also been identified when anxiety was induced in women (Bradford \& Meston, 2006). The excitation-transfer theory states that the residual excitation from one stimulus will amplify the excitatory response to another stimulus, even if the valence of these stimuli differs. In this sample, the stIAT task might have induced a feeling of arousal. This initial excitation might be intensified by seeing the erotic video clip, resulting in higher genital and subjective sexual arousal. However, only when a person, and especially a male person, has a high level of disgust sensitivity this effect appears to be strong enough to result in higher levels of genital and subjective arousal. As was argued in Chapter 4, negative emotions such as fear or performance demand have likewise been found to increase sexual arousal in sexually functional men (Barlow, 1986). This effect was not found in women, 
possibly explaining why the present study only found an effect of disgust sensitivity and arousal in men.

Furthermore, this study indicated that the implicit measurement of disgust is rather difficult. Although not reported in this dissertation, we also used facial electromyography (EMG) of the corrugator supercilii and levator labii regions of the left side of the face (Fridlund \& Cacioppo, 1986). The corrugator supercilii was selected to index general negative affect. The levator labii region was included because of its reactivity specific to disgust, relative to other negative emotions (Vrana, 1993; Wolf et al., 2005; Borg, 2010). It proved difficult to analyze and interpret these data because of the observed noise and therefore, the EMG results were omitted. Other researchers also experience problems regarding EMG data (personal communication). These difficulties might be the result of incorrect electrode placement, overall movement of the face, etcetera. Overall, this can be taken to suggest that another physiological instruments or methods may be more suitable to measure disgust. A study of Oum (2010) suggests that changes in respiratory sinus arrhythmia (RSA) could be used to indicate sex related disgust. These changes could be measured using a simple electrocardiograph (ECG). Furthermore, in the study of Oum (2010) they found no significant effect of facial muscle involvement (as measured with EMG) with respect to disgust, again indicating that a different measure should be used.

\section{Treatment of sexual dysfunctions in adolescents}

Chapters 5 through 7 addressed the clinical and cost-effectiveness of a new treatment, called brief sex counselling, for adolescents with a sexual dysfunction. Combining both costs and effect, the results suggest that brief sex counselling is a suitable treatment strategy for adolescents with a sexual dysfunction. However, based on the results of Chapter 6, no significant improvements in sexual functioning occurred between baseline and end of treatment/waiting list. Furthermore, there were no significant differences between groups. A possible solution would be to first assess the knowledge and skill level the adolescent has (e.g. by using the SCICY). When using the SCICY problems in this area are identified, it may be best to monitor the development of the problems and only start treatment when the adolescent is older, more experienced, and perhaps more motivated to receive treatment. The level of experience and motivation might explain the lack of results in this study.

Secondly, despite the lack of significant improvements in sexual functioning, a significant improvement in sexual confidence and relationship aspects was found. Maybe treatment for adolescents with a sexual dysfunction should be directed at more general relationship aspects.

Adolescents were also asked to describe the strengths and weaknesses of BSC and what they would like to change. Overall, adolescents were very satisfied with the openness and acceptance of the counsellor during the therapy sessions. Some adolescents stated that the duration of treatment was too short; these adolescents suggested adding one or two extra sessions. The counsellors were also very satisfied with BSC. The manual was very helpful and structured. As far as we know, the three PHS's that contributed in this study are planning to continue to offer BSC for adolescents with a sexual dysfunction. The PHS in the northern part 
of the Netherlands recently launched an online version of BSC, www.vrijfijn.nl. Furthermore, if necessary, the counselor has e-mail contact with the adolescent between the second and third session to make sure that the adolescent is able to work with the exercises, etcetera.

A problem that occurs when conducting research among adolescents is that, according to the Dutch law regarding ethical approval for participation in scientific research, a person between the age of 12 and 18, needs a written approval from the parents to participate in scientific research. However, the age at which an individual is legally able to decide whether he or she would like treatment, for example for a sexual dysfunction, is 16 . This means that many adolescents up to 18 years of age will not participate in scientific studies concerning sexual dysfunctions because they would need to ask their parents' permission. As a consequence, no information about the effect of treatment is available for adolescents younger than 18, which is problematic since the average age of first sexual intercourse is around 16.7 years of age (Bakker \& Vanwesenbeeck, 2006). It can be argued that when a person is considered to be old enough to engage in sexual activities and seek treatment for possible problems, they should also be old enough to participate in scientific research.

\section{STRENGHTS AND LIMITATIONS}

Additional to the methodological considerations stated in each chapter, there are some overall remarks.

The major strength of this dissertation is that it is comprised of studies that evaluated several understudied aspects of sexual dysfunction among adolescents, such as their perspective of sexual dysfunction, factors that might play a role in the development and maintenance of sexual dysfunctions, etcetera. This dissertation addressed the need for educating adolescents better about all aspects of sexual health. Furthermore, we suggest that a lot is still unknown about the role of disgust in sexual dysfunction. Finally, a treatment was designed that aimed to help adolescents who are struggling with sexual difficulties.

To our knowledge, the RCT addressed in this study, combining both the clinical effectiveness and economic evaluation of a treatment for adolescents with a sexual dysfunction, is unique. One of the strengths of the RCT was the inclusion of a no treatment group. The inclusion of a group in which participants receive no treatment accounts for the natural course of the sexual dysfunction. In light of this, the cost-effectiveness study indicates that brief sex counselling is preferable over doing nothing. Another strength was that, due to the inclusion of participants from different regions in the Netherlands, the results of the study can be easily generalized to the entire population.

A major limitation of the RCT study concerns the inclusion and dropout rates of participants. First of all, we included far less participants that we intended to include. When the inclusion process started, it was thought that the total number of participants that were needed could be included from the referrals of adolescents who had the STI consultations. Each year 4000 adolescents visit the STI consultations at the Rotterdam-Rijnmond Public Health Service, so it was thought that when at least $10 \%$ of them would experience sexual 
problems the required number of participants could be included. However, in reality it was very hard to motivate adolescents to participate. Nurses only had little time during their STI consultation to discuss sexual functioning and, maybe due to the lack of knowledge of the adolescents, possible problems were often not identified. Another difficulty was that the nurses had a lot of information material that they had to hand out and, as a result, this may have overwhelmed the adolescents.

A great effort was made to improve the recruitment and inclusion of participants. First, the procedure to discuss the study during the STI consultations changed. The nurse asked the adolescent if he/she experienced any sexual problems and wrote down the adolescent's email address if he/she would like to participate in the study. The researcher then provided information concerning the study via email. Second, information about the study was posted on several websites. Furthermore, we expanded the recruitment locations with one location in the southern and one location in the northern part of the Netherlands. Interviews were published in local and national newspapers, posters were placed at schools and university, and business cards were distributed at gathering places for adolescents. However, these results were not effective to realize the required number of participants. Next, we decided to create our own website (www.sexcounselling.eu), and to advertise in a national newspaper. This resulted in an increased and steady flow of participants. Unfortunately, these efforts were not enough to include the 450 participants that were originally anticipated. The possibility that one could be randomized into the no treatment condition was the most important factor why adolescents were not willing to participate. An effort to shorten the no treatment option to 3-month period could not be accomplished.

The two recruitment procedures that were used in the RCT might partially explain the high dropout pattern. In the first procedure, adolescents were included who visited an STI consultation and were asked if they experienced problems regarding their sexual functioning. In the second procedure, adolescents were included who had sent an email after they visited the research website. It might be the case that there is a difference in motivation or acknowledgement of the problem between participants from both recruitment routes. It can be speculated that adolescents, who visited the STI consultations, did so because they thought that they had an STI infection, not because they had a sexual problem. If they responded positively when asked during the STI consultation whether they perceived any problems, they were prompted to do something about it. It might be the case that they were still in the contemplation phase of change; they just realized that they had a problem, but did not yet have a strong enough commitment to take action. On the other hand, the adolescents who were searching the Internet for help for their sexual problem, found our internet site and then applied for help for their problem were already in the action stage of change (Prochaska, DiClemente, \& Norcross, 1992). Thus the motivation to commit to the treatment and this study might have been higher in the second group. This suggestion is corroborated by the finding that the percentage of dropouts in the first group was higher than in the second group (37.5\% vs. $25.7 \%$ ).

Creating new and better incentive options, could also decrease the number of dropouts. However, this does not conform to current rules of medical ethical committees. It was intended in the RCT that every participant who completed all measurements would have a 
chance to win an Ipad. This was not allowed by the medical ethical committee because the incentive should be equal for every participant and for every measurement. The problems experienced with inclusion and dropout in this and other studies may indicate that rules need to be different for adolescent populations.

Finally, it was not possible in all studies described in this dissertation to include adolescents between the age of 12 and 25 . We were bound to the rules of the medical ethical committee, and adolescents were not willing to participate in the treatment study if they would need their parents' permission. The results might be different if this age category could have been included.

\section{RECOMMENDATIONS}

\section{For future scientific research}

- Future research using the $\mathrm{SCICY}$ should include a diverse sample in terms of sex, age and sexual orientation to corroborate and extend its applicability. To address its robustness, a confirmatory factor analysis (CFA) of the SCICY has to be performed. Furthermore, the discriminant validity has to be confirmed by using clinically diagnosed adolescents with sexual dysfunctions. Finally, norm scores have to be developed for both males and females.

- With respect to the relationship between sex and disgust it would be important to replicate our study in a larger sample and use various (including lower) levels of erotic stimulation.

- Further research with respect to the treatment of adolescents with a sexual dysfunction should pay more attention to the level of motivation to change in adolescents. Since the results of a single study are not sufficient, it is advised to further investigate the effect of BSC. Furthermore, the effect of BSC might also be examined in adults with a sexual dysfunction.

\section{For policy makers}

- It is important that the 'Long live love' program is implemented at every secondary school in the Netherlands in order to improve the overall sexual health of adolescents.

- In order to stimulate younger adolescents to participate in scientific research, the maximum age for double consent (consent of both the adolescent and his/her parents) would need to be lowered from 18 to 16 years of age.

\section{For healthcare professionals/parents/school}

- Our findings point to the need to increase adolescents' knowledge and awareness of the complexity of sexuality, sexual health and sexual problems. Sexual health 
education in schools and at home are important tools by which adolescent's knowledge and awareness can be enhanced, and through which perception of sex and sexuality can develop such that it encompasses more than just the physical aspects of sex and sexuality. Furthermore, by providing more accessible information, possible problems can be alleviated quicker and more directly.

- The SCICY may have particular utility in sexual health education interventions. Because of its ability to differentiate between high and low sexually functioning adolescents, a lower score on the SCICY might indicate current or future sexual problems.

- It is suggested that BSC should be implemented as a regular treatment at every public health service (PHS). Furthermore, BSC would be almost the only option that remains for treating adolescents (and also adults) with sexual dysfunctions if the current plans of the Dutch 'College voor Zorgverzekeringen' become general policy. The plans state that "sexual dysfunctions are caused by biological, psychological and maybe also social factors which can be easily treated by a general practitioner". This would imply that the treatment of sexual dysfunctions within a regular mental healthcare setting (the aforementioned intensive sexual healthcare in Chapter 6 and 7) would no longer be covered by the health insurance system. This would mean that individuals with a sexual dysfunction can no longer be treated, unless they themselves pay all costs. As it has been documented (Bakker \& Vanwesenbeeck, 2006) that adolescents have difficulties to seek treatment within a regular mental healthcare setting because of the higher costs, treatment of sexual dysfunctions among adolescents would not be possible. BSC would provide a solution for this problem because this treatment is not covered by health insurances law but is financed using public resources. 


\section{REFERENCES}

Bakker, F., \& Vanwesenbeeck, I. (2006). Seksuele gezondheid in Nederland 2006. Delft: Eburon.

Bradford, A., \& Meston, C. (2006). The impact of anxiety on sexual arousal in women. Behaviour Research and Therapy, 44, 1067-1077.

Borg, C., de Jong, P., \& Weijmar-Schultz, W. (2010). Vaginismus and dyspareunia: Automatic vs. deliberate disgust responsivity. Journal of Sexual Medicine, 7, 2149-2157.

Cantor, J., Zillmann, D., \& Bryant, J. (1975). Enhancement of experienced sexual arousal in response to erotic stimuli through misattribution of unrelated residual excitation. Journal of Personality and Social Psychology, 32, 69-75.

de Graaf, H., Meijer, S., Vanwesenbeeck, I., \& Poelman, J. (2005). Seks onder je 25e. Seksuele gezondheid van jongeren in Nederland anno 2005. Delft: Eburon.

de Graaf, H., Kruijer, H., van Acker, J., \& Meijer, S. (2012). Seks onder je 25e: Rutgers WPF.

de Jong, P., \& Peters, M. (2009). Sex and the sexual dysfunctions: The role of disgust and contamination sensitivity. Washington, DC: American Psychological Association.

Fagen, M. C., Stacks, J. S., Hutter, E., \& Syster, L. (2010). Promoting implementation of a school district sexual health education policy through an academic-community partnership. Public Health Reports, 125, 352358.

Fridlund, A., \& Cacioppo, J. (1986). Guidelines for human electromyographic research. Psychophysiology, 23, 567-589.

Meston, C. (2000). Sympathetic nervous system activity and female sexual arousal. American Journal of Cardiology, 86, 30-34.

Meston, C., \& Frohlich, P. (2003). Love at first fright: Partner salience moderates roller-coaster-induced excitation transfer. Archives of Sexual Behavior, 32, 537-544.

Meston, C., \& Gorzalka, B. (1995). The effects of sympathetic activation on physiological and subjective sexual arousal in women. Behaviour Research and Therapy, 33, 651-664.

Meston, C., \& Gorzalka, B. (1996). The effects of immediate, delayed, and residual sympathetic activation on sexual arousal in women. Behaviour Research and Therapy, 34, 143-148.

Oum, R. (2010). Psychophysiological responses to disgust: Cardiovascular and facial muscle patterns associated with different functional domains. Dissertation University of Miami.

Poelman, J. (2008). Databank Effectieve Jeugdinterventies: beschrijving 'Lang leve de liefde 3'. Amsterdam: SOA Aids Nederland. Downloaded at http://www.nji.nl/jeugdinterventies

Prochaska, J., \& DiClemente, C., \& Norcross, J. (1992). In search of how people change. Applications to addictive behaviours. American Psychologist, 1102

Rutgers Nisso Groep (2007). Pubers en seks: handige tips voor ouders. www.rutgersnissogroep.nl

van Overveld, M., de Jong, P., Peters, M., Cavanagh, K., \& Davey, G. (2006). Disgust propensity and disgust sensitivity: separate constructs that are differentially related to specific fears. Personality and Individual Differences, 41, 1241-1252

van Lunsen, R., Weijenborg, P., Vroege, J., \& Meinhart, W. (2009). Diagnostiek en interventies. In L. Gijs, W. Gianotten, I. Vanwesenbeeck \& P. Weijenborg (Eds.), Seksuologie. Houten: Bohn Stafleu van Loghum.

Vrana, S. (1993). The psychophysiology of disgust: Differentiating negative emotional contexts with facial EMG. Psychophysiology, 30, 279-286.

Wellings, K., \& Parker, R. (2006). Sexuality education in Europe - A reference guide to policies and practices: IPPF European Network.

Wolf, K., Mass, R., Ingenbleek, T., Kiefer, F., Naber, D., \& Wiederman, K. (2005). The facial pattern of disgust, appetence, excited joy and relaxed joy: An improved facial EMG study. Scandinavian Journal of Psychology, 46, 403-409 
Appendix: $\mathrm{SCICY}$ 


\section{Sexual Competence \& Interaction Competence in Youth (SCICY)}

Geef aan in hoeverre je het eens bent met de volgende stellingen of in hoeverre deze op jou van toepassing zijn. Zet een kruisje bij het voor jou passende antwoord.

\begin{tabular}{|c|c|c|c|c|c|c|}
\hline & & 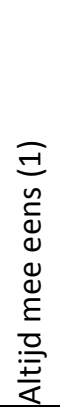 & 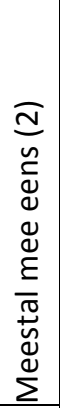 & 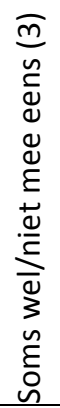 & 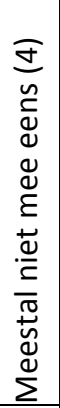 & 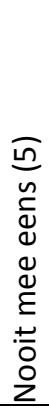 \\
\hline 1 & Seks is alleen leuk als je een orgasme krijgt & & & & & \\
\hline 2 & Je eigen seksuele plezier is belangrijker dan dat van je partner & & & & & \\
\hline 3 & Als een man een erectieprobleem heeft, is hij minder mannelijk & & & & & \\
\hline 4 & $\begin{array}{l}\text { Je kunt seks niet weigeren, want dat zou betekenen dat je niet van je } \\
\text { partner houdt }\end{array}$ & & & & & \\
\hline 5 & $\begin{array}{l}\text { Als een vrouw geen zin heeft om te vrijen, kan zij dit beter toch maar doen } \\
\text { anders gaat haar partner vreemd }\end{array}$ & & & & & \\
\hline 6 & $\begin{array}{l}\text { Als mijn partner dingen wil op seksueel gebied die ik liever niet wil, geef ik } \\
\text { hier toch aan toe }\end{array}$ & & & & & \\
\hline 7 & Als een vrouw geen zin heeft om te vrijen, is zij een slechte partner & & & & & \\
\hline 8 & $\begin{array}{l}\text { Als een vrouw niet klaar komt, komt dit omdat de man zijn werk tijdens de } \\
\text { seks niet goed doet }\end{array}$ & & & & & \\
\hline 9 & $\begin{array}{l}\text { Als je andere dingen wilt op seksueel gebied dan je partner, dan moet je dit } \\
\text { onderdrukken }\end{array}$ & & & & & \\
\hline \multirow[t]{2}{*}{10} & $\begin{array}{l}\text { Als je een seksueel probleem hebt kun je daar beter niet over praten met je } \\
\text { partner }\end{array}$ & & & & & \\
\hline & & 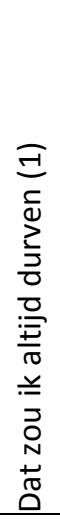 & 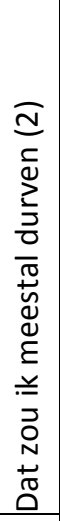 & 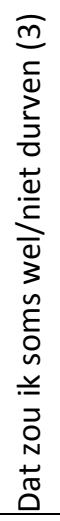 & 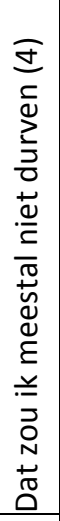 & 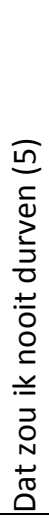 \\
\hline 11 & Neem je het initiatief als je zin hebt in seks? & & & & & \\
\hline 12 & Durf je je partner te vertellen dat je minder vaak seks wilt? & & & & & \\
\hline 13 & $\begin{array}{l}\text { Durf je je partner te vertellen dat je je schaamt voor (bepaalde delen van) } \\
\text { je lichaam? }\end{array}$ & & & & & \\
\hline 14 & $\begin{array}{l}\text { Denk je dat je in staat bent om tegen je partner te zeggen dat het vrijen } \\
\text { pijn doet? }\end{array}$ & & & & & \\
\hline
\end{tabular}




\begin{tabular}{|c|c|c|c|c|c|c|}
\hline & & 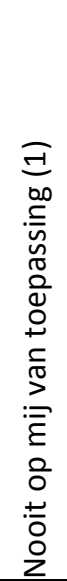 & 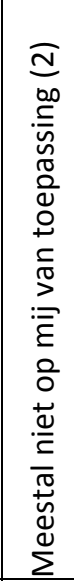 & 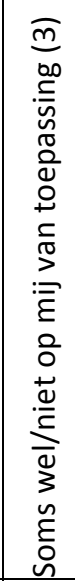 & 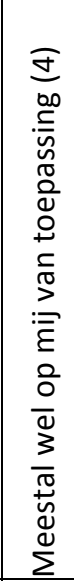 & 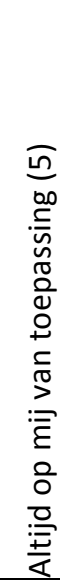 \\
\hline 15 & $\begin{array}{l}\text { Over het algemeen wordt wat ik wil en niet wil door mijn sekspartner } \\
\text { gerespecteerd }\end{array}$ & & & & & \\
\hline 16 & Over het algemeen vraag ik aan de ander wat hij/zij lekker vindt & & & & & \\
\hline 17 & Over het algemeen laat ik precies weten wat ik lekker vind & & & & & \\
\hline 18 & Mijn sekspartner en ik praten over het gebruik van voorbehoedsmiddelen & & & & & \\
\hline 19 & $\begin{array}{l}\text { Mijn sekspartner en ik praten over het voorkomen van zwangerschap en } \\
\text { SOA's }\end{array}$ & & & & & \\
\hline 20 & Over het algemeen voel ik me op mijn gemak tijdens het vrijen & & & & & \\
\hline 21 & $\begin{array}{l}\text { Ik praat met mijn sekspartner over wat ik graag doe of zou willen doen op } \\
\text { seksueel gebied }\end{array}$ & & & & & \\
\hline 22 & Over het algemeen respecteer ik wat mijn sekspartner wil en wat niet & & & & & \\
\hline 23 & Over het algemeen heb ik een blij gevoel na het hebben van seks & & & & & \\
\hline \multirow[t]{2}{*}{24} & Over het algemeen vind ik het leuk om seks te hebben & & & & & \\
\hline & & 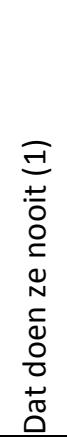 & 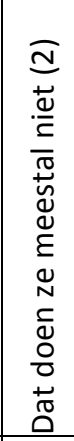 & 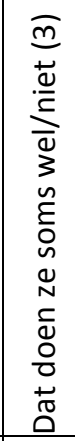 & 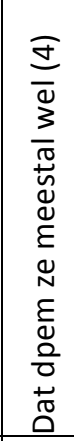 & 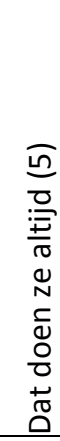 \\
\hline \multirow[t]{2}{*}{25} & Mannen denken alleen aan zichzelf tijdens de seks* & & & & & \\
\hline & & 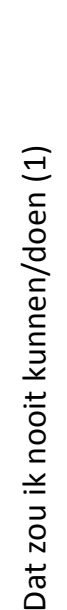 & 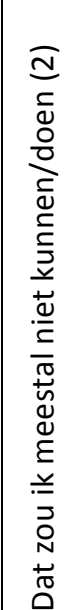 & 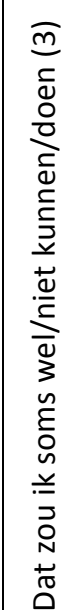 & 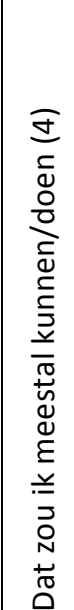 & 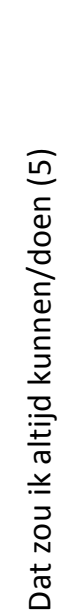 \\
\hline 26 & $\begin{array}{l}\text { Als je al besloten hebt om met iemand seks te hebben, zou je dan alsnog } \\
\text { nee kunnen zeggen? }\end{array}$ & & & & & \\
\hline
\end{tabular}


Om score te berekenen: Spiegel de scores op items 11, 12, 13 en 14 (1 wordt 5, 2 wordt 4). Subschalen berekenen: Subschaal $1=(11+12+13+16+17+21) / 6$; Subschaal $2=(4+5+6$ $+7) / 4$; Subschaal $3=(15+20+22+23+24) / 5 ;$ Subschaal $4=(3+8+25) / 3 ;$ Subschaal $5=$ $(18+19) / 2$; Subschaal $6=(9+10) / 2$; Subschaal $7=(14+26) / 2$; Subschaal $8=(1+2) / 2$. Totaal score $=$ alle items optellen $/ 26$. Des te hoger de score des te beter de seksuele en interactie competentie. 
Samenvatting 


\section{INTRODUCTIE}

Dit huidige proefschrift beschrijft verschillende aspecten die te maken hebben met seksualiteit en seksueel functioneren van adolescenten. Voorgaand onderzoek heeft zich voornamelijk gericht op het voorkomen van seksueel overdraagbare aandoeningen (soa's), HIV of ongewenste zwangerschappen. Vanuit dit oogpunt zijn Nederlandse jongeren, wat betreft hun seksuele gezondheid, vrij gezond. Echter, wat betreft de aanwezigheid van seksuele disfuncties zijn de vooruitzichten minder rooskleurig. Tot nu toe is er maar weinig bekend over het hoe en waarom van seksuele disfuncties bij jongeren, dit proefschrift probeert hier een duidelijker beeld van weer te geven.

In hoofdstuk 2 werd er meer weergegeven over de perceptie die jongeren hebben omtrent seksualiteit en seksuele problemen. Verder werd er in hoofdstuk 3 in gegaan op de validatie van een nieuw instrument dat gericht is op het in kaart brengen van de seksuele competentie en interactie competentie van jongeren. In hoofdstuk 4 werd in gegaan op de mogelijke relatie tussen walging en seksueel functioneren. Tenslotte werd een onderzoek gepresenteerd waarin de klinische effectiviteit (hoofdstuk 6) en kosteneffectiviteit en kosten-utiliteit (hoofdstuk 7) van een nieuwe behandeling voor jongeren met een seksuele disfunctie, kortdurende sexcounselling, werd besproken.

\section{SAMENVATTING VAN DE BEVINDINGEN}

In de exploratieve kwalitatieve studie (interview studie gehouden onder 22 adolescenten tussen de 13 en 25 jaar oud), beschreven in hoofdstuk 2, was het doel de perceptie van adolescenten omtrent seksuele gezondheid en seksuele problemen te identificeren. Gezien het feit dat educatieve programma's vooral aandacht besteden aan het voorkomen van soa's, HIV en ongewenste zwangerschappen, meenden we dat deze studie een beter zicht kon geven op de daadwerkelijke kennis en perceptie die jongeren hebben omtrent seksualiteit en seksuele gezondheid. Daarnaast werd er gedacht dat de resultaten van deze studie kon zorgen voor meer informatie die gebruikt kon worden bij de ontwikkeling, implementatie of aanpassing van educatie programma's.

De resultaten lieten zien dat, indien adolescenten werd gevraagd alles te beschrijven wat in hun opkomt omtrent seksualiteit, dit vooral te maken had met geslachtsgemeenschap, soa's, voorkomen van zwangerschap en seksuele oriëntatie. Emotionele aspecten speelden een ondergeschikte rol. Verder werden psychische en de sociale/interactie functie van seksualiteit helemaal niet benoemd. Verder werden scholen, ouders en cultuur waarin men opgroeit gezien als factoren die de seksuele ontwikkelingen kunnen beïnvloeden.

Ook werd er gekeken naar de communicatie over seksualiteit en seksuele voorkeuren tussen (seks)partners. De resultaten gaven aan dat het hebben van een langdurige relatie de kans vergroot dat er werd gesproken over seksualiteit en de wensen en grenzen omtrent seksuele activiteiten. Redenen om het niet te doen hadden veelal te maken met onzekerheid over het verliezen van de relatie. 
Tenslotte werd er gesproken over seksuele problemen en behandeling of zorg die adolescenten dachten nodig te hebben voor deze problemen. Net zoals bij de beschrijving van het begrip seksualiteit werd er hierbij niet verder gedacht dan soa's en zwangerschap. De adolescenten hadden geen kennis over het bestaan van seksuele disfuncties. Als gevolg konden de jongeren ook geen suggesties geven waar ze voor hulp zouden gaan als ze deze problemen zouden ervaren, of wat dan gezien zou worden als goede zorg.

Deze studie geeft aan dat adolescenten nog veel kunnen leren over de verschillende aspecten van seksuele gezondheid. Vooral ouders en scholen zouden hier een rol in kunnen spelen.

In hoofdstuk 3 werd er ingegaan op de ontwikkeling en validatie van een vragenlijst die de seksuele competentie en interactie competentie van jongeren (SCICY) tracht te meten. De zo net beschreven interviewstudie geeft aan dat er een gebrek aan kennis bestaat omtrent seksuele disfuncties. Dit gebrek aan kennis kan ten grondslag liggen aan het ontstaan en voortduren van een seksuele disfunctie. Dit zorgt ervoor dat het belangrijk is dat we het kennis niveau van jongeren omtrent seksuele gezondheid kunnen meten, om zo de ontwikkeling van seksuele disfuncties voor te zijn. Daar er nog geen goede bestaande vragenlijst bestond hebben we een nieuwe vragenlijst ontwikkeld die de seksuele competentie en interactie competentie van jongeren meet, de SCICY (Sexual Competence \& Interaction Competence in Youth). De totale studie sample bestond uit 276 vrouwelijke studenten tussen de 18 en 25 jaar. Van deze totale groep gebruikten we verschillende subgroepen om de factor structuur $(N=276)$, interne consistentie en validiteit $(N=236)$ en test-hertest $(\mathrm{N}=82)$ te meten.

De factor analyse resulteerde in een vragenlijst bestaande uit 8 verschillende subschalen (communicatie over seks, het weigeren van seks, positieve attitudes ten aanzien van seks, de rol van mannen in seksuele interactie, gebruik van anticonceptie, het niet onderdrukken van problemen en wensen ten aanzien van seks, seksuele assertiviteit en seksueel hedonisme). Alle subschalen vertoonden een redelijke tot goede interne consistentie. De test-hertest betrouwbaarheid was redelijk tot zeer goed voor de totale schaal en alle subschalen. Verder werden de convergente en discriminerende validiteit onderzocht. De SCICY correleerde goed met de instrumenten die de communicatie tussen partners en algemene aspecten van seksualiteit pogen te meten, daarmee werd de goede convergente validiteit aangegeven. De discriminerende validiteit was eveneens goed, de SCICY kon een goed onderscheid maken tussen vrouwen met een hoog en laag seksueel functioneren.

De resultaten van deze studie tonen aan dat de SCICY een valide en betrouwbaar instrument is om de seksuele competentie en interactie competentie in jongeren te meten.

Tot een aantal jaar geleden waren angst en angst voor pijn de meest voorkomende psychologische mechanismen die geassocieerd werden met de ontwikkeling en het voortduren van seksuele disfuncties (de Jong \& Peters, 2009). Recentelijk wordt walging ook steeds vaker genoemd als factor in seksuele disfuncties, voornamelijk de verhoogde walg neiging (de verhoogde neiging om een bepaalde stimuli walgelijk te vinden) en walg gevoeligheid (het ervaren van walging evalueren als iets negatiefs) worden geassocieerd met 
het voorkomen van dyspareunie en vaginisme bij vrouwen (van Overveld, de Jong, Peters, Cavanagh, \& Davey, 2006; Borg, de Jong, \& Weijmar-Schultz, 2010). Echter deze studies richten zich vooral op personen met een seksuele disfunctie en includeren alleen maar vrouwen. Verder werden er in deze studies geen genitale en subjectieve metingen van opwinding gedaan.

De studie zoals beschreven in hoofdstuk 4 richtte zich op de associatie tussen seks en walging in een non-klinische, zowel mannelijke als vrouwelijke $(N=43)$, groep waarbij gebruik werd gemaakt van zowel impliciete (impliciete associatie taak en genitale meting van opwinding) als expliciete maten (subjectieve meting van opwinding en vragenlijsten). Het werd verwacht dat adolescenten met een hogere walg neiging- en gevoeligheid een lager niveau van seksueel functioneren zouden ervaren.

Resultaten lieten zien dat vrouwen sterkere seks-walg associaties hadden en een hogere walg-neiging rapporteerden dan mannen. Onverwacht, en alleen gevonden in mannen, leidde een hogere walg gevoeligheid tot een hogere genitale en subjectieve seksuele opwinding. Deze studie kan als beginpunt worden gezien voor het verder onderzoeken van de associatie tussen seks en walging in een gezonde groep adolescenten.

Het laatste gedeelte van deze dissertatie hield zich bezig met de behandeling van seksuele disfuncties van jongeren. Tot op heden is er nog geen data beschikbaar die aanbevelen welke vorm van behandeling van toepassing zou zijn voor het behandelen van adolescenten met een seksuele disfunctie. Door observaties van de GGD en voorgaand onderzoek werd er wel opgemerkt dat adolescenten waarbij een seksuele disfunctie, of in ieder geval een seksueel probleem, geconstateerd werd niet goed konden worden doorverwezen naar de tweedelijns GGZ (de Graaf, Meijer, Vanwesenbeeck, \& Poelman, 2005). Adolescenten gaven aan dat ze het te duur vonden, dat bij deze vorm van behandeling hun anonimiteit verloren zou gaan en dat ze geen vertrouwen hadden in de behandeling of het ontvangen van een behandeling door een psycholoog. Het gevolg hiervan was dat adolescenten die behoefte zouden hebben aan hulp deze niet kregen, resulterend in het erger worden van hun klachten. De aangeboden zorg was op dat moment dus niet geschikt genoeg voor het behandelen van jongeren met seksuele problemen, daarom werd er door de Universiteit Maastricht in samenwerking met de GGD Rotterdam-Rijnmond, kortdurende sekscounselling ontwikkeld. Een gratis, anonieme en kortdurende behandeling waarvan werd gehoopt dat dit de drempel zou verlagen en jongeren deze vorm van hulp zouden accepteren.

In hoofdstuk 6 en 7 werden de resultaten van deze langdurige studie besproken. $\mathrm{Er}$ werden 71 mannelijke en vrouwelijke adolescenten met een seksuele disfunctie tussen de 18 en 25 jaar geïncludeerd. Na een korte screening werd de adolescent ingeloot in een van de 3 groepen; kortdurende sekscounselling (BSC), een seksuologische behandeling binnen de tweedelijns GGZ (ISH) en een wachtlijst controle groep (NT). Het doel van de studie was om de klinische (hoofdstuk 6) en economische (hoofdstuk 7) effectiviteit van BSC te vergelijken met ISH en NT.

Met betrekking tot de klinische effectiviteit werd verwacht dat BSC een beter effect zou hebben dan NT, en waarschijnlijk minder effectief zou zijn dan ISH. De resultaten lieten zien dat er geen significante verschillen gevonden konden worden tussen de baseline meting en 
de nameting, noch het verschil tussen de groepen. Er werd wel een significante verbetering gezien in het zelfvertrouwen en de kwaliteit van de relatie na het einde van de behandeling voor alle groepen. Daarnaast was er een significante verbetering van het seksueel functioneren 6 maanden na het eind van de behandeling ten opzichte van de baseline voor BSC en ISH (voor DT was er geen 6 maanden follow-up meting beschikbaar).

Met betrekking tot de economische evaluatie werd verwacht dat de totale kosten van BSC gelijk of lager zouden zijn dan NT en lager dan ISH. Verder zou de kosten-effectiviteit en kosten-utiliteit hoger zijn voor BSC dan ISH en NT. De resultaten lieten zien dat de hoeveelheid kosten voor de samenleving significant hoger zijn voor ISH dan voor BSC en NT. Indien de samenleving bereid is om tot $€ 35000$ euro te betalen voor 1 punt verbetering wat betreft seksueel functioneren, kon BSC worden geïdentificeerd als de meest optimale behandeling voor jongeren met een seksuele disfunctie. Gezien het feit dat er geen verschil in klinische effectiviteit is gevonden, wordt dit effect vooral veroorzaakt door het verschil in kosten. Wanneer kosten en effect, gemeten met kwaliteit van leven als uitkomstmaat, worden vergeleken is BSC de voorkeursoptie tot een bedrag van $€ 50,000$, indien de samenleving bereid is meer te betalen, dan geniet NT de voorkeur.

Uit deze resultaten kan gesuggereerd worden dat, gebaseerd op het combineren van kosten en effect, BSC een optimale behandeloptie is voor het behandelen van adolescenten met een seksuele disfunctie. 


\section{REFERENTIES}

Borg, C., de Jong, P., \& Weijmar-Schultz, W. (2010). Vaginismus and dyspareunia: Automatic vs. deliberate disgust responsivity. Journal of Sexual Medicine, 7, 2149-2157.

de Graaf, H., Meijer, S., Vanwesenbeeck, I., \& Poelman, J. (2005). Seks onder je 25e. Seksuele gezondheid van jongeren in Nederland anno 2005. Delft: Eburon.

de Jong, P., \& Peters, M. (2009). Sex and the sexual dysfunctions: The role of disgust and contamination sensitivity. Washington, DC: American Psychological Association.

van Overveld, M., de Jong, P., Peters, M., Cavanagh, K., \& Davey, G. (2006). Disgust propensity and disgust sensitivity: separate constructs that are differentially related to specific fears. Personality and Individual Differences, 41, 1241-1252 
Dankwoord 
Langs deze weg wil ik iedereen bedanken die op wat voor een reden dan ook heeft bijgedragen aan de totstandkoming van mijn proefschrift en ervoor heeft gezorgd dat ik de afgelopen 4,5 jaar niet veel gekker ben geworden. Ik zou nog een proefschrift kunnen schrijven om iedereen persoonlijk te bedanken, maar dat lijkt me een beetje veel van het goede. Ik wil dus jou, (vul hier je naam in), heel erg bedanken. Kom gerust een drankje drinken op mijn receptie. Toch zijn er een aantal personen die ik graag persoonlijk wil bedanken.

Mijn promotores, Jacques, Silvia en Madelon. Jacques, jij bent eigenlijk de reden geweest dat ik ooit aan dit project ben begonnen. Je hebt me tijdens mijn studie laten zien hoe leuk onderzoek kan zijn, en gelukkig heb ik toen ook al gezien dat je veel geduld moet hebben en dat er van alles mis kan gaan. Ondanks de tegenslagen en je vertrek bij de UM heb ik me nooit alleen gevoeld. Bedankt voor alle steun en leuke gesprekken, ook buiten het werk om. Silvia, hartelijk bedankt voor je hulp aan de zijlijn en de hulp bij de economische evaluatie. Ik denk dat je soms ook moet hebben gedacht "wat moet ik met dit project". De reisjes naar Eindhoven en terug waren ook een stuk aangenamer door onze gesprekken. Madelon, ook al werd je pas later bij dit project betrokken, heb ik veel aan je bijdrage en hulp gehad. Vooral je inhoudelijke kennis en objectieve blik op mijn stukken hebben me veel geholpen.

Projectleden en verpleegkundigen van de GGD Rotterdam-Rijnmond, Noord-Nederland en Zuid-Limburg; hartelijk bedankt. Zonder jullie harde werk, het luisteren naar mijn verhalen en smeekbedes, en werven van jongeren was me dit nooit gelukt. Katy, je hebt de reisjes naar Rotterdam een stuk leuker gemaakt. Je betrokkenheid met het project, en ook hoe het met mij ging, hebben me enorm geholpen. De lunchafspraken, vooral de keer bij Hotel New York, zullen me altijd bijblijven. Anja, zonder jou was sekscounselling er nooit geweest. Ik bewonder je initiatief en betrokkenheid bij het welzijn van de jongeren (en nog wel een veel grotere groep). Ga zo door! Meike, jij was mijn schakel naar de verpleegkundigen in Rotterdam. Fijn dat ik jou als doorgeefluik kon gebruiken en niet gek bent geworden van al mijn verzoeken en formulieren. Jolanda, Denise, Anouk, bedankt dat jullie de honneurs hebben waargenomen in het noorden en zuiden! Zonder de toevoeging van deze locaties was het nooit gelukt.

Bedankt aan alle medewerkers van PsyQ, in het bijzonder Eva, Trudy en Janneke. Daarnaast ook mijn hartelijke dank aan mijn middelbare school, het Sint-Janscollege te Hoensbroek, waar ik een heel aantal jongeren mocht interviewen.

Bedankt aan al mijn lieve collega's van CPS! Vooral bedankt aan mijn paranimfen, Marjolein en Lottel. Marjolein, wij waren al gangmaatjes, bedankt voor de leuke gesprekken, dat ik mijn kennis over onderwijs wat aan jou heb mogen doorgeven, je leuke verhalen en het in het leven roepen van idiote dingen met bammie (zoals de olympische spelen hunk, en Hans en Jani). Lotte, we go way back, dus voor mij was het niet moeilijk wie een van mijn paranimfen zou worden. Bedankt voor de gezellige tijd, dat ik mocht klagen over mijn project en het ervoor zorgen dat er ook echt vrij werd genomen (ik zal zorgen dat jij dat ook 
blijft doen (:)). Daarnaast veel dank aan mijn collega's van de eerste; mijn kamergenootjes Lotte, Johanna en Sjoertje. Bedankt dat ik bij jullie mocht aanschuiven na de zoveelste verhuizing. Ik heb het erg leuk gevonden en veel van jullie geleerd. Ik heb me altijd welkom gevoeld en vooral de gesprekken die niet over werk gingen erg gewaardeerd. Yvo, Marlies, Ken, Pim, Rilana, Saskia, Jantine, Bastiaan, bedankt voor de leuke gesprekken op de gang, lunches, EPP bijeenkomsten en "rookpauzes".

Graag wil ik hierbij ook alle jongens van de technische dienst bedanken. Jullie moeten vaak hebben gedacht "daar komt zij weer", als er weer eens een knopje verkeerd stond of er iets raars op mijn scherm stond. Ik denk dat ik namens al mijn collega's spreek als ik zeg dat we veel van onze studies niet zonder jullie hulp kunnen uitvoeren.

Bedankt aan al mijn vriendjes en vriendinnetjes. Ondanks dat jullie misschien niet altijd weten waar ik me nu precies mee bezig houd, zijn jullie altijd geïnteresseerd en hebben jullie me gesteund in de mindere tijden.

Pap, mam, broertje, opa, oma, bedankt voor jullie steun. Jullie hebben altijd achter me gestaan en gestimuleerd, wat ik ook wilde doen.

Tenslotte, Dave en mijn meiden, zonder jullie had dit proefschrift er niet gelegen. We hebben het er nog vaak over dat jij dit nu ook had kunnen schrijven, en dat we er beiden blij om zijn dat dat niet zo is. Bedankt dat ik ideeën of problemen altijd met je heb kunnen delen en dat je ervoor hebt gezorgd dat ik genoeg afleiding heb gehad de afgelopen jaren. Nu ik aan mijn nieuwe avontuur ben begonnen hoop ik dat ik dat ook met je kan delen, hoewel je taarten een stuk leuker zult vinden dan het lezen van mijn artikelen $(;)$. Bedankt, hou van je piep! 

Curriculum Vitae 
Andrea Grauvogl was born in Brunssum, the Netherlands on November 3th, 1984. In 2004 she graduated from secondary school, St. Jan in Hoensbroek (the Netherlands), after which she started her university studies Health Sciences at Maastricht University, the Netherlands. She obtained her master's degree in Mental Health Sciences in September 2008. From September 2008 until March 2009 she worked as a teaching assistant at Maastricht University. From March 2009 to August 2013 she conducted her PhD research at the Department of Clinical Psychological Science at Maastricht University. During these years, she took additional courses in Health Technology Assessment and Statistics and worked partly as a lecturer (Mental Health Sciences) and as a therapist at the sexology department at the academic hospital Maastricht. Currently she works as a lecturer at Maastricht University and is studying to be a pastry chef. In 2014 she will receive her teaching qualification (Basis Kwalificatie Onderwijs). 


\section{PUBLICATIONS}

Grauvogl, A., Stutterheim, S., Evers, S. \& van Lankveld, J. (2012). Perceptions of sexuality and sexualhealth among young people in the Netherlands. Sexual and Relationship Therapy, 272: $110-121$

Hiemstra, J. \& Grauvogl, A. (2012). Online hulpverlening voor jongeren met seksuele problemen: een literatuurstudie. Tijdschrift voor Seksuologie, 36-1: 1-11

Grauvogl, A., Schaafsma, D. \& van Lankveld, J. (2011). 37e Annual meeting van de International Academy of Sex Research. Tijdschrift voor Seksuologie, 35-4: 247-251

Grauvogl, A. (2011). Sexuality under 18: How the social environment influences sexual development. Tijdschrift voor Seksuologie, 35-1: 37-38

Grauvogl, A. \& van Lankveld, J. (2010). Verbetering van de seksuele gezondheid van Nederlandse jongeren: kortdurende sekscounselling. Hiv/aids nieuwsbulletin, 3:13-14

Grauvogl, A., Evers S., van den Hoek, K., van der Veen, E., Franke, A. \& van Lankveld, J. (2009). Research into the efficacy and cost-effectiveness of brief, free of charge and anonymous sex counselling to improve (mental) health in youth: Design of a randomized controlled trial. BMC Public Health, 9:459

\section{Manuscripts submitted or in preparation}

van Lankveld, J., Grauvogl, A., van den Hoek, K., Franke, A., \& Evers, S. Inclusieproblemen bij een multicenter RCT naar de (kosten)effectiviteit van kortdurende sekscounselling voor seksuele problemen van jongeren: Survival tips.

Grauvogl, A., de Jong, P., Peters, M., Evers, S., \& van Lankveld, J. Disgust ans sexual arousal in young adult men and women.

Grauvogl, A., Peters, M., Evers, S., \& van Lankveld, J. A new instrument to measure Sexual Competence and Interaction Competence in Youth (SCICY): Psychometric properties in female adolescents.

Grauvogl, A., Evers, S., Peters, M., van Lankveld, J. The clinical effectiveness of brief sex counselling for sexually dysfunctional adolescents.

Grauvogl, A., van Lankveld, J., \& Evers, S. Economic evaluation of brief sex counselling for sexually dysfunctional adolescents. 


\section{PRESENTATIONS}

Grauvogl, A. (2013). Let's talk about sex! Sexual health among adolescents. Oral presentation at the Dutch-Flemish postgraduate school for research and education "Experimental Psychopathology", Heeze, the Netherlands.

Grauvogl, A. (2011). Brief sex counselling. Poster presentation at the annual congress of the International Academy of Sex Research, Los Angeles, USA.

Grauvogl, A. (2011). Brief sex counselling. Oral presentation at the annual congress of the Scientific Association for Sexual Dysfunctions [Wetenschappelijke Vereniging voor Seksuele Disfuncties], Ede, the Netherlands.

Grauvogl, A. (2011). Brief sex counselling. Oral presentation at the annual congress of the International Academy of Sex Research, Prague, Czech Republic.

Grauvogl, A., \& van Lankveld, J. (2010). Efficacy and cost-effectiveness of brief, cost free and anonymous sex counselling to improve (mental) health in youth. Poster presentation at the 6th World Congress of Behavioral \& Cognitive Therapies (WCBCT), Boston, USA.

Grauvogl, A., Franke, A., \& van Lankveld, J. (2009). Brief sex counselling. Workshop at the annual World SOA/AIDS day 2009, Amsterdam, the Netherlands.

Grauvogl, A., \& van Lankveld, J. (2010). Efficacy and cost-effectiveness of brief, cost free and anonymous sex counselling to improve (mental) health in youth. Poster presentation at "Pain Meeting" University of Leuven, Leuven, Belgium.

Grauvogl, A., \& van Lankveld, J. (2010). Efficacy and cost-effectiveness of brief, cost free and anonymous sex counselling to improve (mental) health in youth. Poster presentation at the Dutch-Flemish postgraduate school for research and education "Experimental Psychopathology", Utrecht, the Netherlands. 